\title{
Mission-Oriented Innovation Policies in Austria \\ - a case study for the OECD
}

Final Report

Peter Biegelbauer*, Christian Hartmann**, Wolfgang Polt** (Project Coordinator), Anna Wang*, Matthias Weber*

${ }^{*}$ Austrian Institute for Technology / ** Joanneum Research

Study commissioned by the Austrian Federal Ministry for Climate Action, Environment, Energy, Mobility, Innovation and Technology (BMK) 


\title{
Mission-Oriented Innovation Policies in Austria - a case study for the OECD
}

\author{
Final Report
}

Peter Biegelbauer*, Christian Hartmann ${ }^{\star *}$, Wolfgang Polt** (Project Coordinator), Anna Wang*, Matthias Weber*

*Austrian Institute for Technology / **Joanneum Research

JOANNEUM RESEARCH Forschungsgesellschaft mbH Institut für Wirtschafts- und Innovationsforschung

\author{
Büro Graz \\ Leonhardstraße 59 \\ 8010 Graz, Austria \\ Tel.: +43-316-876 1488 \\ E-Mail: policies@joanneum.at
}

Büro Wien

Haus der Forschung, Sensengasse 1

1090 Wien, Austria

Tel.: +43-1-5817520

E-Mail:policies@joanneum.at

\section{Büro Klagenfurt}

Lakeside B08a, EG

9020 Klagenfurt am Wörthersee

Tel.: +43-1-876 7553

E-Mail: policies@joanneum.at 


\section{Table of content}

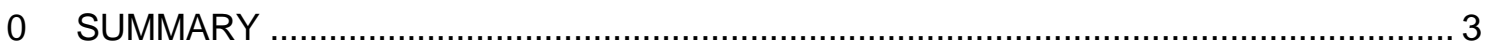

1 BACKGROUND AND METHODOLOGICAL FRAMEWORK .......................................... 10

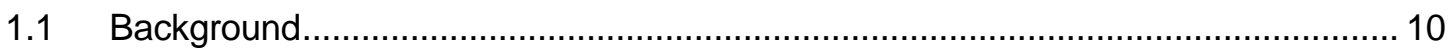

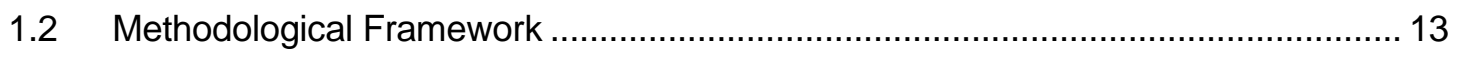

2 FRAMEWORK CONDITIONS FOR MOIP IN AUSTRIA …......................................... 16

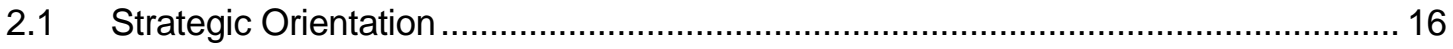

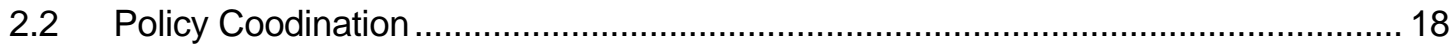

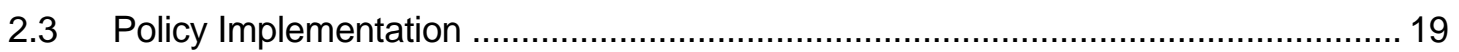

3 CASE STUDIES: MISSION-ORIENTED INNOVATION PROGRAMMES IN AUSTRIA 21

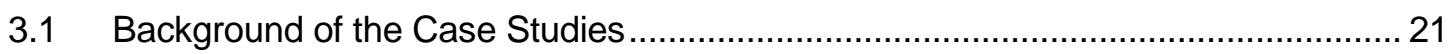

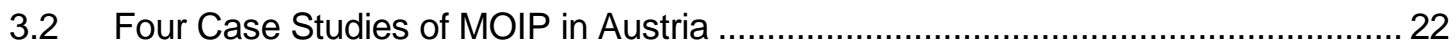

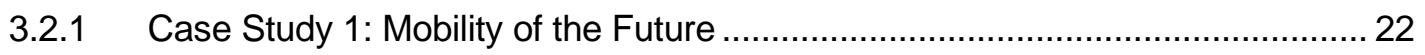

3.2.2 Case Study 2: Benefit / Ambient Assisted Living …......................................... 33

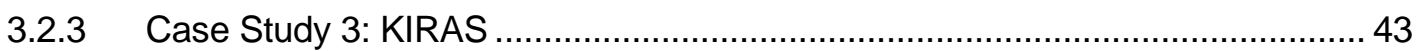

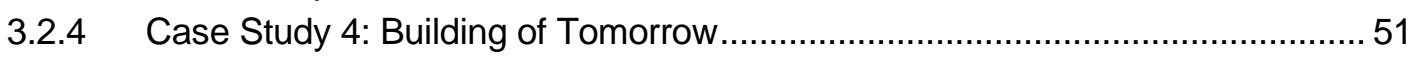

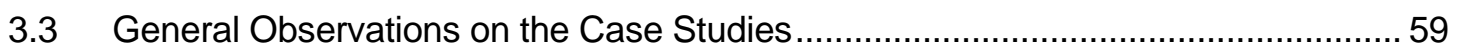

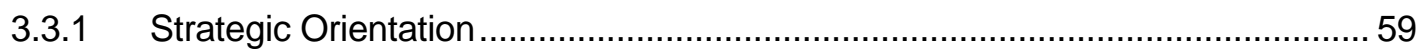

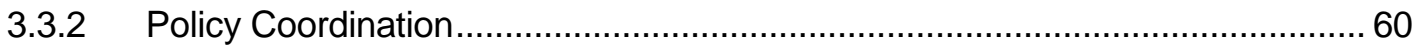

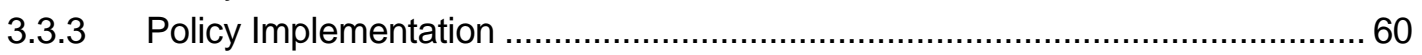

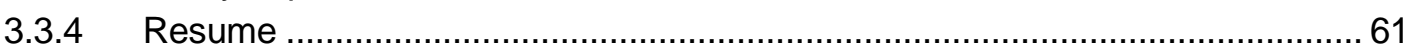

4 SUMMARY, CONCLUSIONS AND SUGGESTIONS FOR MOP IN AUSTRIA ..............67

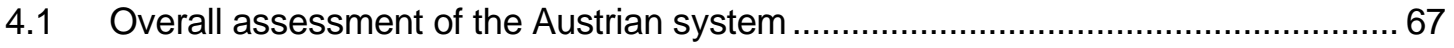

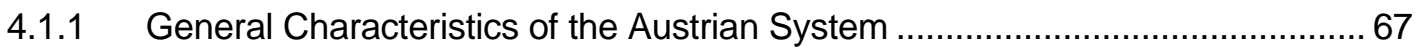

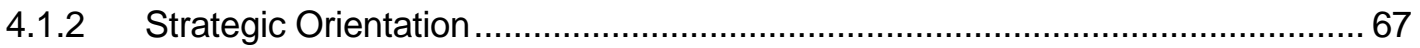

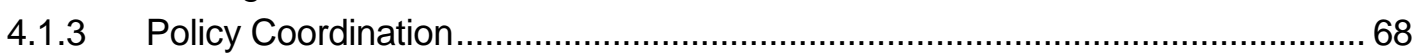

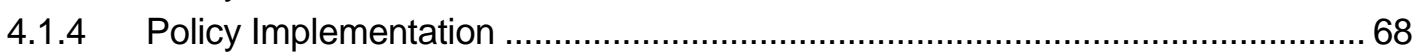

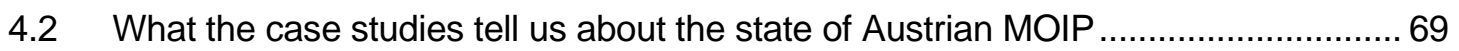

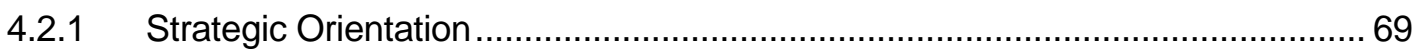

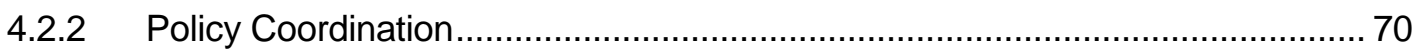

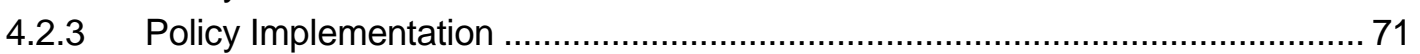

5 SUMMARY AND TENTATIVE SUGGESTIONS FOR FUTURE MOIP IN AUSTRIA ..... 72

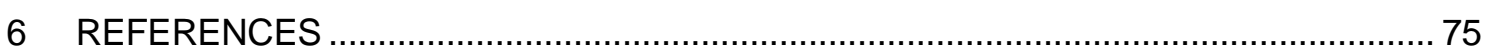

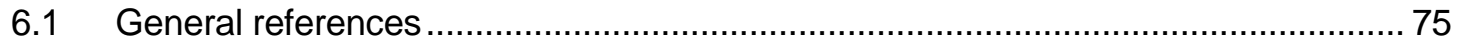

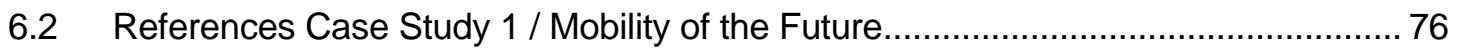

6.3 References Case Study 2 / Benefit-Ambient Assisted Living .................................. 77

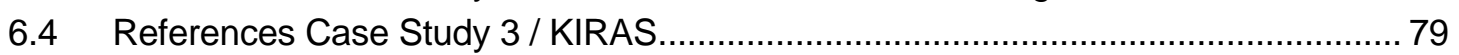

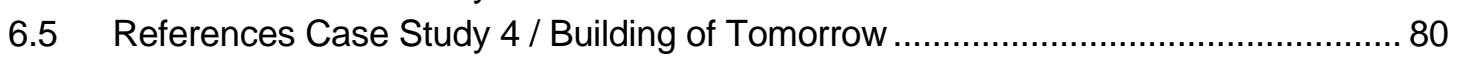

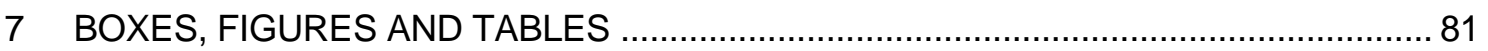




\section{Summary}

\section{BACKGROUND AND OBJECTIVES}

In recent years, mission-oriented approaches have received growing interest in science, technology and innovation (STI) policies against the background of two developments. First, while so-called "horizontal" or "generic" approaches to research, technology and innovation policies have largely been successful in improving the general innovation performance or the rate of innovation, there are perceived limitations in terms of insufficiently addressing the direction of technological change and innovation. Second, "grand societal challenges" emerged on policy agendas, such as climate change, security, food and energy supply or ageing populations, which call for thematic orientation and the targeting of research and innovation efforts. In addition, the apparent success of some mission-oriented initiatives in countries like China, South Korea, and the United States in boosting technological development for purposes of strengthening competitiveness contributed to boosting the interest in targeted and directional government interventions in STI.

Against the backdrop of this renewed interest in mission-oriented STI policy, the OECD has addressed the growing importance of this topic and launched a project looking into current experiences with Mission-Oriented Innovation Policy (MOIP). The present study on MOIP in Austria was commissioned by the Austrian Federal Ministry for Climate Action, Energy, Mobility, Environment, Innovation and Technologiy (BMK) and comprises the Austrian contributions to this OECD project. The study aims at contributing Austrian experiences to the international debate and to stimulate a national debate on MOIP. The main parts of the Austrian coproject were

(i) An overall assessment of the Austrian innovation (policy) system and its characteristics and the implications of these characteristics for Austria's capacity to carry out MOIP initiatives,

(ii) Four case studies on recent policy initiatives, which were selected to highlight the potential (and the current limitations) of this approach in the Austrian context. The four case studies selected are the programmes „Benefit/Ambient Assisted Living“, „Building of Tomorrow“, the Austrian Security Research Programme "KIRAS", and "Mobility of the Future“.

(iii) To synthesise the main findings at case study and national levels, and to formulate some first tentative recommendations.

The OECD project emphasizes the importance of looking both at the specific mission-oriented programmes and at the wider innovation policy system because historically grown institutional settings are crucial framework conditions that help understand why and how specific MOIP have been successful (or not).

The case studies, as well as the overall assessment of the Austrian STI policy system, draw on the analytical framework developed by OECD, which emphasizes three key dimensions of MOIP: Strategic orientation, Policy coordination, and Policy implementation.

While the focus of the work in the context of the current OECD project was to compare the general characteristics of the policy processes that come along with MOIP, it became apparent that the characteristics of these processes differ with respect to the specific type of mission 
under study. For instance, a necessary distinction has to be made between missions that aim at more narrowly defined scientific and technological goals (so-called 'accelerator missions') and those that address larger societal problems ('transformer missions'). These types of missions differ considerably e.g. with respect to the challenges for governance and the appropriate governance modes to be employed.

\section{OVERALL ASSESSMENT OF THE AUSTRIAN INNOVATION POLICY SYSTEM}

Over the past decades, Austria has seen an increasing STI intensity, which has made it one of the most R\&D intensive countries in Europe. Its support for business STI is also among the highest in Europe. In the same vein, during this period, it has also put in place agencies (e.g. the Austrian Research Promotion Agency FFG, the Austrian Promotional Bank aws, and the Climate and Energy Fund KLIEN) and instruments (e.g. thematic programmes like the ones covered in this report) which would lend themselves well to the development of a missionoriented innovation policy.

However, it is important to recognize that most of the public STI funding in Austria is not exante thematically oriented, with large parts of the increases in recent years going to tax support measures to promote private sector R\&D and to institutional funding of Higher Education Institutions.

While assessments of the STI policy mix (including the OECD Innovation Policy Review of 2018 or an earlier 'systems evaluation') find a developed and far-reaching set of instruments, the balance of the portfolio of the instruments has shifted very much to non-oriented instruments in the recent past which limits the public capabilities to steer thematically. Another weak side of the instruments' toolbox is a lack of emphasis on the use of demand-side instruments, which would be very important in a number of mission-oriented policies.

Another feature of the Austrian STI policy mix is that the plethora of instruments is rarely applied in a coordinated manner and does not take into account the effects of other measures.

\section{Strategic Orientation}

In the 2011 STI strategy, the need to develop a strategic policy approach to address 'grand societal challenges' was explicitly recognized as well as the need for changes in the governance of STI policies that would have to come along with this orientation. Subsequently, a number of funding channels and programmes were developed which tried to address these challenges. Some of these thematically oriented programmes fall under or come close to the core definition of 'mission-oriented' programmes, however without having been designed from the outset in this framework. Austria has accumulated some experience with a thematically oriented policy approach in STI, which could form the basis for a broadening and widening of the missionoriented approach.

A thematic orientation towards 'grand challenges' was introduced, not least in response to a similar orientation of the EU Framework Programmes. Especially Horizon 2020 increasingly addresses these challenges, and the Austrian attempts to 'align' with EU policies also appear to have 'imported' elements of such a thematic orientation. The establishment of missions in the new Framework Programme 'Horizon Europe' and the Austrian support for this pillar of the programme also have the potential to strengthen a strategic orientation towards MOIPs. Most 
of all, the development of a new STI Strategy is an opportunity to position MOIPs as a core part of the Austrian STI strategy 2030.

\section{Policy Coordination}

In order to be able to address grand societal challenges, Austrian STI policy not only needs better co-ordination within its own realm but increasingly also with other policy domains (health, energy, transport, security ...). Current policy coordination between STI ministries so far is mostly informal and non-binding, and coordination with other policy domains beyond the confines of STI (such as energy, environment, health ...) is by and large piecemeal and patchy. An exception might be transport policy, which for many years has been under the responsibility of the same ministry as the Mobility of the Future programme. The current cross-ministerial coordination framework (i.e. the 'Task Force STI', comprising the main ministries in charge of STI matters) has mainly been used for mutual information exchange and not as a mechanism for joint strategic priority setting. Thus, the OECD Innovation Policy Review from 2018 re-stated and reinforced the need for changes in governance and funding, especially in policy coordination spanning across policy areas, which is essential for the implementation of most of MOIPs.

In order to align to the missions in Horizon Europe, but also to be able to act to the new approaches to industrial policy in Europe (e.g. the 'IPCEls' or 'Important Projects of Common European Interest '), it is increasingly acknowledged that enhanced cross-ministerial coordination is required, and there are some attempts underway to recognize the importance of new governance mechanisms.

\section{Policy Implementation}

On the level of implementing institutions, there are capacities in place in the respective funding agencies to systematically implement thematically oriented funding programmes. These capacities could be used and further strengthened for the implementation of mission-oriented programmes. What is lacking, though, is the capacity to apply the funding and other instruments in a concerted way. This problem probably cannot be solved at the level of the implementing agencies but would have to be resolved at a higher level of governance.

It has to be added, though, that the respective governance structures and policy mixes have to be tailored to the respective missions. As the case studies and experiences from other countries have shown, the requirements and settings for governance differ considerably between the mission areas.

Assessments, monitoring processes and evaluations are well established at the programme level in Austria. Mostly, they are focussing on 'formative evaluation' and aim at supporting and improving programme management. Therefore, 'reflexivity' often resides with the institutions directly responsible for the implementation of the measure. Monitoring, assessment and evaluation are almost exclusively performed on the level of the individual measures and rarely in a 'systems' or 'portfolio' perspective (a 'systems evaluation of research funding' from 2009 being a noteable exception). The more widespread adoption of mission-oriented policies would there imply a shift in the evaluation practices towards more systemic considerations. 


\section{KEY FINDINGS FROM THE CASE STUDIES}

The four cases analysed in the context of this project (the programmes „benefit/Ambient Assited Living, „Building of Tomorrow”, „KIRAS“ and „Mobility of the Future) display a number of similarities, e.g. that all four programmes focus on topics, which are not solely within the confines of one policy area, but rather run across policy areas. In addition, the programmes typically involve interdisciplinary research, affording a combination of socio-economic and scientific-technological research. However, the case studies also show a number of differences, some of which might be traced back to the specificities of each topical area, which has implications for the goals pursed and the instruments used in these programmes.

\section{Strategic Orientation}

All case studies feature stakeholder participation processes, although to varying degrees. At minimum, other than STI policy officials were involved in programme steering committees, quite often also stakeholders in a broader sense (potential users/addressees) in the specification of calls. In general, directionnality was high, with all four programmes featuring clear overarching objectives, which are broken down into more detailed goals at lower aggregation levels.

On the national level, BMK, the ministry responsible for the four programmes, has clear ownership in these cases (for KIRAS until end of 2019), and it exercises clear leadership in defining and steering them. Operational implementation of the programmes has been delegated to FFG, which interacts regularly with BMK in the definition of calls.

The intentionality of the programmes is clearly visible, with a number of goals and an explicit intervention logic in place. However, in all cases, no ex-ante key performance indicators allow an impact evaluation of the programmes against preset goals.

All programmes display a certain degree of flexibility, e.g. "Mobility of the Future" has implemented new instruments on several occasions, which then have been scrutinised internally and externally. Moreover, all schemes are regularly evaluated; yet, formalised processes for institutionalising changes in the programmes in response to evaluation results are not common. In this respect, the programme "Building of Tomorrow" stands out, as it understands itself as a learning programme featuring also an international exchange of practices.

\section{Policy Coordination}

In all programmes, both horizontal and multi-level coordination are present only to a limited extent. This can be attributed to the specific characteristic of Austrian STI policy-making, where ministries are autonomous in implementing their policies. Coordination between federal and regional levels is limited to single initiatives and instruments. As can generally be observed in Austria (but also specifically in the programmes studied), coordination between federal ministries is geared towards 'negative coordination', i.e. ministries define their respective stakes rather than designing joint initiatives and strategies.

Although there are some attempts of formal coordination (e.g. the case of the steering committee of KIRAS), these mechanisms are rarely used for launching joint actions. At the same time, the intensity of coordination is also limited. In addition, the forward-looking and strategic potential of policy coordination is hardly exploited in any of the programmes. 
Outside the sphere of intra-governmental coordination, the situation is different for all case studies, as all of them feature frequent and intensive cooperation of the responsible ministerial departments with actors and stakeholders from a variety of branches.

\section{Policy Implementation}

All programmes analysed employ varying degrees of policy mixes. In 'Mobility of the Future' the varying logics and market structures of the different thematic fields are reflected in the differentiated use of instruments, with instruments directly targeting social and socio-technical innovations acquiring greater prominence in recent years only. 'Benefit/Ambient Assissted Living' features policy mix diversity in terms of ensuring cross-sectorial diversity and involving end users such as care and support providers, but it shows only limited diversity when it comes to covering the different stages of the innovation cycle. In KIRAS the available instruments cover the value chain of knowledge production from feasibility and usability studies to demonstration projects and thus show sufficient policy mix diversity for security research. The policy mix of Building of Tomorrow similarly covered the whole value chain of knowledge production from basic research to demonstration projects and was complemented by accompanying measures to foster competence development and dialogues between different stakeholder groups. However, limited attention was paid to the coordination with demand-side instruments such as regulation or innovation-oriented public procurement.

Leverage of private sector activity is not achieved to the same extent in the four programmes (and was not aimed at either). While Mobility of the Future shows high leverage in terms of programme additionality, the leverage of private sector contributions within benefit/Ambient Assissted Living, Building of Tomorrow and KIRAS is mainly limited to the requirement of (private sector) co-funding of projects.

With respect to measurability, evaluability and reflexivity', a heterogeneous picture emerges: While measurability can be observed only at limited scale in the analysed programmes, with only a small number of predefined impact indicators, all cases under scrutiny have been repeatedly subject to external evaluation studies. Also reflexivity can be observed, be it in using evaluation results to revise programme structure as in the cases of benefit/Ambient Assisted Living and Mobility of the Future, or learning activities in the programme Building of Tomorrow under the umbrella of accompanying measures that led to the evolution of the programme to Building of Tomorrow plus.

In summary, the Austrian case studies show the following characteristics:

- In all programmes considered, good stakeholder involvement in both programme development and implementation can be observed.

- They are all characterised by clear directionality and intentionality, achieved by a mix of policy instruments that emphasizes the use of supply-side instruments (i.e. R\&D funding) and less so demand-side instruments.

- Furthermore, in all programmes, evaluations are conducted regularly, indicating a rather well developed level of 'reflexivity'.

- On the other hand, weaknesses can be identified with regard to vertical and horizontal coordination, the intensity of coordination, and the effectiveness of evaluations (in terms of institutionalised learning processes). 


\section{FINDINGS AND RECOMMENDATIONS}

The case studies in their strength and weaknesses - though just a small sample of the Austrian STI programmes - can be considered as a good reflection of the general characteristics of the level of development of MOIP in the Austrian STI policy system. The programmes - which were developed at a time before the resurgence of the debate on MOIPs - do not show all the characteristics of what we would define today as a 'fully fledged MOIP'. Yet, they have the potential to be developed in this direction, e.g. by increasing coordination across policy areas, by securing a more comprehensive policy mix and by building in systematic reflection and steering capacities.

The four case-studies presented in this report - even though they are well-chosen goodpractice examples - are a too limited empirical basis to draw strong overarching conclusions and recommendations that could apply across the entire range of MOIPs in Austria. However, based on the cross-cutting analysis of the cases in conjunction with accumulated findings on the framework conditions for MOIPs in Austria, they provide some important pointers to critical issues that will require attention in the future, if the ambition is to strengthen the missionoriented character of thematic STI programmes.

\section{Overarching findings and recommendations}

- Austria provides some promising starting points for setting up and implementing MOIPs successfully on a larger scale.

- At the same time, it needs to be recognized that there is no simple recipe for the design of mission-oriented programmes, because the conditions in the different fields addressed by the programmes differ considerably, and they will achieve their goals only if well harmonized with adjacent policy areas (e.g. sectoral policies) and levels (e.g. local/regional as well as European)

- In order to further develop MOIPs in Austria and fully exploit their potential, a clear commitment by government is needed (e.g. in the STI Strategy 2030); this is crucial because of the cross-cutting nature of missions, affecting several policy areas simultaneously.

- Following on this commitment, the elaboration of a concrete 'mission strategy' aiming to identify and implement a small number of missions should be started. This mission strategy should be harmonized with European missions, European Green Deal actions and IPCEls (Important Projects of Common European Interest). Next to national missions that are congruent with these EU mission-type initiatives, some selected missions that are complementary to EU initiatives could also be considered.

\section{Recommendations regarding strategic orientation}

- Maintain strong ownership by ministries in charge of the specific MOIPs to be implemented (e.g. BMK for Climate-oriented missions, BMLV for defence-related missions...);

- Maintain or even enhance stakeholder engagement in directing MOIPs (e.g. like in KIRAS); 
- Better specify appropriate goals ex-ante, and - in the case of longer-term and transformative programmes and policies - correct them explicitly if new evidence is available (e.g. in energy- or mobility-related programmes);

- Build up organisational and institutional capacities for strategic governance of longer-term missions, underpinned by corresponding policy learning processes (e.g. in terms of better aligning national and regional policy initiatives).

\section{Recommendations on policy coordination}

- Recognise the need for time and other resources for effective (positive) coordination among different policy areas (rather than just negative coordination);

- Strengthen and empower existing coordination mechanisms (e.g. inter-ministerial STI Task Force or respective sub-groups thereof) for purposes of effectively providing direction to programmes;

- Intensify interaction with stakeholders, because government policy alone will not be able to reach mission goals. This includes putting stakeholders in a steering role as well (see e.g. KIRAS, Building of Tomorrow);

- Provide experimental spaces for better harmonising STI policy with sectoral "demand side" policies (e.g. regulatory sandboxes, procurement).

\section{Recommendations on policy implementation}

- Provide a strong and proactive management of MOIPs with appropriate implementation capacities and support infrastructure (e.g. by expanding the mandate of existing agencies, or even creating dedicated mission-centric agencies);

- Include instruments for addressing social and behavioural as well as technological innovations, in line with a broader understanding of innovation needed for missions (e.g. innovation themes "Active Mobility" and "Multimodal Lifestyles" within Mobility of the Future);

- As consequence, mobilise a wider range of non-R\&D actors in programmes and projects;

- Provide instruments to accelerate scaling and generalisation of novel solutions (e.g. Urban Mobility Labs);

- Enhance and strengthen operational reflexivity and new "impact-oriented" monitoring and evaluation processes

In taking up some of these findings and further elaboration of the recommendations, Austria's STI policy has a good basis to enhance its capacities to implement mission-oriented innovation policies, which are likey to be a major strand of STI policy in the future. 


\section{Background and Methodological Framework}

\subsection{BACKGROUND}

By mission-oriented innovation policy (MOIP), we understand "initiatives [which] typically are ambitious, exploratory and ground-breaking in nature, often cross-disciplinary, targeting a concrete problem/challenge, with a large impact and a well-defined timeframe. More specifically, they have a clearly defined (societal or technological) goal with preferably qualified and/or quantified targets and progress monitored along predefined milestones. Directionality and intentionality of these initiatives is what differentiates them from other types of initiatives, such as systemic or challenge-oriented policies" (JIIP, 2018a, 4).

Mission-oriented policy approaches have again received growing interest against the background of two developments: While so-called "horizontal" or "generic" approaches to research, technology and innovation policies have largely been successful in improving the general innovation performance or the rate of innovation, there were perceived limitations in terms of insufficiently addressing the direction of technical change and innovation. At the same time "grand societal challenges" emerged such as climate change, security, food and energy supply or ageing populations that called for orientation and targeting of innovation efforts. In addition, the success of (some, though not all) mission-oriented approaches in countries like Korea, China and the United States in boosting technological development and competitiveness also gave rise to a debate which pointed to the potential of successful government intervention (Mazzucato, 2013).

The debate on the appropriate role of government in research and innovation is not new, though. Since World War II, several waves of policy approaches have succeeded each other, each with a different emphasis on the main rational and intervention logic (for a recapitulation of the historical development, see Gassler, Polt, Rammer, 2006 and 2008). These paradigmatic changes of science, technology and innovation policies were also reflected in the European context: Already in the preparation of the fourth Framework Programme for Research and Technological Development (FP 4), the so-called 'Maastricht Memorandum' (see Arundel and Soete, 1993), prepared by an EC expert group, emphasised the importance of a new ${ }^{1}$ type of mission-orientation. Based on a systems approach to innovation, the idea of this new type of mission-orientation in STI policy was suggested for long-term goals, exemplified by the area of environmentally sustainable development, which needs to be well embedded into societal needs and requirements. The influence of this programmatic document on the shaping of FP 4 was limited, but it seems to have been more influential on the next framework programme (FP 5), which introduced key actions targeting long-term ambitions cutting across established areas of research and technology development.

\footnotetext{
${ }^{1}$ As opposed to the old, more narrow approaches of the immediate post-war period with their focus on defence, aerospace and nuclear energy.
} 
The Aho Report (Aho et al., 2006) called for "resurrecting the demand side of innovation" (Edler and Georghiou, 2007), and the subsequent expert group on European Research Area (ERA) rationales reintroduced the notion of key societal challenges to the debate about $R \& \mid$ policy in Europe (Georghiou et al., 2008). While this term was inspired by the "Grand Challenges" debate in the US, it differed by stressing the societal nature of long-term future challenges rather than focusing on scientific-technological challenges. The Lund Declaration of the European Council (2009) took up this idea and stressed the key role of Europe to tackle such challenges, like global warming, tightening supplies of energy, water and food, ageing societies, public health, pandemics, security or an eco-efficient economy. With Horizon 2020, this approach was put into practice in programmatic terms, with the third pillar of Horizon 2020 and other multi-lateral initiatives in Europe (e.g. Joint Programming Initiatives) being dedicated to societal challenges.

While the orientation towards societal challenges thus has been well established in European STI policies, the interim evaluation of Horizon 2020 found that it was insufficiently translated into concrete action with measurable outcomes (Lamy et al., 2017). Hence the Lamy report and a programmatic paper on mission-orientation in European STI policy (Mazzucato, 2018) asked for the explicit inclusion of a mission-oriented approach in the Framework Programme. This approach was further elaborated by the recommendations from European expert groups (ESIR, 2017, RISE, 2017), two major analytical studies on the empirical evidence on missionoriented policies (JIIP et al., 2018a and 2018b) and foresight activities (Weber et al., 2018). This finally led to the adoption of a Mission-Oriented approach as part of Horizon Europe, the up-coming European Framework Programme starting in 2021. Currently, five mission boards, established by the European Commission, are working on the specification of concrete missions to be addressed as part of the upcoming Horizon Europe framework programme.

In parallel to these developments at a European level, several countries have embraced similar concepts for redefining their research and innovation policies. For example in Germany, the High-Tech Strategy may have been initially motivated by the ambition to strengthen primarily the competitiveness of German industry, but it subsequently combined this goal with other, for instance environmental, goals (Dachs et al., 2015). The German 'Energiewende' is yet another example of an ambitious policy aiming to trigger a process of transformation by combining new impulses from research and innovation with changes in the regulatory and institutional framework as well as with major infrastructure investments. The French Commission Innovation 2030, the Dutch Top sector approach and the Swedish Challenge-Driven Innovation programme equally frame STI policy in the context of ambitious wider-ranging policy goals.

Against the backdrop of this renewed interest in mission-oriented STI policy, the OECD has addressed the importance of a more comprehensive and at the same time, more 'directional' approach to innovation policy and has launched a project looking into current experiences with MOIP in its member countries. The present study on Mission-Oriented Innovation Policies (MOIPs) in Austria comprises the Austrian contributions to the current OECD project on mission-oriented innovation policy (MOIP) initiatives. It was commissioned by the Austrian Federal Ministry of Climate Action, Environment, Energy, Mobility, Innovation and Technology 
(BMK - formerly BMVIT [Federal Ministry of Transport, Innovation and Technology]) ${ }^{2}$ to contribute Austrian experiences to the international debate about these initiatives, but also to stimulate a national debate on mission-oriented innovation policy. ${ }^{3}$ In particular, results can feed into the current preparations for a new Austrian STI strategy, which will replace the existing one that ends in 2020. The OECD project on mission-oriented innovation policy can thus be seen as a follow-up of the recommendations from the recent OECD Innovation Policy Review of Austria that explicitly addressed the topic of Mission-Oriented STI Policy 4 .

The main parts of the project were

(i) an overall assessment of the Austrian innovation (policy) system and its characteristics and the implications of these characteristics for its capacity to carry out MOIP initiatives (Chapter 2) and

(ii) Four cases studies on recent policy initiatives in this vein, which were selected to highlight the potential (and the current limitations) of this approach in the Austrian context (Chapter 3 ). The selection of the case studies was done jointly with representatives from BMK to select those, which came closest to the definition of MOIP as developed in the context of this project.

(iii) In Chapter 4, we provide a synthesis of the main findings.

\footnotetext{
${ }^{2}$ Throughout this report, the notions of BMK and BMVIT are both used, reflecting the circumstances. We would especially thank Brigitte Weiss from BMK for the support and active contributions throughout the project. She is also supporting the project in the function of a member of the Steering Committee. For information on the project steering group see: https://community.oecd.org/community/cstp/mission-oriented-policies

${ }^{3}$ In the context of this project, a workshop was held in Vienna on September 27, 2019, which brought together policymakers and researchers on MOIP from various OECD countries and Austria and discussed the conceptual framework of the project and its theoretical underpinnings.

${ }^{4}$ See OECD 2018 Reviews of Innovation Policy: Austria 2018. Paris. https://read.oecd-ilibrary.org/science-andtechnology/oecd-reviews-of-innovation-policy-austria-2018_9789264309470-en\#page1),
} 


\subsection{METHODOLOGICAL FRAMEWORK}

The case studies and the overall country description were carried out following the methodological framework elaborated during the first phase of the OECD project ${ }^{5}$. Parts of this work have been already taken up in the progress report of the OECD on the project, comparing Austria and Norway as the first fully developed country cases available (OECD 2020).

The main underpinning hypothesis is that the forms and types of MOIPs in a given country can only be understood within:

- the national institutional setting in which they are embedded and that determines to a great extent what is politically and socially feasible at one point in time; e.g. countries differ in their capabilities in steering, funding and implementing systemic policies (such as MOIPs);

- the policy trajectory that has gradually shaped them, moving forward through experimentation, negotiation and learning. A number of factors, among others the general stance of policy regarding the role of state intervention, the respective choice of policy instruments (e.g. generic vs. specific measures), etc forms this trajectory.

These national factors pertain to different dimensions of the overall analytical framework: strategic orientation, policy coordination and policy implementation (Box 1).

\footnotetext{
${ }^{5}$ The analytical framework was detailed in the project progress report [DSTI/STP(2019)29] presented at the 115th meeting of the CSTP in October 2019.

${ }^{6}$ See OECD DSTI/STP(2020)6/PART2: Mission-oriented innovation policy initiatives to address societal challenges.

Comparative analysis of two national case studies and online explorable policy guide. 27 March 2020
} 


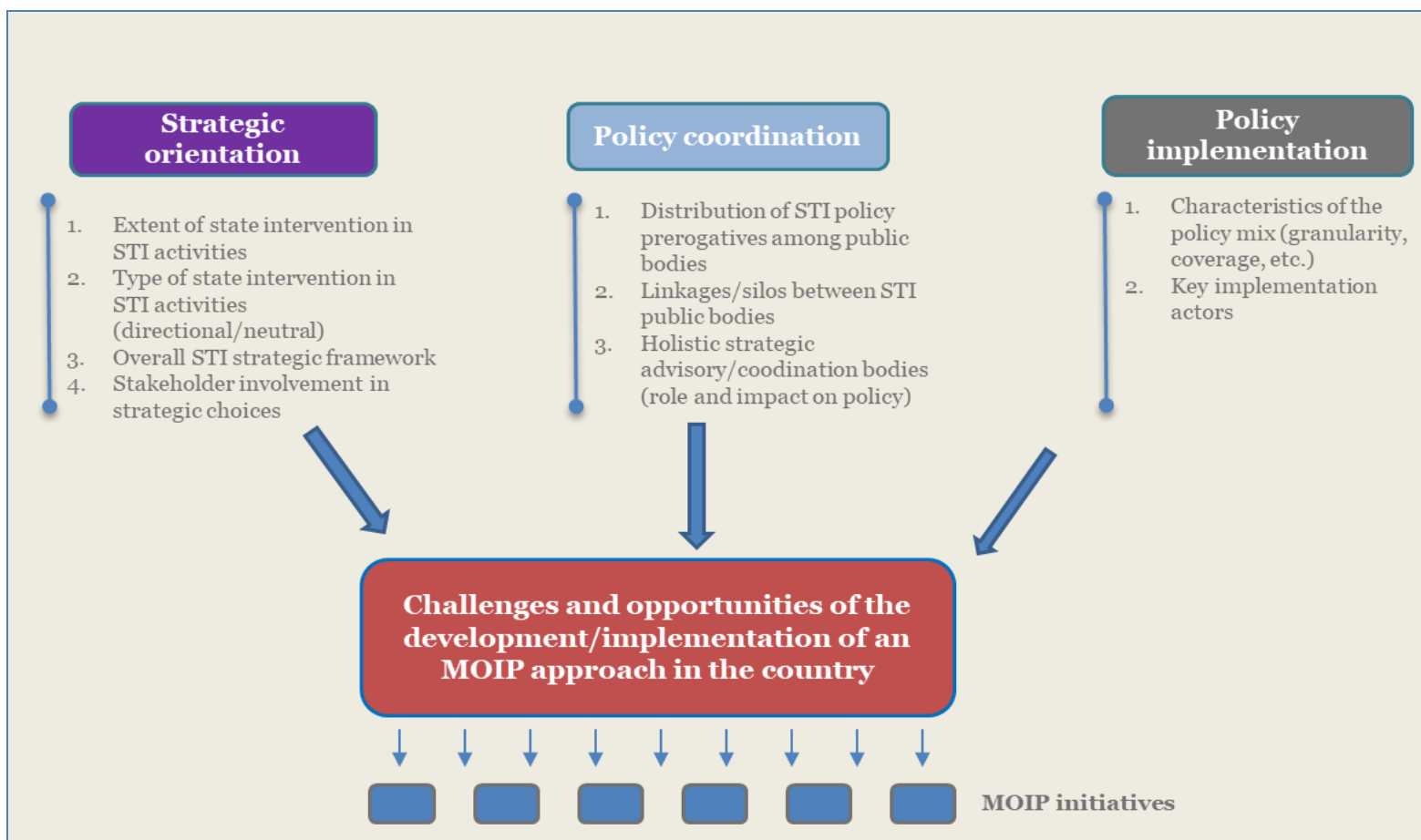

Strategic orientation - Governments differ significantly in the extent to which and how they can prioritise their public intervention in certain challenge areas. Within one given country, these priorities and the way they are addressed by STI policy tends to evolve over time in line with changes in political majorities as well as with structural changes and policy learning. This can be captured by the extent and the type of priority-setting, the features of the national STI strategic framework as well as the process for developing and implementing this framework (e.g. the type and extent of stakeholder involvement, the 'action plan' and the modalities to coordinate the plan's interventions). One key feature of MOIPs being, as their name suggests, that they aim towards a specific challenge and are monitored against concrete goals and milestones, these features of a national innovation system will greatly influence both the acceptance and appetite for such policies and their ability to make and implement selective choices.

Policy coordination - Aiming to address societal challenges and developing the adequate policy interventions to succeed in achieving this contrast with traditional policy approaches. It creates an imperative to 'reverse' and 'expand' the innovation chain:

- Reverse the innovation chain - Starting from a challenge, in place of the more linear - supplypush - approach, requires strong connection and articulation between the different stages of the innovation chain, and that the demand side steers the whole chain. Practically, this calls for instance for users of a specific innovation and representatives of stakeholders impacted by the challenge to be included in the process from the start;

- Expand the innovation chain - Contrary to scientific and technological challenges upon which focused the 'old' mission-oriented policies (e.g. the Apollo programme in the United-States in the 1960s or the French Grand Programmes in the 1970s-80s), societal challenges do not originate from and are not confined to the STI arena. A wider set of actors beside research and innovation implementers must, therefore, be included in the process (at the policy, programme or project levels). 
These two features of the MOIP approach have important implications for the intensity and scope of policy coordination: although it is not a new issue - as witnessed by its prominent position in almost all OECD Innovation Policy Reviews - the silos between the authorities in charge of respectively higher education, research and innovation policies (at the levels of strategic councils, ministries and/or agencies) are particularly detrimental to MOIPs as they fragment the innovation chain. Furthermore, coordination should extend beyond these STI policy bodies to also include sectoral authorities in areas such as agriculture, environment or health, depending on the type of societal challenges.

Policy implementation - In the end, MOIPs' impact depends on the actions taken, and in particular the package of instruments articulated and mobilised to address the targeted challenges. In many countries, at least as an initial approach, MOIPs build upon existing policy instruments and implementation bodies. The existing policy landscape therefore greatly conditions the design of such policies that can be implemented. Even in countries that develop new initiatives, the novelty is most often at the level of the strategic and coordination framework, while the modes of intervention are those that are available in the participating agencies.

Source: OECD (2020, p.8/9)

While the focus of the work in the context of the current OECD project was to compare the general characteristics of the policy processes that come along with MOIP, it has to be stressed that the characteristics of these processes also are different with respect to the specific type of mission. Current work (e.g. Polt and Weber 2019 and Wittmann et al 2020) tries to identify these characteristics and has come up with a broad distinction between missions that aim at more narrowly defined scientific and technological goals ('accelerator missions') and those that address larger societal problems ('transformer missions'). These types of missions apparently differ considerably with respect to the challenges for governance and the approproiate governance modes to be employed. While in the past, most types of missions have been of the 'accelerator type', in recent years, and with growing emphasis on tackling complex societal problems 'transformer type' of missions have been increasingly proposed, These missions address grand societal challenges and are thus inherently more complex and difficult to turn into programmes that have and can achieve clearly defined goals ${ }^{7}$.

Table 1: Characteristics of different types of missions

\begin{tabular}{|c|c|c|c|c|}
\hline & \multicolumn{2}{|c|}{ Accelerator Mission } & \multicolumn{2}{|c|}{ Transformer Mission } \\
\hline & Type 1 (A1) & Type 2 (A2) & Type 1 (T1) & Type 2 (T2) \\
\hline $\begin{array}{l}\text { Type of } \\
\text { problem }\end{array}$ & $\begin{array}{l}\text { Market } \\
\text { failure }\end{array}$ & $\begin{array}{lr}\text { Market and } \\
\text { structural failure }\end{array}$ & $\begin{array}{l}\text { Transformational } \\
\text { system failure }\end{array}$ & $\begin{array}{l}\text { Transformational } \\
\text { system failure }\end{array}$ \\
\hline Type of solution & $\begin{array}{l}\text { Scientific } \\
\text { innovation }\end{array}$ & $\begin{array}{l}\text { Technological/ } \\
\text { regulat. change }\end{array}$ & $\begin{array}{l}\text { Transformation of } \\
\text { system }\end{array}$ & $\begin{array}{l}\text { Transformation of } \\
\text { system (behavior) }\end{array}$ \\
\hline $\begin{array}{l}\text { Problem vs. } \\
\text { goal oriented }\end{array}$ & $\begin{array}{l}\text { Problem- } \\
\text { oriented }\end{array}$ & Goal-oriented & Goal-oriented & Problem-oriented \\
\hline $\begin{array}{l}\text { Demand for } \\
\text { governance }\end{array}$ & Low & Medium & High & Very high \\
\hline
\end{tabular}

\footnotetext{
${ }^{7}$ For a discussion of the difficulties in implementing missions, see the seminal contribution by Nelson (1977): "If we can land a man on the moon, why can't we solve the problem of the ghetto?
} 


\section{Framework conditions for MOIP in Austria}

This section focuses on the identification and analysis of the main factors that hinder or enable the ability of the Austrian governments to more fully adopt and implement a mission-oriented policy approach. This analysis is carried out using the three dimensions of the OECD analytical framework:

(i) Strategic orientation, the ability of a country to engage a wide array of public and private actors in the selection of well-informed societal challenge(s) and the legitimation of focused policy interventions towards these challenges.

(ii) Policy coordination, i.e. the ability of a country to ensure the consistency of the action frameworks of different public and private bodies covering various policy fields and actors in order to address the targeted societal challenges.

(iii) Policy implementation, i.e. the ability of a country to implement, monitor and evaluate in a consistent way an integrated package of instruments/modes of interventions covering different sectors/areas, stages of the innovation cycle and/or disciplines to address the targeted societal challenges.

\subsection{STRATEGIC ORIENTATION}

Over the past decades, Austria has seen an increasing R\&D intensity, which has made it one of the most R\&D intensive countries in Europe ${ }^{8}$. In this period, it has established new and reoriented existing funding agencies (e.g the Austrian Research Promotion Agency FFG, the Climate and Energy Fund KLIEN, Austria Promotional Bank AWS, etc.), it formulated for the first time a national STI strategy in 2011 and established a large number of structural and thematic programmes to support science, technology and innovation. As the share of public funding is a bit higher than in other OECD countries, and the share of public support to business $R \& D$ is (considerably) higher than the OECD average, Austria would - in principle - have the financial means and the institutions in place to develop effective policy interventions to orient research and innovation actors towards societal challenges.

In the STI strategy $2020^{9}$,, the need to develop a strategic policy approach to address 'grand societal challenges' was explicitly recognized, pointing to challenges like climate change, ageing societies and resource and energy supply as potential target areas. The strategy also clearly pointed out that the pursuit of such policy approaches would need changes in the governance of STI policies. Subsequently, a number of funding channels (e.g. the Climate and Energy Fund KLIEN) and programmes were developed which tried to address these challenges. Hence, there was a certain thematic orientation towards 'grand challenges', also to some extent driven by a similar orientation of the EU Framework Programmes. Especially Horizon 2020 increasingly addressed these challenges as well, and Austrian researchers participated very successfully in the respective parts of the program. However, in spite of this well-intentioned strategy, several of the ambitions formulated in the STI strategy2020 have not been materializing. Moreover, the Austrian Parliament is not a "working Parliament" (different

\footnotetext{
${ }^{8}$ See e.g. the annual Austrian Reports on Science and Technology for a description of the development

${ }^{9}$ Becoming an Innovation Leader. Strategy for research, technology and innovation of the Austrian Federal Government. Vienna 2011
} 
from e.g. the US Congress and the German Bundestag), featuring a subcommittee on the policy area of science, technology and innovation, which however rarely is proactive. ${ }^{10}$

In this period, though, the main thrust of STI policy was predominantly geared towards an improvement of the overall research and innovation system (e.g., industry-science relations, as reflected in its largest scheme for direct support, the competence center programme COMET) or specific parts of the system and their functioning. Through institutional reforms (e.g. the reform of the Higher Education system) the building up of new institutions (e.g. the establishment of Institute for Science and Technology Austria (ISTA), and the foundation of major new institutes at the Austrian Academy of Science, and substantial public investments in basic research, the international visibility and level of excellence was reinforced. The concrete topics of these institutes were selected primarily with respect to scientific excellence or, in the case of COMET and its predecessor programs, were formulated bottom-up based on existing industrial and scientific specializations. This is in line with the approach fo the Austrian Science Fund (FWF), which deliberately refrained from setting thematic priorities, accepting solely scientific excellence as a selection criterion for funding research. Institutional funding of $\mathrm{HEI}$ without specific thematic orientation is considerably higher in Austria in comparison to comparator OECD countries. In addition, in the performance agreements - another major invention in governance of the R\&l system introduced in recent years - with research institutions (universities, academy of sciences) no such thematic prioritization was aimed for, even when universities were asked to better profile themselves against each other.

A similar tendency can be observed in public support to business R\&D, where the most rapidly growing source of funding for $R \& D$ was the $R \& D$ tax credit, which was meant to raise the $R \& D$ intensity of business in general, but not to give it specific thematic orientations. In addition, the General Programme of FFG (Basisprogramme) is non-thematic nature and provides public $R \& D$ funding to single applicants, in particular from the private sector.

Building on thematic programmes established in the 1990s (and predominantly developed in the realm of BMK), the FFG has a specific strand of activities devoted to thematic programmes'. In these thematically oriented programmes some of which even fall under the core definition of 'mission-oriented' programmes (see e.g. the four case studies presented in this report), Austria has gained long-standing experience with a thematically oriented policy which could form the basis for a broadening and widening of the mission-oriented approach in Austria.

As the majority of measures and funding streams primarily affected the rate and to a much lesser extent the direction of research and innovation and in most of them, no (top-down, exante) thematic prioritization was applied, it is fair to say that Austrian STI policy, while in some strands addressing grand societal challenges, was not 'mission-oriented' to a large extent. In the Austria debate, this was discussed very often as an (overly) 'input-oriented' approach, while 'output-orientation' (in terms of innovations both on the side of the business sector as well as

\footnotetext{
${ }^{10}$ Biegelbauer 2013, Dinges et al 2018
} 
on the side of society). Hence, the OECD's Innovation policy review of Austria from 2018, challenged Austrian STI policy to:

"Establishing clearer priorities in the innovation system overall and effecting more concerted action among Ministries. An opportunity exists to better articulate Austria's many public STI policies with societal challenges. Focussing on societal challenges (and "missions") is a way to achieve higher impact from STI investments by producing more spillovers from individual research and innovation activities and by better transforming research results into economic activity and social practice. For a small country, a main challenge is the limited number of large actors in the business sector that could take up policy initiatives and transfer them into economic results" (OECD 2018) ${ }^{11}$

\subsection{POLICY COODINATION}

The STI Strategy from 2011 had already pointed to the fact that, in order to be able to address grand societal challenges, STI policy not only needs better and co-ordination within its own realm, but increasingly with other policy domains (health, energy, transport, security ...) and across different policy levels. Austria features a federal system, which makes vertical coordination necessary, but it is seen as a difficult, cumbersome and time-consuming effort by politicians, civil servants and the broader public. The STI Strategy did not specify exactly how the governance mechanisms should look like, though. In the aftermath of the agreement on the STI strategy, a coordination forum was established to monitor and coordinate the implementation of the strategy. The so-called 'Task Force STI' comprised major ministries deemed relevant for the task. Assessments of the implementation of the strategy (see the respective chapters in the Austrian Research and Technology Reports from 2016 and 2019 respectively) concluded that the coordination worked mainly as flow of mutual information and not as a mechanism for joint strategic priority setting. Thus, it amounted more to 'negative coordination' (the delineation of areas of what not to do) and hardly to the positive one needed for real mission-oriented policy. Against this background, the OECD Innovation Policy Review from 2018 re-stated and reinforced the need for changes in governance and funding, especially in policy coordination spanning across policy areas.

In the future, an 'external' source for policy (thematic) co-ordination could come in with the new policy initiatives of the EU. In the new Framework Programme 'Horizon Europe' due to start next year, the EU has defined the (currently five) so-called 'mission areas', from which subsequently concrete mission topics will be developed. In addition, based on a streamlining of the number and types of partnership initiatives to be supported by Horizon Europe (i.e. former Public-to-Public and Public-to-Private Partnerships), a further element of thematic focusing will be introduced. Austria is trying to align with these initiatives and is building up support for the Austrian members of the 'mission board' (the bodies tasked with identifying and communicating the concrete missions) and of the governing bodies of the new partnership initiatives. 'Alignment' with EU policies is an important issue for Austrian STI policy and will also be covered prominently in the new STI strategy.

\footnotetext{
11 OECD (2018): OECD Reviews of Innovation Policy: Austria 2018, OECD Reviews of Innovation Policy, OECD Publishing, Paris, https://dx.doi.org/10.1787/9789264309470-en.
} 
In the same vein, Austria tries to align with another sort of 'directional' policy initiated by the EU, namely the 'Important Projects of Common European Interest (IPCEI)'. In these projects, aimed at increasing European competitiveness in selected value chains, state aid rules are being alleviated to allow for 'new industrial policy approaches'. The selection of these projects requires cross-ministerial coordination and involves considerable monies. So far, the former Ministry of Transport, Innovation and Technology (now BMK) had a leading and coordinating role, but involved all relevant ministries and agencies in the process of identifying and selecting IPCEls potentially interesting for Austria.

Current policy coordination between STI ministries so far is mostly informal and non-binding, and coordination with other policy domains beyond the confines of STI (such as energy, environment, transport ...) is piecemeal and patchy ${ }^{12}$. Thus, while the existing structures are not yet fully developed for formulating and implementing a coherent mission-oriented policy, there are some attempts underway to recognize the importance of new governance mechanisms in the future.

\subsection{POLICY IMPLEMENTATION}

While assessments of the STI policy mix (including the OECD Innovation Policy Review of 2018 or an earlier 'systems evaluation') frequently and consistently find a developed and farreaching set of instruments, there are observations that the balance of the portfolio of the instruments has shifted very much to non-oriented instruments in the recent past (e.g. the STI Tax Credits) which limits the public capabilities to steer thematically. Another weak side of the instruments' toolbox is probably a lack of emphasis on the use of demand-side instruments, which are very important in a number of mission-oriented policies. While this instrument has been developed conceptually ('Innovative Öffentliche Beschaffung') and has resulted in some activities (e.g. Pre-Commercial Procurement (PCP) and Public Procurement of Innovative Solutions (PPI)), a recent assessment found the instrument not being adopted to great extent and impact (KMUF et al 2018). ${ }^{13}$

Another feature of the policy mix is that the plethora of instruments is rarely applied in a coordinated manner and does not take into account the effects of other measures. On the level of the individual measures, stakeholder involvement and close interaction between policymakers and implementing agencies are working very smoothly. The overall coordination of instruments remains a formidable challenge, though.

On the level of implementing institutions, there are capacities in place in the respective funding agencies to systematically implement thematically oriented and even 'mission-oriented' funding

\footnotetext{
12 See Biegelbauer, P. (2013). Wie lernt die Politik - Lernen aus Erfahrung in Politik und Verwaltung. Wiesbaden, VS Verlag für Sozialwissenschaften. or Dinges, M., et al. (2018). "The Tower of Babylon in the Governance of Research, Technology and Innovation: Participatory Foresight as a Method of Policy Coordination." Futures 100: 34-44.

${ }^{13}$ KMUFA et al (2018): Evaluierung der Umsetzung des Leitkonzepts für eine innovationsfördernde öffentliche Beschaffung in Österreich, Endbericht, KMU Forschung Austria, Wien
} 
programmes. The FFG has a specific branch of its activities dedicated to 'thematic programs' and one dealing with space and aeronautics specifically. These departments have a longstanding tradition of addressing specific areas of technology with R\&D funding instruments. The Climate and Energy Funds (KLIEN) addresses climate change, and transitions in the areas of Energy and Mobility. It addresses the research communities in these areas but also operates major funding schemes to support a wide range of climate-related investment initiatives and change processes at regional level (so-called 'model regions').

Assessments, monitoring and evaluations are well established in Austria. Mostly, they are focussing on 'formative evaluation' and aim at programme and management improvement therefore, 'reflexivity' often resides with the institutions directly responsible for the implementtation of the measure. Monitoring, assessment and evaluation are almost exclusively performed on the level of the individual measures and not in a 'systems' or 'portfolio' perspective (the above mentioned 'systems evaluation of research funding' from 2009 being an exception). The more widespread adoption of mission-oriented policies would need changes in the evaluation practices as well. 


\section{Case Studies: Mission-Oriented Innovation Programmes in Austria}

\subsection{BACKGROUND OF THE CASE STUDIES}

In the framework of the project, we have selected four case studies, i.e. the programmes „benefit/Ambient Assisted Living“, „Building for Tomorrow“, „KIRAS“ and „Mobility of the Future". They were selected in consultation with the civil servants of BMK with respect to the (potential) presence of elements of mission-oriented innovation policies in the programmes. All four programmes have been devised and funded by the BMK, and they have been already active for several years, ensuring that ample experience exists regarding planning, implementation and adaption of the schemes. The four programmes that are being investrigated have initially not been designed in view of the currently discussed MOIP and the criteria that are used for assessing them now have not been available when the programmes were planned and implemented.

The case study analysis features several steps. First, a general overview was given, based upon document and literature analysis (including, inter alia, programme documents, policy papers, evaluation studies and social science literature). Second, the authors led interviews with experts from the ministry, research organisations, the Austrian Research Promotion Agency (FFG) and project coordinators, leading to a more fine-grained picture of the programmes and associated processes of programme development, planning, implementation, evaluation and adaptation. Third, after debating the reports within the project team, draft versions of the case studies were discussed with BMK civil servants, whose input led to a further refinement of the case descriptions. Finally, comments from a workshop on 20 May 2020, during which the project outcomes were discussed with experts from ministries and agencies, led to the final case study versions.

The case studies were developed in parallel with similar efforts in Norway, together with Austria the first country to deliver national cases on mission-oriented innovation policies, and with the more conceptual work carried out by the OECD staff. Further case studies are under ways in Japan and South Korea. There was an exchange between the national study team and the OECD in which the cases became part of the OECD's ongoing considerations on the methodology of its work on mission-oriented innovation policies. Moreover, the OECD framework, as well as first experiences with its application, were debated with the OECD in two workshops on 27 September 2019 and 20 May 2020. 


\subsection{FOUR CASE STUDIES OF MOIP IN AUSTRIA}

\subsubsection{Case Study 1: Mobility of the Future}

\subsubsection{Introduction}

Against the background of the OECD's Committee for Scientifc and Technological Policy (CSTP) project with a focus on establishing an analytical framework and typology of new mission-oriented innovation policy initiatives, the case studiesare a test case for the analysis of mission-orientated policies. In this approach, mission-orientation concerns three levels of policymaking: i) strategic orientation, ii) policy coordination, iii) policy implementation.

The case studies presented beloware based on desk research of programme documents, strategies, existing studies and evaluations of the Austrian programme, as well as interviews with key policymakers, programme officers, and other stakeholders ${ }^{14}$.

\subsubsection{The Programme "Mobility of the Future" (MdZ)}

The programme MdZ is active from 2012-2020. It is based upon the experiences with two precursor programmes, i.e. IV2S (Intelligente Verkehrssysteme und Services 2002-2006) and IV2Splus (Intelligente Verkehrssysteme und Services plus 2007-2012). MdZ focuses on research, technology and innovation in the mobility sector. The programme is funded by the Federal Ministry for Climate Action, Environment, Energy, Mobility Innovation and Technology, in short: Federal Ministry for Climate Action (BMK), ${ }^{15}$ and is implemented by the Austrian Research Promotion Agency (FFG). It features an annual funding budget of $€ 15$ - $€ 20$ million.

Similar to the two previous programmes IV2S and IV2Splus, MdZ has been designed as a new mission-oriented policy, linking social and technological innovation, including stakeholders and integrating social and societal objectives. In all three programmes, sustainability was understood as a central feature and paralleling the three dimensions of sustainability, three strategic objectives were targeted, i.e. social, environmental and economic objectives.

In comparison to the two previous programmes, MdZ features a number of changes: ${ }^{16}$

- no fixed programme lines, but four thematic fields, i.e. „mobility of persons“, „mobility of goods“, „transport infrastructure" and "vehicle technologies“. Within these fields flexible thematic priority areas are regularly identified as part of STISTI-roadmaps, which are the basis for project calls,

- intervention flexibility covering several thematic priorities as well as other national and international programmes in joint project calls,

- emphasis on social and organisational innovations in addition to technological innovation,

\footnotetext{
${ }^{14} \mathrm{~A}$ list of interviewed persons is provided in Appendix I of the respective case study

15 Until 2019: Federal Ministry for Transport, Innovation and Technology (BMVIT)

${ }^{16}$ BMVIT 2015, page 5
} 
- supporting measures regarding implementation and quality management,

- the effort to introduce comprehensive thematic management covering several funding instruments from FFG as well as international networking.

MdZ funds Austrian industry, engineering companies, university and non-university research centers, corporations, NGOs and public organisations, such as infrastructure operators and providers of mobility services, public administration units as well as international partners (budget maximum 20\%). There are calls for proposals twice a year with varying thematic focuses. Funding is possible for cooperative and strategic applied research, dissertations and several FFG instruments such as cooperative projects, feasibility studies, supporting studies, innovation labs, endowed professorships and lighthouse projects. ${ }^{17}$

The programme has a clear mission statement, recurring on the rising mobility needs of society against the backdrop of societal challenges, economic competitiveness and negative externalities of mobility. MdZ is described as based on the offering of new solutions through research, technology and innovation. It has a systemic STI approach, having in mind at the same time the interests of society, environment and economy (see Fig.2). Mobility needs should be satisfied, negative effects of mobility should be minimised. ${ }^{18}$

Figure 2: Focus of projects, based on 4 operational programme objektives (2017)

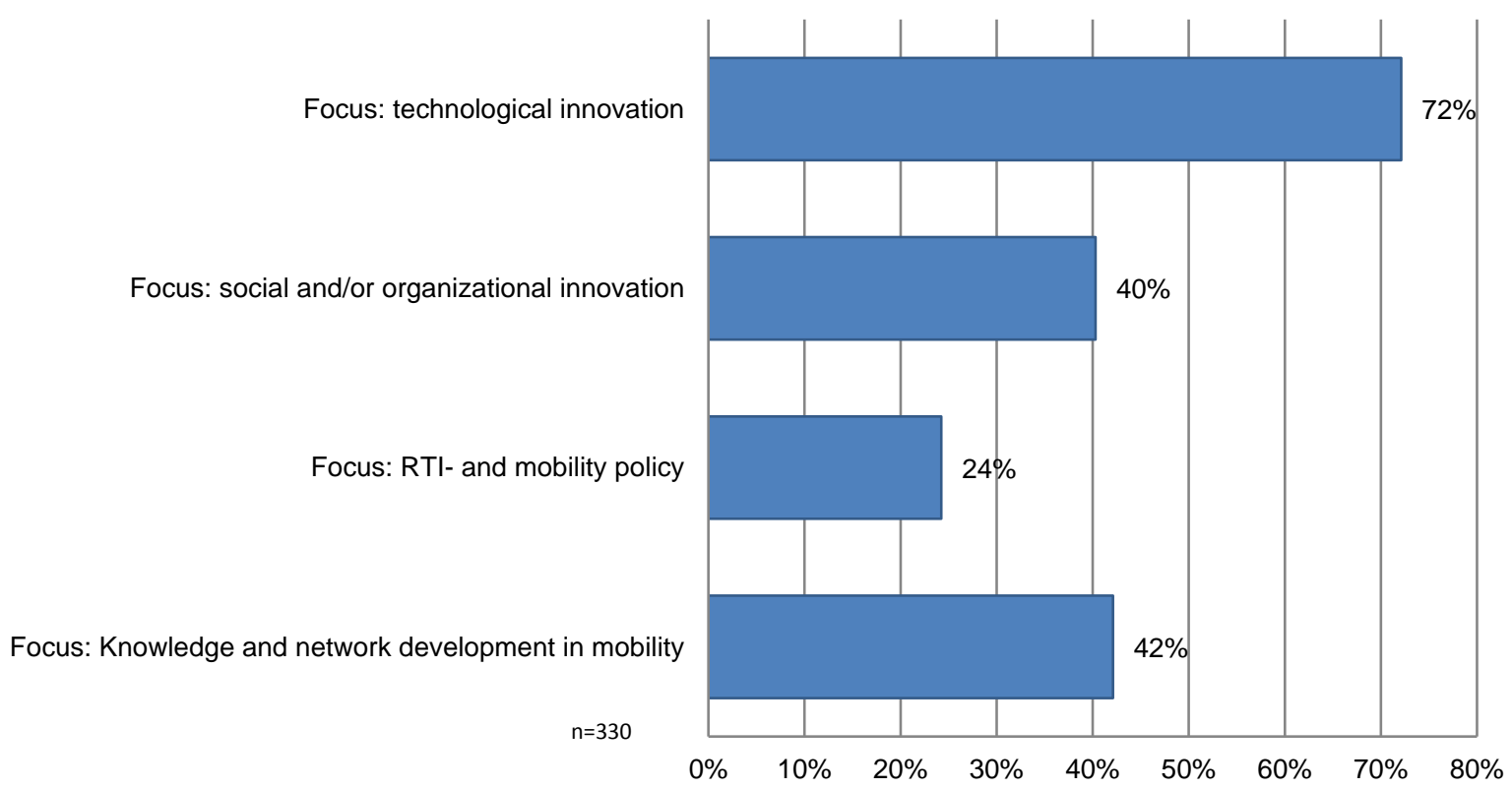

Quelle: BMVIT 2018a; (multiple answers possible)

\footnotetext{
${ }^{17}$ BMVIT, page 3

${ }^{18}$ BMVIT, page 8
} 
In the interim evaluation of the programme from 2018, which took into account the years 2012 to $2016, \mathrm{MdZ}$ in general is assessed very positively, e.g. for its overall structure, goal setting, the way in which the programme is carried out and especially its additionality. However, it received also some criticism, e.g. on the usage of indicators as well as cross-thematic activities, which may profit from more intensive coordination. ${ }^{19}$

In the following, we will analyse MdZ following the OECD guidelines on new mission-oriented innovation policy initiatives.

\subsubsection{Mission-orientation at strategic orientation level}

According to the OECD definition, mission-orientation at strategic orientation level concerns setting broad policy directions to inform and select societal challenges and strengthen the legitimacy of subsequent policy interventions. At strategic orientation level, mission-orientation is associated with five expected attributes:

- Legitimacy

- Directionality

- Leadership

- Intentionality

- Flexibility

\section{Legitimacy}

Stakeholder participation is in the DNA of Austrian policy-making, which features the "Social Partnership" (Sozialpartnerschaft), a neo-corporatist policy arrangement of regular negotiations between employers' organisations, employees' organisations and the state (Karlhofer/Talos 2005). Therefore, it may come as no surprise that, similar to the two previous programmes IV2S and IV2Splus, MdZ has been created with frequent input from stakeholders in various forms, including workshops and conferences including various actors.

Stakeholder processes prominently featured Austrian universities, research and technology organisations, corporations, NGOs, but also public organisations, such as infrastructure operators and providers of mobility services as well as representatives of diverse public administration units, specifically federal ministries. Moreover, also evaluation activities frequently incorporate surveys and interviews, offering stakeholders the possibility to proffer their opinion on MdZ. The only stakeholder group, which is not often represented, are citizens in the sense of the general public. An exception are the urban mobility labs, where citizens are involved in bottom-up processes linking researchers with the stakeholders, such as idea competitions.

${ }^{19}$ BMVIT 2018a, pp. 13 


\section{Directionality}

The programme has a pronounced directionality, in the sense that societal, environmental and economic goals are targeted. ${ }^{20}$ Regarding societal sustainability, goals are:

(i) the usability of the traffic system, questions of access including issues of inclusion, barrier freedom, accessibility, safety and security,

(ii) sustainable forms of mobility,

(iii) to raise the quality and accessibility of the mobility infrastructure,

(iv) to cost-efficiently secure the transport of goods and services.

Concerning ecological sustainability, the programme aims at:

(v) the reduction of emissions and imissions,

(vi) the reduction of energy and resource consumption,

(vii) balancing of interests between mobility and ecosystem.

Goals pertaining to economy and STI are to:

(viii) raise the economic competitiveness of the mobility sector,

(ix) advance the scientific-technological competences in the sector,

(x) build international cooperations.

The programme goals are very rich, understandable and clear in their formulation. In the midterm evaluation, the programme calls were received positively. They have been qualified as legitimate and derived in an equally detailed and comprehensible manner, being linked to operational objectives. The last part is especially important for mission-oriented innovation policy, which has a clear impact orientation and therefore needs operationalised objectives. In the case of $\mathrm{MdZ}$ this is also part of the tasks of roadmaps, which are important for specifying the areas of future calls for proposals. ${ }^{21}$ In the mid-term evaluation, the large number of subobjectives and the sometimes narrowly defined topics in the calls have been interpreted as sometimes overshooting. ${ }^{22}$ This leads also to the question of the priorisation of topics, within and between the four MdZ thematic fields.

\section{Leadership}

Austrian STI policy does not suffer from a lack of strategies, which are endorsed by varying bodies - on the federal level these are usually federal ministries. The most important federal strategy is the Austrian federal government's Strategy for Science, Technology and Innovation Policy from 2011, which is also one of the bases for MdZ. ${ }^{23}$ Contrary to the generally rather limited commitment of the executive branch to STI policy (see Section 2.1), within the area of mobility research the BMK has shown clear leadership and commitment since the late 1990s, which has been proven by the fact that MdZ is the sole Austrian programme systematically funding mobility-related STI. The programme has been developed by the

\footnotetext{
${ }^{20}$ BMVIT 2014, p. 7/8

${ }^{21}$ Compare BMVIT 2018b

${ }^{22}$ BMVIT 2018a, p.13

${ }^{23}$ BKA et al 2011
} 
responsible department on mobility and transport technology of the BMK, which is part of a directorate ("Sektion") on innovation and technology.

Intentionality

The programme has a pronounced intervention logic, laid down in several documents, such as the programme brochure. In this context, the need for intervention regarding the mobility system is seen in areas:

- where societal needs and goals are not addressed by the market either fastly or adequately enough,

- where innovations are not adequately aligned with societal needs, although it would be possible to generate a macroeconomic return,

- when there is not yet demand in the market, although new solutions for societal challenges would exist and business/operating models would be required from a societal point of view. ${ }^{24}$

The intervention logic and the corresponding goals described under the section on directionality are clear and comprehensive, as are the goals, which are laid down as subgoals in documents such as the roadmaps concretising the specific goals of the programme for a certain period as well as the following calls. Indeed, these goals have been criticised in the sense of being sometimes too narrow, which is for example reflected in a rather high level of prescriptiveness for the calls for proposals. ${ }^{25}$

Flexibility

FFG has a continuous monitoring of all its programmes. Moreover, already in the programme document of MdZ, an interim evaluation had been planned for 2018 and a final evaluation after the end of the programme. Judging from the changes from the two precursor programmes, IV2S and IV2Splus, as compared to MdZ one can infer a reflection of programme goals and instruments with evaluations and stakeholder engagement processes as milestones.

Yet in the mid-term evaluation, MdZ received some criticism on the fact that changes in the programme were bound to evaluations and therefore not continuous. In a nutshell, there is flexibility, which however might become steadier.

${ }^{24}$ BMVIT, p. 10

${ }^{25}$ BMVIT 2018a, pp.13 


\subsubsection{Mission-orientation at policy coordination level}

Mission-orientation at policy coordination level serves to ensure the consistency of public interventions by different policymaking institutions across policy fields. Mission-orientation at this level is associated with the following expected attributes:

- Horizontality

- Verticality

- Intensity

- Exploratory

- Demand-articulation

\section{Horizontality}

Horizontal coordination firstly takes place between ministries and agencies. Whilst the ministry develops a strategy, contents and topics, the agency FFG takes care of the operational execution of the programme. AustriaTech, an agency owned by the ministry, is supporting ministry and FFG regarding e.g. strategy development, implementation of innovative solutions and stakeholder involvement. In this setup, stakeholder involvement is more of a priority for ministry and AustriaTech than for FFG. Originally, a thematic cooperation was planned also with another agency, the Austrian Promotional Bank $(a w s)^{26}$, which however did not materialise over the programme's lifetime.

Traditionally coordination between federal ministries in Austria is focusing on negative coordination, i.e. rather than creating a common agenda, ministries report what they are doing, thus rather claiming stakes than designing joint activities. ${ }^{27}$ This is true also for science, technology and innovation policy. Regarding MdZ, there has however been selected cooperation between federal ministries, focusing on interactions e.g. in the framework of the Austrian federal STI strategy working group 3 on the "Quality of Life and Demographic Change". ${ }^{28}$ In addition there has been an ongoing cooperation within BMK, most importantly with the transport directorate, but also with other departments of the innovation and technology directorate, responsible for programmes such as benefit or City of Tomorrow.

Coordination in a broader sense - stepping outside the borders of the political system - also takes place with industrial sectors, especially with A3PS, the Austrian Association for Advanced Propulsion Systems, which has been founded and sponsored by the BMK. Research on traffic infrastructure is co-funded by the Austrian Federal Railway Corporation (ÖBB) and ASFINAG, the agency responsible for financing Austrian motorways. Coordination is also an issue at the international level, i.e. ERANET or the International Energy Agency (IEA).

\section{Verticality}

With MdZ vertical coordination takes place in some cases with the federal states ("Länder"), e.g. in the form of memorandums of understanding (e.g. Vienna), with endowed professorships

\footnotetext{
${ }^{26}$ BMVIT 2015, page 5

${ }^{27}$ Pichler et al 2007 , Biegelbauer 2013

${ }^{28}$ Dinges et al 2018
} 
or when cooperating in the financing of innovation labs, a new instrument similar to living labs, which usually are co-financed by ministry, federal states, cities and local administrations. Coordination extends beyond the borders of Austria, e.g. on the European level through the Conference of European Directors of Roads (CEDR) as well as the European rail initiative Shift2Rail. Again, coordination takes place also with industrial sectors on the national level, e.g. in the case of automobile clusters, i.e. regional agglomerations of automobile suppliers, automotive being an important industrial sector for Austria.

$\underline{\text { Intensity }}$

The intensity of coordination regarding MdZ related issues is rather strong between ministry and AustriaTech as well as FFG, in the latter case especially concerning the operational execution of the programme. It is clearly less pronounced in the case of cooperation with other federal ministries. However, it is important to notice that there is an ongoing discussion with the transport directorate, which is part of BMK, and where different departments are in regular contact with the mobility and transport department responsible for MdZ.

In fact, in the STI strategy working group on the Quality of Life and Demographic Change, there was a general exchange of information on STI-related activities. Moreover, other ministries were asked, in cases federal strategies were designed, such as with strategies on dementia and active mobility, two cases of cooperation between innovation and health ministries. There were no activities such as joint calls for tender or similar. ${ }^{29}$

\section{Exploratory}

MdZ features a number of policy instruments, which would allow for horizontal coordination of e.g. ministerial actors, from supporting studies to innovation labs. However, coordination activities featured an exploratory character rather in strategic orientation measures such as a foresight exercise, taking place in the framework of a supporting study, where six different ministries were invited. The study was to contribute to setting up the foundations for a research and innovation policy roadmap for the future development of mobility research and innovation which firstly tackles the societal challenge of demographic change, and secondly incorporates an emphasis on quality of life. ${ }^{30}$

In the case of vertical coordination, the innovation labs are an instrument to create innovation ecosystems, where the cooperation between federal, federal state and local (i.e. cities) level is inscribed into its definition. In these five mobility labs and the Centre for Mobility Change, a large number of local and national actors are testing innovative mobility solutions in the real world. The labs are also addressing complementary activities for the creation of innovation ecosystems, which cannot be realised in the framework of single STI projects. The six units are funded by the BMK and accompanied (regarding e.g. knowledge exchange and monitoring) by AustriaTech. However, non-systematic cooperation between different actors sometimes takes place also in the framework of other instruments such as lighthouse projects and cooperative $R \& D$ projects.

\footnotetext{
${ }^{29}$ Dinges et al 2018

${ }^{30}$ Dinges et al 2018
} 
Demand-articulation

The involvement of stakeholders and regulatory authorities is an icon of MdZ. A number of different stakeholder groups are involved in creating and rethinking MdZ, its precursor and follow-up programmes. A specific strength are the industrial relations, less pronounced are relations to civil society, especially the broad public. Moreover, departments from the transport section provide input to MdZ.

Regulatory authorities are part of other mobility-related cooperative relations of the ministry also extending above activities, e.g. in the case of the Lighthouse E-Mobility Programme of the Austrian Climate and Energy Fund (Klien). Another example is Innovative Public Procurement (IÖB), a cooperative initiative of BMK and the economics ministry (Federal Ministry for Digital and Economic Affairs, BMDW).

\subsubsection{Mission-orientation at policy implementation level}

Mission-orientation at the policy implementation level serves to ensure the consistency of implementation efforts regarding a package of policy instruments, varying stakeholders and the ability to learn from experience. Mission-orientation at this level is associated with the following expected attributes:

- Policy mix diversity

- Leverage

- Measurability and evaluability

- Reflexivity

Policy mix diversity

In comparison to the two precursor programmes, MdZ features an enlarged set of funding instruments. The most important instrument still is cooperative $R \& D$ projects, followed by $R \& D$ services (often supporting studies) and exploratory/feasibility studies. All other instruments are utilised markedly less, i.e. pre-commercial procurement, operative assignments, innovation / living labs, lighthouse projects and endowed professorships, which partially has to do with the fact that some of them are larger than others or have been developed during the lifetime of MdZ (comp. fig. 2). 
Figure 3: Instrument Utilisation by Beneficiaries and Organisationtype in MdZ (2017)

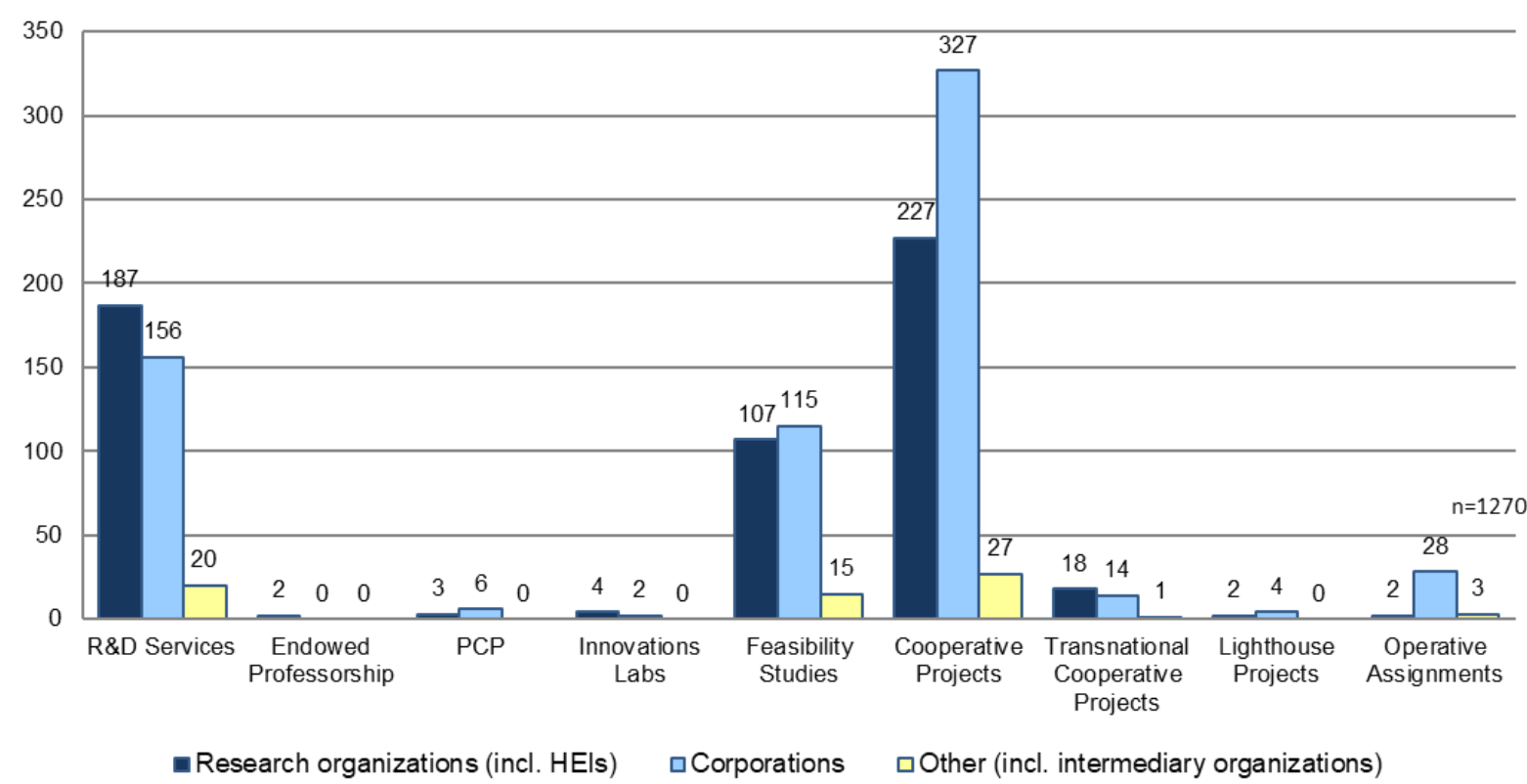

Quelle: Online-Survey (BMVIT 2018a)

Cooperative R\&D projects entail the cooperation of several consortium partners in a project with clearly defined R\&D goals. They may be funded for a maximum of three years with $€ 100,000-€ 2$ million and reimbursed from $35 \%$ to $80 \%$, depending on the technology readiness level. This funding model applies to all four programmes studied. R\&D services answering to a clearly defined tender of the ministry aim at the production of new knowledge utilising scientific methods (funded with up to $€ 120,000$ ). Feasibility studies preparing applied science projects, are being funded for a maximum of one year with up to $€ 200,000$ and a funding rate of 40- $80 \%$, depending on the size of the funded institution.

Pre-commercial procurement and operative assignments are much less often used and most common for infrastructure development projects. Innovation labs are experimentation areas focusing on solving societal problems with new combinations of STI instruments. Lighthouse projects are combinations of other projects obtaining visibility through their size and aiming at systemic problem-solving approaches with 2 - 4 years of activity, a minimum of $€ 2$ million budget and a funding rate between $35 \%$ and $80 \% .{ }^{31}$

MdZ features a broad use of funding instruments, which makes sense in light of its mission orientation and the varying logics and market structures upon which the different thematic fields are based. Lighthouse projects and innovation laboratories are still fairly new. They seem to have resulted in numerous experiences, which should allow for learning for the successor programme of MdZ. The interim evaluation's remarks on the preparatory, accompanying and dissemination activities seem to have been taken up and are in good fit with the mission orientation of the programme. 


\section{Leverage}

As pointed out in the previous section and in adherence with EU funding rules, the different instruments allow for different funding rates. Most instruments are based on co-funding by the private sector. In 2017 , over the whole programme $67 \%$ of project costs are covered by MdZ funds. Differences exist i.a. between the thematic fields, which display varying setups of actors and issues. ${ }^{32}$

Table 2 Project Costs and Lever (28.11.2017)

\begin{tabular}{|l|c|c|c|c|c|c|c|}
\hline & MdZ total & $\begin{array}{c}\text { Autonomous } \\
\text { Driving }\end{array}$ & $\begin{array}{c}\text { Vehicle } \\
\text { technologies }\end{array}$ & $\begin{array}{c}\text { Mobility of } \\
\text { goods }\end{array}$ & $\begin{array}{c}\text { Mobility of } \\
\text { persons }\end{array}$ & $\begin{array}{c}\text { Traffic } \\
\text { infrastructure }\end{array}$ & $\begin{array}{c}\text { Other cross-cutting } \\
\text { topics }\end{array}$ \\
\hline Funding granted $\mathbf{( M} \in \mathbf{E})$ & 108,6 & 11,9 & 27,4 & 16,9 & 13,6 & $30^{2}$ & 8,9 \\
\hline Project costs $\mathbf{( M} \in \mathbf{E}$ & 163 & 22 & 47,5 & 25,4 & 19,1 & 33,7 & 15,2 \\
\hline
\end{tabular}

${ }^{1}$ Incl. GLOMVF, goods and vehicles, PCP eHybridlok, shift2rail, UML and operative assignments.

${ }^{2}$ Without budgets from ÖBB and ASFINAG approx. $€ 19,5$ Mio lower total budget for infrastructure, i.e. lever of 1,7. Quelle: BMVIT 2018a

\section{Measurability and evaluability}

The programme indicators are directly linked with the Austrian impact assessment scheme (Wirkungsorientierte Folgenabschätzung, WFA), which has been informed by the Swiss system and has been introduced in 2013 based on the federal budget law from 2007 (Bundeshaushaltsgesetz 2007). It asks the civil service on the federal level to assess the impact of planned regulation ex-ante. Part of the exercise is also to develop indicators allowing for an ex-post impact assessment.

With the exception of the indicator displaying as its target value that half of the projects should have more than three partners (which was not likely to be reached), all indicators have been on track in 2018. The indicators themselves are already set out in the programme document and are a subset of the targets laid down there. The goals of the programme are broader than the indicators set as part of the WFA, although they in principle already show considerable variety. However, indicators reflecting societal targets are missing ${ }^{33}$.WFA indicators measuring primarily output, considerations on outcomes and impact of $M d Z$ have been part of several R\&D service projects, such as WIFAS, SAMOA and GÜMoS. ${ }^{34}$

\section{Reflexivity}

As has been pointed out, there is a variety of monitoring efforts, as for example on the side of the FFG or, pertaining specifically to the innovation labs, also AustriaTech. Evaluations such

\footnotetext{
32 BMVIT 2018a, p. 42

${ }^{33}$ BMVIT 2018a, p. 62

34 https://projekte.ffg.at/
} 
as the MdZ mid-term evaluation from 2018 are and additional rich source of knowledge. An expost evaluation is planned; several years after the end of MdZ. ${ }^{35}$ However, there was no final evaluation of the predecessor programme IV2S+, although originally there had been plans to carry out such an evaluation. Summative evaluations have the potential to provide evidence for decision-making by assessing the long-term effects of the programme, something which cannot be delivered by a mid-term evaluation.

There is also an effort on the side of the ministerial representatives to interact with the subcommunities of the specific programme lines. They also closely follow the trends on the European, but also the international level, adapting MdZ frequently. Examples on the European level are the involvement in ERANET Transport as well as on the international level the committees of the International Energy Agency (IEA) and the International Partnership for Hydrogen and Fuel Cells in the Economy (IPHE). The roadmap processes offer a possibility to have these iterations of programme development also during the lifetime of the programme. These activities could be supplemented by a more regular and systematic learning process, including "systematic identification of insights, exchange/transfer of insights, and implementation“. ${ }^{36}$

\footnotetext{
${ }^{35}$ BMVIT 2014, p. 33

${ }^{36}$ BMVIT 2018a, p. 15
} 


\subsubsection{Case Study 2: Benefit / Ambient Assisted Living}

\subsubsection{The Programme Benefit}

Ambient Assisted Living (AAL) aims to improve the quality of life for an ageing society through ICT-based services and technologies that support individuals, their carers, families, and care organizations. AAL developed in response to the challenges of an aging population on health and social care services. It is estimated that by $2060,30 \%$ of the EU's population will be over 65 while the projected effective economic old age dependency ratio (ratio of number of individuals aged 65 and over per 100 people of working age) is estimated to rise from $41.5 \%$ in 2013 to $64.5 \%$ in $2060^{37}$. Total government spending on pensions, health care, long-term care, unemployment benefits, and education is projected to increase by almost $20 \%$ between 2010 and 2060 while expenditures for long-term care are predicted to double over this period. At the same time, leveraging ICT technologies and services could effectively take advantage of market opportunities associated with the emerging "silver economy" 38 that promises more economic and employment growth.

In Austria, interest in research and innovation in Ambient Assisted Living developed in step with the broader discussions at European level and efforts to establish a transnational Ambient Assisted Living Joint Programme (based on Art. 169 TEC, now Art. 185 TFEU) during the preparation for the Seventh European Framework Programme for Research and Innovation. A transnational Joint Programme based on Art. 185 was deemed necessary in order to accommodate the different social and health care systems in place in Europe. Thus, in 2008, the first transnational AAL Joint Programme (AAL JP) and the national programme benefit were launched and are now part of the "ICT of the Future" funding initiative of the Austrian Federal Ministry for Ministry for Climate Action, Environment, Energy, Mobility, Innovation and Technology (BMK - known until 2020 as Ministry for Transport, Innovation and Technology (BMVIT)). The first AAL JP (AAL 1) ran from 2008-2013 under the $7^{\text {th }}$ European Framework Programme for Research and Innovation, while its successor 'Active and Assisted Living' (AAL 2 ) is currently active under Horizon 2020. On national level, AAL JP and benefit are implementted by the Federal Ministry for Climate Action, Environment, Energy, Mobility, Innovation and Technology which provides funding for Austrian project partners. It has commissioned the Austrian Research Promotion Agency (FFG) for the operational implementation of the programmes.

AAL JP is an applied research funding programme aiming to support projects developing ICT solutions for ageing well with a 2-3 years to market horizon undertaken jointly by 17 EU member states, Switzerland, and Canada. Both the first and second AAL JP had a total budget of around $€ 600 \mathrm{M}$ each, including $€ 150$ from the European Commission and are implemented under the European Framework Programme for Research and Innovation.

\footnotetext{
${ }^{37} \mathrm{https}: / /$ ec.europa.eu/economy finance/publications/european economy/2015/pdf/ee3 en.pdf

38 https://ec.europa.eu/digital-single-market/en/news/silver-economy-study-how-stimulate-economy-hundreds-millionseuros-year
} 
The AAL JP has three specific objectives ${ }^{39}$ :

(i) Improve the quality of life for the elderly and their carers and help the sustainability of care systems by enhancing the availability of ICT-based products and services for active and healthy aging

(ii) Create a critical mass of trans-European research and innovation for ICT-based products and services addressing active and healthy aging, including the establishment of a favorable environment for participation by SMEs

(iii) Leverage private investments and improve industrial growth by providing a framework for developing European approaches and solutions that meet varying national and regional social preferences and regulatory aspects

Countries joining the transnational RDI initiative must also have a national programme in place to enable Member States (MS)-EC co-funding of AAL JP projects. Therefore, the national programme benefit was established as the basis for Austria joining AAL JP. The benefit programme funds the development of ICT-based products, systems and services which help maintain and improve the quality of life of older adults to enable them to live within their own four walls as independently as possible for as long as possible. The benefit funding programme aims to ${ }^{40}$ :

(i) Maintain and enhance the quality of life of elderly people through innovative ICT products and services

(ii) Increase the operability and applicability of ICT-based products and technologies and ICT-based services

(iii) Increase the societal acceptance for ambient assisted living

(iv) Stimulate new business models, marketing strategies, and value chains to facilitate market niches for domestic (service) suppliers and promote international commercialization of solutions

Both benefit and the AAL JP aim to bring together different groups of end users - older people as well as groups which, for instance, are responsible for providing or financing care and support services - in consortia with partners from business and research organizations. The aim is to develop solutions, which are needed and used through joint project work. The emphasis on end user involvement is expected to improve the usability of the products and services and thus to increase older adults' acceptance and readiness to adopt them.

\footnotetext{
${ }^{39}$ See Interim Evaluation of the Active \& Assisted Living Programme

${ }^{40}$ See benefit programme website https://www.ffg.at/programm/benefit
} 


\subsubsection{Mission-Orientation at strategic orientation level}

\section{Legitimacy}

Ensuring legitimacy requires the engagement of a wide group of stakeholders in building a consensus on the challenge(s) to be prioritized.

Austria's initiative in AAL developed from discussions on national and European levels of how ICT technologies could be used to contribute to matters of societal importance while also addressing the European paradox ${ }^{41}$ (failure to transform scientific advances into innovations and competitive advantages) effectively. CSAs (Coordination and Support Action) were financed in FP6 to feed into the development of the initiative on European level. In Austria, community-building and stakeholder engagement measures were implemented alongside the funding programme benefit to ensure exchange with and between stakeholders. Examples include stakeholder mappings, sector analyses, expert consultations, workshop series, annual stakeholder events, etc. In 2012, the stakeholder platform AAL Austria was established to support community building and drive the needs assessment of the stakeholders through dedicated working groups on topics such as ethics. Especially in the beginning, such measures aimed to raise awareness for the topic and the new programmes, connect relevant stakeholders with each other, and to discuss needs and expectations of the community for initiatives promoting AAL technologies. These stakeholder engagement activities involved actors 'typical' for such programmes (universities, research organizations, businesses). However, according to the interviews, end-user organizations were targeted specifically in order to correspond to the overarching goals of the benefit programme. Early on, it was determined that the effective involvement of end-users should be an important component of the benefit programme; at the same time, such stakeholder groups, e.g., providers of care and support services and insurance providers, are typically less experienced and aware of opportunities and benefits of R\&I programme participation. Special efforts to raise awareness and engage in discussions were made by targeted invitations to exchange formats, dialogue on their needs, and sensibilization of potential benefits stemming from their involvement in the benefit programme (knowledge exchange, co-owning IP results, tailor-made technological solutions). Beyond raising awareness for the benefit funding programme, stakeholder engagement measures and consultations were used to explore the potential and feasibility of thematic priorities of calls and in the programme structure of the programme.

With stakeholder engagement, including involvement of actors less experienced in R\&l activities, their contribution to the challenge of improving quality of life through novel ICT applications is focused on the specific orientation and responsiveness of the funding programme, rather than their involvement in the selection of the topic of Ambient Assisted Living as a response to a societal challenge to be prioritized in policymaking.

\section{Directionality}

The broad objective of benefit is to improve the quality of life of elderly people using ICT technologies. As such, the benefit programme addresses two challenges:

\footnotetext{
${ }^{41}$ See EC Green Paper on Innovation (1995): https://europa.eu/documents/comm/green papers/pdf/com95 688 en.pdf
} 
(i) To counter the increasing burden placed on public health and social care services from an aging population through novel technologies.

(ii) To contribute to closing the perceived gap between scientific advances and translation into marketable innovations by promoting the development of ICT applications for new population groups, thereby taking advantage of potential market opportunities associated with a rising 'silver economy'.

The first challenge can be categorized as ambitious, responding to expected problems of public expenditures on health care and long-term care caused by an aging population. Studies used as evidence and legitimation (EU level) are based on estimates of population aging and public spending by $2060 .{ }^{42}$ The so-called European paradox is a problem long recognized in policymaking, coined in a $1995 \mathrm{EC}$ green paper, which finds that governments and firms must improve their capabilities to translate research into commercial successes to ensure future competitiveness, growth, and employment. The national STI strategy forms the basis of the the benefit programme (as well as participation in the European AAL Joint Programme) initiative, as well as the Open Innovation strategy, and the Mobility Roadmap. Other national strategies such as the "Dementia strategy" 43 and the "Masterplan care" 44 also served as reference documents for the benefit proramme. The government programme 2017 mentions Ambient Assisted Living, and the benefit programme's 'test regions' are also referenced in the Open Innovation Strategy, jointly developed by the then-Ministry for Transport, Innovation and Technology and the Ministry of Ministry of Education, Science and Research.

Based on the two challenges, the benefit programme defined its priorities as promoting innovation in ICT-technologies to be used in improving the quality of life of elderly people, creating a critical mass of R\&I for Ambient Assisted Living, and promoting commercialization and industrial growth.

\section{Leadership}

The Austrian funding programme benefit has evolved around broader discussions on European level around how to utilize ICT technologies for societal challenges. In this process, the BMK with broad competences in the area of research and innovation as well as thematic oversight of novel (ICT) technologies was the driver promoting and endorsing this initiative. It is the programme owner and funder of all the benefit programme and the Austrian involvement in the transnational AAL Joint Programme.

Intentionality

As described in the previous chapter, the objectives of the benefit programme are clearly articulated and derived from the broader challenges. However, there are no pre-defined performance targets such as KPIs or milestones set against a fixed timeline. The evaluation of the benefit programme has found that the lack of KPIs and measures to monitor their impacts facilitated the establishment of a thematically broad and open initiative but are a barrier for structured monitoring and impact assessment.

\footnotetext{
${ }^{42}$ See e.g. https://ec.europa.eu/economy finance/publications/european economy/2015/pdf/ee3 en.pdf

${ }^{43} \mathrm{https}: / / \mathrm{www}$.demenzstrategie.at/fxdata/demenzstrategie/prod/media/Demenzstrategie Neu englisch.pdf

${ }^{44} \mathrm{https://www.oegkv.at/fileadmin/user} \mathrm{upload/Aktuell/Masterplan} \mathrm{Pflege.pdf}$
} 


\section{Flexibility}

AAL initiatives (national benefit and transnational AAL JP) are regularly evaluated by independent experts on their results and progress towards objectives. The transnational AAL 1 underwent both interim (2010) and final evaluations (2013), an interim evaluation of its successor AAL 2 was conducted in 2017. Austria's participation in AAL JP and its national benefit funding programme is also regularly evaluated by independent evaluators, and due to the thematic overlap, typically assessed together see e.g., Evaluation of Austria's participation in Ambient Assisted Living (2016) and Evaluation of Austria's ICT R\&D programmes (2018). On the basis of evaluation findings, several re-orientations of thematic priorities and programme structure have been introduced. However, they have not been used to revise or update overarching goals, and the broad objectives have not changed much since benefit's inception. There are also no other formalized processes and information channels for goal revision.

\subsubsection{Mission-Orientation at Policy Coordination Level}

Horizontality

The benefit programme covers a number of policy fields including research and innovation, information and communication technologies, health care, care, social affairs. As such, it is relevant to the portfolio of several ministries (Ministry for Climate Action, Environment, Energy, Mobility, Innovation and Technology; Ministry for Social Affairs, Health, Care; Ministry of Education, Science and Research).

In terms of instruments, the benefit programme funds cooperative, interdisciplinary R\&I projects with involvement of research organizations, companies, and end-users. The European Joint ProgrammeAAL JP requires a transnational dimension of cooperation between partners of at least three countries. Both programmes aim at similar stages of the innovation chain, with an envisaged time-to-market of two to three years. Projects have a duration of three years, and, depending on consortia size, receive max. $€ 2 \mathrm{M}$ in funding. Targeted studies (R\&D services), such as independent evaluations and feasibility studies have also been funded.

On European level, there are thematic synergies with the Framework Programme, the Joint Programming Initiative More Years, Better Lives (JPI MYBL), the European Innovation Partnership on Active and Healthy Ageing (EIP-AHA), the EIT Health, and a number of European public-private partnerships supported by Horizon 2020 (e.g. Big Data, Robotics, 5G). The establishment of AAL JP is intended to complete the innovation chain from basic research (Framework Programme, ERC) to market entry by stimulating innovations that could then be subsequently funded through instruments such as COSME (EU programme for the Competitiveness of Enterprises and Small and Medium-sized Enterprises). 
Although the benefit programme is positioned to close the gap in the innovation chain, it has so far not quite achieved its objectives. The evaluation of Austria's AAL activities ${ }^{45}$ (both AAL JP and benefit) found that it has not met its economic and market-related goals: Only a small share of projects have successfully developed and marketed products and services that use the project results within the envisaged time frame of two to three years and less than one third reported products and services on the market as an outcome of an AAL-funded project. On the one hand, this indicates that projects mostly remain research-focused or technology-driven, on the other hand, this also indicates that there is a lack of appropriate instruments to facilitate bringing results to market: The instruments used for the benefit programme typically fund cooperative $R \& I$ and there are no other instruments, such as tax incentives or regulatory experiments, dedicated to the promotion of AAL technologies. Interviewed stakeholders have pointed out that the commercialization challenge is twofold: Customers for such AAL technologies are primarily public organizations (care facilities, hospitals) that tend to be slower in innovation uptake. Furthermore, projects remain technology-driven and resulting technologies tend to be solutions for single problems instead of integrated solutions. Interviewees have also pointed out that the current challenge is that there are many AAL technologies available, however, health and social care service providers are not sufficiently aware of the usefulness of products, their benefits, product comparisons to aid investment decisions, as well as the lack of integrated systems.

\section{Intensity}

The Ministry for Climate Action, Environment, Energy, Mobility, Innovation and Technology is the sole driver and funder of the benefit programme. Inter-ministerial coordination with sectoral ministries (e.g. Ministry for Social Affairs, Health, Care) and coordination with state-level bodies responsible for financing care remains limited. On inter-ministerial level, informal dialogue, introducing the initiative information exchange, and informal exchange on e.g. call texts, occurred within the working group meetings of the national STI-strategy. The exception is the development of the Mobility Roadmap within the framework of Working Group 3 "Quality of Life and Demographic Change" of the Austrian STI-strategy ${ }^{46}$, for which all relevant ministries received joint funding. Coordination between the federal government and states is limited to information exchange, primarily at the yearly "AAL Conference", hosted in a state with a benefit 'test region', where cities/municipalities and infrastructure providers participate. The evaluation of Austria's AAL activities (2016) found that the placement of the benefit programme in the national ICT R\&I funding programmes does not sufficiently reflect the initiative's broad objectives and societal relevance and highlighted the needs for closer coordination with sectoral ministries and states.

The benefit programme is closely coordinated with the transnational AAL JP: Bothhave similar goals and are closely coordinated on national level. For example, yearly calls are coordinated and timed to avoid overlap (spring / fall).

\footnotetext{
${ }^{45}$ See Geyer, Anton and Good, Barbara (2016). Evaluierung der österreichischen Beteiligung am Ambient Assisted Living Joint Programme (AAL JP 2008-2013) Endbericht. Technical Report. Wien.

${ }^{46}$ In German: "Task Force FTI - Arbeitsgruppe 3: FTI-Schwerpunkt: Lebensqualität und demografischer Wandel"
} 


\section{Exploratory}

The benefit programme is thematically open and supports innovation activities covering the whole field of ICT-technologies. Benefit also allows for R\&I in ehealth-related areas since there are no dedicated funding schemes for such topics in place. 'Ecosystem' approaches to aging, e.g., social perceptions, social environment, learning and education, are not supported. The 2016 evaluation's analysis of keywords showed that, in projects funded in the benefit programme, sensor solutions for activity monitoring related to at-home care and rehabilitation were prominent, as well as alarm system/emergency call management, and smart home topics.

The benefit programme is a competitive $R \& I$ funding programme with pre-defined peer-review selection processes and criteria, hence allowing competition between a range of technological solutions proposed. There is currently no formalized learning process to facilitate learning from projects not selected for funding or those where project results fail to meet expectations.

\subsubsection{Mission-Orientation at Policy Implementation Level}

\section{Policy mix diversity}

\section{Interdisciplinary diversity}

The benefit programme aims to promote interdisciplinary research and over the years, has reoriented towards integrated solutions to AAL technologies, which requires higher levels of interdisciplinarity. Although there are no pre-existing studies assessing interdisciplinarity as such (by e.g. using bibliometric indicators), the evaluation of Austrian AAL participation (2016) analysis of keywords associated with projects can serve as an approximation. The distance in the network analysis represents the frequency of keywords being associated with each other, while the size of nodes represents the total number of times a keyword was mentioned and the width of the links between nodes the number of projects where the two keywords are mentioned together.

In the transnational AAL JP programme, the most common keywords are 'close' to each other, forming a center, thus a relatively large proportion of projects are associated with the most common keywords. Therefore, the projects are thematically quite homogenous. In the benefit programme, the most common keywords are less concentrated, thus less commonly mentioned together in project descriptions. Several thematic clusters are apparent, and therefore, thematically significantly more heterogenous than the transnational AAL JP. Although the keyword analysis cannot serve as an accurate proxy for disciplinary distance, it does suggest that the benefit programme enables more interdisciplinarity than the transnational AAL JP, which exhibits a higher degree of thematic concentration.

\section{Cross-sectorial diversity}

The Austrian Research Promotion Agency (FFG) implements both the benefit programme and the transnational AAL JP (in cooperation with the AAL Association established by participating national ministries and funding agencies) in yearly calls. Both programmes are thematically broad and fund cooperative projects in interdisciplinary constellations with a variety of actors 
outside the 'typical' R\&I sphere, such as end-user organizations, elderly persons, care and support service providers, insurance providers, etc. In the benefit programme, at least one consortium partner has to be a business.

To fulfill its objectives, the AAL Joint Programme has issued 12 calls for proposals to date, with yearly varying thematic objectives (see Appendix II). Since the $10^{\text {th }}$ call in 2017, AAL JP has started implementing more challenge-led calls aiming at integrating solutions instead of addressing only a specific need (compare e.g. call 1 (2008): ICT-based solutions for Prevention and Management of Chronic Conditions of Elderly People vs. call 11 (2018): Smart Solutions for Ageing well).

Similarly, the benefit programme has also issued yearly calls, typically offset by half a year from the AAL JP call. The benefit programme is thematically open, projects tend to be smaller in terms of number of participants and budgets.

Between 2008 and 2016, $€ 55.6 \mathrm{M}$ were allocated to Austrian organizations for a total of 186 national and European projects within the benefit and AAL JP programmes ${ }^{47}$. The benefit programme accounted for 106 projects with a funding of $€ 21.4 \mathrm{M}$. Within AAL JP, 80 projects (out of 220) involved Austrian participants with funding totaling $€ 34.2 \mathrm{M}, € 15.3 \mathrm{M}$ of which funding from the EC due to MS-EC co-financing of the AAL JP.

Figure 4: Number of projects and funding amounts AAL JP and benefit, 2008-2016

Number of projects funded under the benefit and AAL programmes, 2008-2016

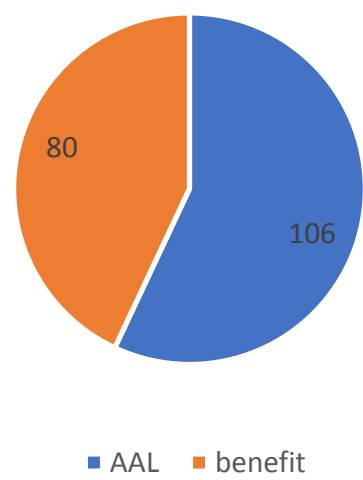

Funding sum in the benefit and AAL programmes in million $€$, 2008-2016

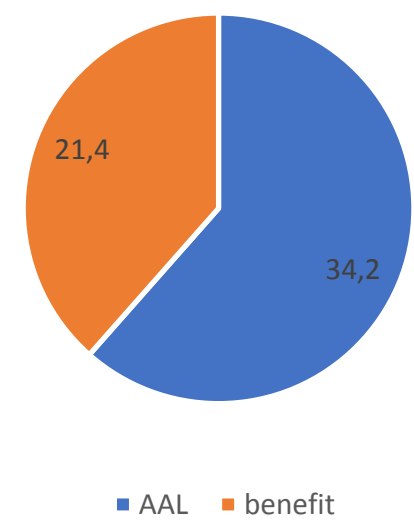

Source: Benefit/AAL brochure 2017, FFG

According to the 2016 evaluation, $58 \%$ of participants in granted the transnational AAL JP projects were universities and research organizations (67.2\% of total funding), enterprises comprised a further $29 \%$ of participants ( $28 \%$ of funding), while organizations providing

\footnotetext{
${ }^{47}$ See benefit/AAL brochure https://www.ffg.at/sites/default/files/brochuere benefit aal e.pdf
} 
services of general interest (e.g. care and support services) represent only $13 \%$ of participants (4.9\% of funding).

Participation in the national benefit programme in the same period is less concentrated than in AAL JP: $45 \%$ of beneficiaries were universities and research organizations (55.3\% of funding), $43 \%$ enterprises (36.5\% of funding), and $12 \%$ providers of services of general interest $(11.1 \%$ of funding). Thus, both programmes display a concentration on research organizations, and within this group, on a small number of actors. However, the benefit programme more successfully involved enterprises than the transnational AAL JP.

The evaluation found that both benefit and AAL JP projects were able to successfully involve end users such as care and support providers, with higher intensity than in other R\&I funding schemes. Thus, the benefit programme could contribute to intensified networking between stakeholder groups, better understanding of end-user needs and requirements, and increase cooperation between $\mathrm{R} \& \mathrm{I}$-related organizations and providers of services of general interest.

\section{Innovation cycle diversity}

The benefit programme provides funding for innovation activities with a two to three year timeto-market horizon (experimental development) as well as demonstration projects, so-called 'test regions'. Besides participation in the transnational AAL JP, there are no other dedicated funding instruments for the topic of Ambient Assisted Living on national level. Applied basic research in AAL can theoretically be funded by the bottom-up general programme of the Austrian Research Promotion Agency, while pure basic research is funded in Austrian Science Fund programmes. Interviews have found that the benefit programme often contributes to preparing national actors for transnational activities in the Joint Programme. Participants of benefit and AAL JP also commonly develop follow-up projects in the European Framework Programme. According to the 2016 evaluation, four out of five surveyed project participants indicated that results from AAL JP/benefit participation were followed-up by applying for funding in (European) programmes. In terms of placement in the innovation cycle, the benefit programme funds applied research and innovation activities up to the demonstration stage and does not provide further support for market launch or regulatory reform to enable take-up. The transnational programme's focus is also in funding experimental development but has in the last years introduced additional measures such as a "business track" for market entry and the AAL Prize to fund specific challenges.

\section{Leverage}

Private funds for $A A L$ projects are leveraged by varying maximum funding rates for different organization types. The transnational AAL JP sets the following maximum funding rates for Austrian participants ${ }^{48}$ :

- $60 \%$ for small enterprises

- $50 \%$ for medium enterprises

- $40 \%$ for large enterprises

${ }^{48} \mathrm{http}: / /$ www.aal-europe.eu/wp-content/uploads/2019/02/National-Eligibility-Criteria-AALCall-2019-Updated-14.02.19.pdf 
- $75 \%$ for research organizations and institutions of knowledge dissemination

The benefit programme sets lower maximum funding rates ${ }^{49}$ :

- $60 \%$ for small enterprises

- $50 \%$ for medium enterprises

- $35 \%$ for large enterprises

- $60 \%$ for research organizations and non-profit organizations

The 2016 evaluation found that in AAL JP, public funding for projects (2008-2013) amounted to $€ 22.3 \mathrm{M}$ (of which $€ 12.7$ national funding, $€ 9.6 \mathrm{M} \mathrm{EC}$ funding), whereas total project costs totaled $€ 33.6 \mathrm{M}$. On average, $66 \%$ of R\&I costs were therefore contributed by the public sector, with the difference raised by contributions by the private sector. In the benefit programme, public funding for projects $(2010-2013)$ totaled $€ 10.9 \mathrm{M}$, while total project costs reached $€ 18.9 \mathrm{M}$. On average, $58 \%$ of total project costs were covered by public funds, with the remainder raised from private organizations.

\section{Measurability and evaluability}

Evaluations are regularly conducted for the benefit programme (typically together with Austria's participation in AAL JP). However, there are no specific outcome or impact indicators established beyond the broadly defined goals and objectives of the initiative. All interview partners have pointed out that the lack of KPIs and methods to monitor impacts are a barrier for structured monitoring and impact assessment. In some ways, this was intentional for the programme in order to enable benefit to remain thematically broad and open.

\section{Reflexivity}

Both transnational and national AAL initiatives are regularly evaluated by independent experts on their results and progress towards objectives. AAL JP 1 underwent both interim (2010) and final evaluations (2013), an interim evaluation of its successor AAL JP 2 was conducted in 2017. Austria's benefit programme and its participation in AAL JP is also regularly evaluated by independent evaluators, see e.g., Evaluation of Austria's participation in Ambient Assisted Living (2016) and Evaluation of Austria's ICT R\&D programmes (2018).

The orientation and implementation of the benefit programme underwent several changes in response to these evaluation findings. In 2012, the benefit programme re-oriented itself towards prioritizing funding for so-called "test regions" instead of smaller, cooperative R\&I projects, as a result of an evaluation that found a lack of commercialization, lack of integration of technological solutions, as well as relatively low levels of end-user engagement and testing/evaluating technological solutions in practice. This re-orientation also included a stronger focus on topics involving integrated solutions and smart homes, a minimum of 100 homes/end-users, and more favorable conditions for companies by imposing funding limits on research organizations. A subsequent evaluation found that commercialization remained low, insufficient framework conditions for implementing AAL solutions (e.g. financing models, customers, technical infrastructure, etc.), and that solutions remain regional and context-

\footnotetext{
${ }^{49}$ https://www.ffg.at/sites/default/files/dok/il kooperativefueprojekte v31.pdf
} 
specific. In response, benefit made business plans, marketing strategies, and involvement of health and care providers mandatory and established a taxonomy of AAL technologies.

Therefore, evaluation results are commonly used to revise the benefit programme structure and have led to a consolidation of thematic priorities and updated participation rules to emphasize market-orientation and decrease the programme's research-focus.

\subsubsection{Case Study 3: KIRAS}

\subsubsection{Introduction}

In the aftermath of the terror attacks in New York City (2001), Madrid (2004) and London (2005), and increase of negative impacts due to natural or technological disasters, the EU has put forward major efforts to increase security research with the $7^{\text {th }}$ EU Framework Programme. The security research Programme KIRAS was the first national programme of this kind within the EU to increase multiple security facets for Austria's citizens (FFG, 2017).

KIRAS $^{50}$ is a result of a paradigm shift with respect to security policy, away from dealing with threats related to military conflicts toward new threats, e.g. technological (infrastructure) or natural threats. At the end of 2004, the Council for Research and Technology Development (RFTE) recommended reserving special funds from research and development for a national security research program. In July 2005, it recommended the reserved funds of EUR 5 million to be released. Another RFTE recommendation of EUR 8 million in 2006 was based on previously formulated requirements. For example, measurable and assessable goals, a suitable indicator system, a reporting system and control mechanisms to prevent multiple funding were required.

Until the end of 2019, the programme was funded by the Federal Ministry for Transport, Innovation and Technology (BMVIT), and managed by the FFG. Since the beginning of 2020, the programme ownership has moved to the BMLRT, while the programme management will remain until the end of 2020 with the FFG. BMVIT planned the entire financial requirements for KIRAS based on a study on the European market potential in the security sector. In this study, this was determined at around EUR 4 billion for Germany. Assuming that Austria has about $10 \%$ of the market potential of Germany, the BMVIT estimated the potential for Austria at about EUR 400 million.

For the first phase a budget of EUR 110 million was foreseen for a period of nine years (20052013) equalling annual funds of up to EUR 12 million (Scheer \& Brüggemann, 2006). The programme was then extended to 2020, and up to 2018 EUR 84.6 million was granted to eligible research projects; in the same period, applications were filed for funds equalling around EUR 224 million. Hence, roughly more than a third of all applications have received funding (BMVIT, 2019).

According to the latest call, ending February 2020, funds of EUR 9 million are made available for 2019. The endowment varied over the years however. For 2011, EUR 5.2 million were made available, while the call for 2012 was funded with EUR 8.3 million (2013: 6.0, 2014: 6.7; 2015: 5.5, 2016: 6.5, 2017: 6.5) (KIRAS, 2011-2017). Funding for cooperative projects

\footnotetext{
${ }^{50}$ KIRAS comes from the Greek and is composed of the words kirkos (ring) and asphaleia (security). In this case, "ring" is to be understood as integrative, since all disciplines and dimensions are included in the KIRAS programme.
} 
is between $35 \%$ and $85 \%$ of total costs depending on the type of project (industrial research vs. experimental development) and type of institution (size, R\&D, etc.). For R\&D services funding is $100 \%$ (KIRAS, 2011).

\subsubsection{Strategic Orientation Level}

\section{Legitimacy}

The legitimacy of KIRAS is somewhat limited. The programme was developed in-house in the BMVIT, without any explicit and/or formal stakeholder involvement. In 2005, the BMVIT set up a department for technology transfer and security research to implement KIRAS, but BMVIT did not carry out a quantitative national needs assessment on the topic of security before the programme was launched. Only after the start of the KIRAS programme did the BMVIT award several study contracts that focused on the demand and supply for security and security research in Austria.

\section{Leadership}

The programme was owned and financed by the Austrian Federal Ministry for Transport, Innovation and Technology (BMVIT) $)^{51}$ and managed by the Austrian Research Promotion Agency (FFG). Since 2020 the Federal Ministry of Agriculture, Regions and Tourism (BMLRT) is responsible for the KIRAS programme. The FFG has been commissioned with the programme and umbrella management for KIRAS until the end of 2020.

In August 2005, the Ministerial Council decided that all relevant federal ministries should be represented on a steering committee for KIRAS under the leadership of BMVIT. Between November 2005 and October 2008, the steering committee comprised between 14 and 18 representatives. In addition to the nine federal ministries, the Federal Chamber of Labour, the Austrian Federal Economic Chamber and the Austrian Chamber of Agriculture as well as the three funding agencies Austria Wirtschaftsservice Gesellschaft $\mathrm{mbH}$, the Austrian Science Fund (FWF) and the Austrian Research Promotion Agency (FFG) were also represented on the steering committee.

Apart from the fact that the original target set by the Council of Ministers was exceeded, the inclusion of additional members in the steering committee made it difficult to reconcile interests. In a fundamental discussion on the role of the steering committee in August 2007, the BKA, the BMI and the BMLV stated that in their opinion the results of the meetings were dominated by the BMVIT. As a result, the requirements of the Ministerial Council's presentation regarding the coordination of all relevant federal ministries were not met. Building on the Austrian Security and Defence Doctrine of 12 December 2001, the National Security Council elaborated specific foreign and defence policy and security policy requirements in connection with internal security. Up to now, their implementation has only been taken into account within the framework of the priority "Critical Infrastructure Protection".

The KIRAS programme document provided for the establishment of a Scientific Advisory Board by the end of 2005 as an "accompanying measure" for programme management, evaluation and operationalisation of operational objectives. The Scientific Advisory Board was not paid from KIRAS programme funds, but from the budget of the BMVIT. Therefore,

\footnotetext{
${ }^{51}$ Now Federal Ministry for Cliamte Action, Environment, Energy, Mobilty, Innovation, and Technology (BMK)
} 
the BMVIT was of the opinion that the Scientific Advisory Board was primarily accountable to the BMVIT and only to the Steering Committee. Finally, in March 2006, the BMVIT commissioned a social science research institute to take over the tasks of the Scientific Advisory Board by means of a contract for work.

The Scientific Advisory Board was renewed twice with different configurations of experts between 2010 and 2016 answering again directly to the BMVIT. The Ministry then ended the process as it was felt that sufficient input by the Board had been created with the coming years needed to implement that input into action.

\section{Directionality}

Directionality is given as the programme was the first national programme of this kind within the EU to increase multiple facets of the security of the country's citizens. With the programme, a broad understanding of security has been addressed reaching from protection of critical infrastructures to the increase of subjective security of citizens.

KIRAS promotes national research projects, which correspond to the strategic objectives of the programme regarding a broad notion of security and awareness. Key strategies are the improvement of the subjective perception and objective level of security of Austrian citizens, the support of the growth of the Austrian security industry and the generation of knowledge needed for security policy. Relevant societal questions are also to be addressed in eligible research projects (FFG, 2017). In addition to the security aspect, the promotion of the strategic objectives was also intended to create or secure qualified jobs and contribute to the Austrian value chain.

The strategic objectives of KIRAS are:

(i) to increase the security and security awareness of the population,

(ii) to generate knowledge relevant to security policy,

(iii) to obtain knowledge, process and technology innovation,

(iv) to foster the growth of the domestic security industry,

(v) to establish and develop excellence in the field of security research.

The first thematic priority addressed by the programme is the protection of critical infrastructure like energy, communication and information, financial and health systems, resources, transport as well as public security. The majority of the funded projects exhibit a clear focus on risk and disaster management under a variety of scenarios, blackout being the most prominent. ICT solutions as well as analysis tools are also predominant (KIRAS, 2018).

\section{Internationality}

While the intention of the programme has been clearly articulated from the beginning, the initiative lacked in the first phase quantifiable indicators to evaluate the achievement of the goals. The milestones of the initiative were also laid down and quantified in the official Austrian security research strategy "E Pluribus Tutum" of 2012. Since 2015 finally defined quantified indicators for the operationalisation of the objectives, are included in the programming document. 


\subsubsection{Policy Coordination Level}

\section{$\underline{\text { Horizontality and Verticality }}$}

KIRAS shows a breadth in terms of policy fields covered in the different calls reaching from prevention from natural and technological disasters to cybersecurity. Also the depth is ensured by the existing mix of funding instruments.

First and foremost, KIRAS is strongly interlinked with the European Security Research Programme ESRP (currently societal challenge 6, "Secure Societies" of Horizon 2020) which was launched back in 2007. As the Austrian security research programme was the first of its kind in Europe, a close exchange between the programmes developed, having the ESRP adopt the mandatory inclusion of end-users on the project level and putting a strong emphasis on the societal dimension of security. The experience from KIRAS allows Austrian participants on EU level to perform way above average regarding successful project applications.

KIRAS is also integrated in the European Programme for Critical Infrastructure Protection (EPCIP). EPCIP sets the overall framework for activities aimed at improving the protection of critical infrastructure in Europe - across all EU States and in all relevant sectors of economic activity. The EPCIP is supported by regular exchanges of information between EU Member States in the frame of the CIP Contact Points meetings.

Since 2013 KIRAS and the German civil security research programme "Forschung für die zivile Sicherheit" have opened joint calls on common research topics like "Fight against Terrorism", "Supply Chain Security" or "Security \& Artificial Intelligence". The initiative is based on a formal bilateral agreement between the responsible Ministries in Austria and Germany.

Since 2018, KIRAS is complemented by the defence research programme FORTE, the first of its kind in Austria. It closes the thematic gap in national research funding programmes in the field of security policy and complements the existing security research programme KIRAS, which clearly excludes armaments and defence research. It effectively contributes to the best possible protection of the state and its citizens and thus supports the fulfilment of an indispensable constitutional mandate. Together, the defence research programme FORTE and the civil security research programme KIRAS form the "security bracket" in which all federal security policy research funding is concentrated to maximise efficiency and minimise processing costs.

\section{Intensity}

KIRAS was owned by the BMVIT and implemented by FFG until the end of 2019. Within this framework, decisions regarding the intervention (objectives, modalities, level of resources) were taken and binding to the involved actors. Programme ownership has moved in the beginning of 2020 to the BMLRT while the operational implementation has remained with the FFG. The programme steering committee that also included representatives from other ministries and other relevant stakeholders proved to be less involved in the decision taking processes. 


\section{Exploratory}

The programme has not intentionally foreseen exploratory elements. Cooperative R\&D projects are confined to applied research themes that reflect the current needs of end users. However, in addition to the five strategic objectives, the inclusion of humanities, social and cultural sciences (GSK) as a cross-cutting objective was defined in all programme lines. The KIRAS programme document broke down the listed strategic objectives to twelve operational objectives. These operational objectives were not defined in terms of their feasibility - at least in terms of medium- to long-term results. The only short-term objective of the programme document was the "creation of a large number of co-operation projects".

\section{Flexiblity}

The holistic approach of the research programme ("comprehensive security") led to a great variety of studies, which aimed to increase the national security and awareness reaching from disaster relief and food security to cyber security, surveillance and counterterrorism. Security research in the context of this programme is understood as multidimensional, longterm, multidisciplinary and integrative. The programme focuses on a civilian definition of the term security as aspects like armaments and military defence are strictly excluded from the programme.

Comprehensive security means the permanent guarantee for a high level of livelihood and development opportunities for all members of society. In order to meet this goal, it is necessary to identify and compensate for potential threats, risk probabilities and risk dimensions that vary over time, by region, are gender-specific and socio-culturally diverse.

\section{Demand-Articulation}

Eligible projects exhibit a strong emphasis on the end-user, which ensures demand-driven research, contributing to marketable technologies, products and services and specifically addresses the inclusion of societal aspects in eligible research projects. The improvement of the security and the awareness of the Austrian citizens is a top priority of the KIRAS initiative. The society can be seen as the main beneficiary of the initiative.

In line with the programme's objectives, positive effects on public security were perceived by end-users (78\% of the users saw positive effects according to a survey in 2014). The survey shows that KIRAS projects typically addressed areas facing tangible threat potentials. In the course of the programme, the issue of crime played a major role in addition to the programme-specific focus on protecting critical infrastructure; with this and the extensive number of projects in the areas of terrorism and natural disasters, the programme thus simultaneously addressed areas that reflect existing fears and perceived threats among the population (Heinrich et al., 2014).

Additionally, $92 \%$ of the funded companies and $84 \%$ of the research institutions have, developed new fields of research at least partially. $66 \%$ and $74 \%$ respectively have acquired new competencies in the field of security research (Heinrich et al., 2014).

Citizens were also involved in the research process of a variety of projects. Some projects conducted household surveys or held emergency exercises where civilians could be actively involved in eligible research projects. Presentations and conferences where held publicly and received considerable coverage in the media. 
By mandatory involving potential end-users (companies and public agencies) in collaborative R\&D projects, the programme seeks to strengthen the application orientation in the supported security R\&D projects. Furthermore, KIRAS-supported R\&D projects are to contribute to creating and securing high-quality jobs in Austria in the long term. In addition, the programme addresses multiple security aspects, which are not solely focused on technical aspects but features societal questions, knowledge generation as well as the improvement of the awareness of Austrian citizens.

\subsubsection{Policy Implementation Level}

\section{Policy mix diversity}

Available instruments have been covering the value chain of knowledge production from feasibility and usability studies to demonstration projects. The programme requires the participation of at least one agent from the public sector, the research sector, business sectors as well as a participant from the field of the humanities, social or cultural sciences (KIRAS, 2010). Eligible projects can be categorised into four complementary tiers.

(i) Tier 1 projects (probing action) comprise feasibility and usability studies. Probing Actions are used to assess innovative high-risk project ideas on their feasibility and implementation potential based on basic research with the aim to create new knowledge.

(ii) Tier 2 projects ("cooperative research and innovation projects" are part one of the funding instrument "cooperative research and innovation projects") feature application oriented R\&D with the aim to support the development of technologies.

(iii) Tier 3 projects ("development of components and demonstration activities" are part two of the funding instrument "cooperative research and innovation projects") target concrete applications. They focus on the development of products, processes and systems.

(iv) Tier 4 projects (R\&D services) comprise studies and R\&D services that support security research in general.

KIRAS is one of the thematic programmes of the FFG. Other thematic programmes exist in the areas Life Sciences, Aerospace, Information Technology, Materials and Production, Energy and Environment and Mobility.

\section{Leverage}

Up to 2018 EUR 84.6 million were granted to 254 eligible research projects in the course of the programme's existence. The initiative contributed to the development of a series of security strategies but also to the invention and implementation of more tangible outputs like the ultra-light photovoltaic energy station for disaster response teams, drone surveillance systems for flood and firefighting hazards, or mobile devices including an integrated database for rescue teams like ambulance and firefighters.

During 2016, 79 projects with Austrian partners were funded in the framework of ESRP (FP7Security), of which 13 were coordinated by Austrian partners. During 2014, FP7 Security projects were led in Austria with a value added of EUR 81 million and 1500 jobs were created 
or utilised. In 2016, 28 projects with Austrian partners were funded in the framework of ESRP (H2020 - Secure Societies), of which three were coordinated by Austrian partners. A high share of successful partners in projects of ESRP was also successful within the KIRASframework. Hence, KIRAS can be thought of as having a leverage effect.

Until 2018, EUR 84.6 million of funding (25 projects) led to EUR 165.8 million of value added. Over 3,000 jobs were created or utilised, $50 \%$ of which can be classified as high skilled employment. Additionally, EUR 80.8 million were created in terms of tax and contributions to social security (BMVIT, 2019).

Impacts from the increased level of security and preparation as well as the increased efficiency of communication and surveillance stemming from the realisation of the programme's objectives are yet to be evaluated.

\section{Measurability and Evaluability}

The FFG should monitor the use of the funds in accordance with their intended purpose and monitor the success of the project. However, due to lack of resourcesno accompanying monitoring was carried out, nor any content-related or scientific evaluation of the success of the projects upon completion ${ }^{52}$. In addition to increasing Austrian economic growth, the creation and securing of jobs was another quantifiable programme goal of KIRAS. While the FFG assessed on the one hand the funding applicants in course of submitting a project application, with regard to the number of secured and newly created jobs in the forms of "highly qualified jobs" and "jobs"; these figures where on the other hand not further validated after the end of a project.

The evaluation process was initiated in 2009 with a first interim evaluation report published in 2012, the ex-post evaluation was published in 2014. The initiative has been extended until the end of 2020 however and another yet unpublished evaluation was completed in 2018.

The evaluation of security research projects, which have received funding through the KIRAS programme are subject to continuous evaluations (interim evaluations and ex-post evaluation) regarding their contribution to the programmes' objectives.

The results of the evaluation are based on a combination of quantitative and qualitative evaluation methods. To analyse the impact and outcome of KIRAS includes a logic chart analysis, and an analysis of the programme and enterprise database of the FFG. In addition, online surveys of all programme participants at the beginning and end of the project as well as two years after the conclusion of the project, a multi-regional input-output model, and a number of case studies on selected KIRAS projects, and a peer review of the findings are generated.

The latest evaluation focused on two aspects:

- To what extent were the projects able to contribute to the strategic objectives of the initiative?

- Which framework conditions of the R\&D support programme constituted positive or negative factors for project participants in achieving project success?

Additionally, recommendations have been formulated based on the evaluation's results.

\footnotetext{
52 Rechnungshof (2010), Sicherheitsforschungsprogramm KIRAS, Bund 2010/2.
} 


\section{Reflexivity}

The end of the programme period was initially foreseen in 2013. In the same year the decision has been taken for an extension of the programme to 2020 , as the programme was seen to be successful while the factors that led to the establishment of the programme in the first place were still prevalent; the extension did not lead to significant changes in the programme design itself.

All submitted project proposals are evaluated by means of an efficient and transparent review process, which also allows for a regulated handling of classified data. For each programme line, specific evaluation criteria are drawn up and published in new calls for proposals.

To ensure that the humanities, social and cultural sciences (GSK) are taken into account in the projects in an integrative approach, the GSK aspects relevant to the respective programme lines are integrated into the evaluation criteria. This ensures that the social dimension of a project is present as an object of consideration at all levels (scientifictechnical, security policy, economic, consortial).

\subsubsection{Main Challenges and Opportunities}

The programme exhibits a number of opportunities for the development of innovation and $R \& D$ in the area of security:

- The results of the evaluations in 2009 and 2014 have fed back into the programme objectives and design, which allows the programme to adjust to evolving trends and needs. This helped the programme to evolve fairly efficient, which is also evident with the decision to continue with the programme to the end of 2020.

- The programme's wide breadth of policy instruments and policy fields covered in the different calls reach from prevention from natural and technological disasters to cybersecurity, which ensured the availability of relevant funding instruments.

- Available instruments have been covering the entire value chain of knowledge production from feasibility and usability studies to demonstration projects.

At the same time, the programme faces a number of challenges that impede the initiative to be more efficient in supporting innovation in the area of security:

- The programme was developed in-house in the BMVIT, without explicit and formal stakeholder involvement. Furthermore, the BMVIT did not carry out a quantifiable national needs assessment on the topic of security before the programme was launched.

- Within the programme's framework, decisions regarding interventions (objectives, modalities, level of resources) were taken by the BMVIT and binding to the involved actors, limiting the overall reflexivity of the programme. 


\subsubsection{Case Study 4: Building of Tomorrow}

\subsubsection{Introduction}

Building of Tomorrow is a research and technology programme supporting the transition to lowenergy buildings, and the concept of zero energy passive housing. It supports incorporating ways of using environmentally friendly and renewable materials in construction, new designs and emissions free construction materials. The programme supported higher energy efficiency throughout the entire life-cycle of a building, greater use of sustainable raw materials and efficient use of materials in general. Greater use of renewable energy sources, especially solar energy, increased consideration of user needs and services. The programme was developed by the Austrian Federal Ministry for Ministry for Climate Action, Environment, Energy, Mobility, Innovation and Technology (BMK - known until 2020 as Ministry for Transport, Innovation and Technology (BMVIT)) in co-operation with a network of experts and stakeholders, and with the assistance of the Austrian Industrial Research Promotion Fund.

Against the background of the emerging topic of sustainability (Rio conference, Brundtland report) on the global level, discussions between different Austrian ministries emerged if and how new technologies could contribute to a more sustainable development. Thus a process called Austrian Programme on Technologies for Sustainable Development (at:sd) was set up. Eventually an initiative called "Nachhaltig Wirtschaften" (which can be translated as sustainable economy) was set up by the Federal Ministry for Ministry for Climate Action, Environment, Energy, Mobility, Innovation and Technology (BMK). This initiative started in 1999 with the programme "Building of Tomorrow" ("Haus der Zukunft").

However, activities and initiatives already started a decade earlier played an important role for the setup of the "Building of Tomorrow" programme. Already in the late 1980s/early 1990s different concepts of low energy houses, solar houses and passive houses were developed and discussed, in particular in Southern Germany. In 1996 the first Austrian passive house was built in the province of Vorarlberg (the most western province of Austria bordering Germany and Switzerland). In the following years, numerous activities concerning passive houses took place in Vorarlberg, facilitated by the Energy Institute Vorarlberg (Energieinstitut Vorarlberg, EIV). The EIV played a key role for the knowledge transfer from Germany and served as a platform for communication, cooperation and learning (BMVIT, 2007).

In 1997, the Upper Austrian Energy Utility company Energie AG OÖ presented a so called building/house of the future at a trade fair. This project caught the attention of the responsible officials in the ministry of transport, innovation and technology, since it demonstrated the technological feasibility of passive houses. The house was described as being very futuristic, including many smart home applications and automated functions. Since it was designed as a technology demonstrator many components and systems of the house were overdesigned. Moreover, many technologies were used in parallel (heat pumps, photovoltaics, etc), while probably one technology would have met the needs of the potential users of such a house. Altogether, the construction of such a house, slightly larger than a single family house, was estimated at a cost of around ATS 8 million (appr. 580.000 EUR) without the costs for the land it was built on, and which was considered far too expensive at the time, yet , the building proved that passive housing was technically feasible. In addition to this influential technology demonstrator, the Energy Institute Vorarlberg was involved in an EU project CEPHEUS (Cost 
Efficient Passive Houses as European Standards), which stimulated several demonstration projects across Austria.

At the time, these activities (Vorarlberg, CEPHEUS project, and the technology demonstrator in Upper Austira) coincided, and it was decided to setup a research, technology and innovation programme in the area of the "building of tomorrow".

Since 2013, the funding activities have been continued in a wider framework in the "City of the Future" technology programme. This initiative pursues the mission of enabling the implementation of plus-energy neighbourhoods through research and development of technologies, system integration, new solutions and digitalisation. Its focus is on innovative technologies and concepts for energy generation, distribution, conversion and storage, but also on consumption optimization in buildings and building associations, as well as technologies and efficiency for new construction and renovation. Funding for the programme was provided through the then BMVIT. For the first phase, a budget of EUR 21.7 million was foreseen for a period of six years (1999-2005) equalling annual funds of up to EUR 3.6 million (Pöchhacker et al., 2016). The programme was then transformed to the building of tomorrow plus initiative and up to 2013 EUR 37.8 million was granted to eligible research projects over the same period.

\subsubsection{Strategic Orientation Level}

\section{Legitimacy}

Legitimacy was achieved in the design of the programme and is linked to a process called Austrian Programme on Technologies for Sustainable Development (at:sd) that was set up in the late 1990s. Within this process, several focus groups were formed to create visions of a sustainable future for Austria. Additionally to these focus groups several studies (surveys, Delphi, studies, etc.) were drafted to provide relevant recommendations. In these discussions, the idea that something should be done to promote research and development with regard to innovative technologies potentially contributing to a more sustainable society was developed. From the at:sd process different focus groups were set up with relevance for the built environment (Solar energy, bio energy, building \& living, regional development). In addition, to these focus groups several studies (surveys, Delphi, studies, etc.) were drafted to come up with recommendations.

\section{Directionality}

The programme's primary objective was to support the development of energy efficient and sustainable buildings, and addressing relevant challenges, such as the high cost, which had to be reduced for innovations like passive houses to be diffused to a large number of customers. When the programme was developed, already existing activities and concepts like solar low energy houses, passive houses and ecological building materials were integrated in the programme. Thus, it provided an additional incentive for the actors to integrate their technologies into one concept. 
Key objectives of the programmes were to take into account service and utilization aspects (usability and comfort) and in particular the reduction of costs to the same level or slightly above the level of conventional buildings. In Phase 2 of the programme - Building of Tomorrow Plus - the following objectives were prioritized:

(i) Creating the technological basis for the building of tomorrow, especially the plusenergy house.

(ii) To expand the focus of the programme to include office and factory buildings and on modernizing existing buildings.

(iii) Adapting innovative technologies and products for large-scale industrial manufacturing.

(iv) Initiating demonstration projects (buildings, settlements, networks) to put new technologies and approaches in place.

(v) Supporting the international linkages of key Austrian providers of know-how, boosting the transfer of know-how across borders, accumulating human resources and integrating existing knowledge into suitable training schemes.

\section{Leadership}

The programme was initiated, implemented and financed under the responsibility and guidance of the Austrian Federal Ministry of Transport, Innovation and Technology (BMVIT). Partner institutions were commissioned for operational programme activities. BMVIT, The Austrian Society for Environment and Technology (ÖGUT), Research Promotion Agency (FFG) and Austria Wirtschaftsservice $\mathrm{GmbH}$ (aws) formed the management team of the programme, which ensured a smooth operation of the programme implementation within the framework of regular fixed meetings. The accompanying measures were implemented through tenders or commissioning to external service providers.

In many cases, ÖGUT was also responsible for the implementation of accompanying measures in the areas of public relations, organisation of workshops, and the presentation of the programme at meetings and conferences. ÖGUT was responsible for monitoring the content of the programme. In this context, ÖGUT was responsible, in coordination with BMVIT, for the orientation and further development of the programme, the support and networking of potential submitters and project participants, and the integration of important stakeholders. Furthermore, ÖGUT has taken over measures for project generation, project coaching and dissemination, e.g. preparation of calls for proposals, support of calls for proposals, pre-proposal checks, statements on interim and final reports of the project participants, or networking activities in Austria and abroad.

\section{Intentionality}

The programme's specific objectives and clear timelines are developed only to some degree. The programme's objective were derived from the grand challenge of sustainability and climate change, but performance targets lacked precision and clear milestones were missing. Yet, from the second programme phase, "Building of Tomorrow Plus", was intended to make a central contribution to the development and preparation or support of the market launch or market penetration of economically feasible, innovative technical and organisational solutions with 
regard to a $\mathrm{CO}_{2}$-neutral construction sector. This should support the security of future energy supply and a reduction of greenhouse gas emissions from the construction sector.

Flexibility

Project types have evolved over time. Building of tomorrow was designed as a learning program. Jury meetings, expert workshops or consultations for submitters were deliberately used to identify and, if possible, consider possibilities for improvement. In this context, emphasis was also placed on international exchange with other ministries and agencies. This took place within the framework of IEA research cooperation or through bilateral exchanges, e.g. with representatives of the Dutch "EnergieSprong" programme, as well as the reception of international delegations.

\subsubsection{Policy Coordination Level}

\section{Exploratory}

The programme did not foresee exploratory elements. However, as a research programme, building of tomorrow generally supported the preparation of basic research studies at 100 percent, while only part of the project costs (usually 20 - $50 \%$ ) was funded for basic economic research or technology and component development. Furthermore, particularly innovative construction and renovation concepts were supported in most tenders. This was intended to investigate the basic feasibility of a technology development or the combination of different project results in preparation for a demonstration project.

This instrument proved to be particularly helpful in managing the transfer from basic research to concrete application testing. Another special feature were the demonstration and lead projects with the objectives to bring innovative solutions into application in accordance with the programme objectives. Funding was based on the additional costs arising from the innovation, and not on the total construction costs. Under the umbrella of the accompanying measures, end-users were involved during the programme implementation. A further important aspect is also the development of standards for sustainable buildings in Austria.

\section{Demand-articulation}

Citizens were engaged through dedicated accompanying measures. These actions were directly related to the objectives of the programme, not only the technology development but also the establishment of a corresponding community, the promotion of the application and market penetration of innovative solutions, and the development of competence.

These activities were particularly important given very heterogeneous building technologies that at the same time rely to a large extent on the interaction of different actors. In many cases, ÖGUT took over the programming and implementation of accompanying measures, for example in the areas of public relations, organisation of workshops, and presentation of the programme at meetings and conferences. 
In addition, the 'aws - Austria Wirtschaftsservice', the central development bank of the Federal Government, was closely involved in "Building of Tomorrow" in order to provide optimal support for the market transfer of the research results. This was particularly relevant in the second phase of the programme, where a stronger market orientation was sought. Furthermore, aws handled the administration of the investment projects and took over the coordination of the lead projects.

\subsubsection{Policy Implementation Level}

\section{Policy mix diversity}

Between 1999 and 2007, the "Building of Tomorrow" programme organised five calls for proposals, for which projects could be submitted in the different categories. Parallel to this, topics for concrete technology and component developments were tendered, which should enable a technological leap in the overall "building" system. The aim was and is the development of innovative components and innovative system solutions. In the field of new buildings, the aim was and is the development of innovative storage technologies, technologies for the increased use of renewable energy sources, components and elements based on renewable raw materials as well as innovative components and parts.

Five calls for proposals were issued for the Building of Tomorrow programme:

- Basic research: aimed at the development of projects on the future of building refurbishment, the analysis of the refurbishment process, the further development of tools and labels and the definition of quality criteria with regard to building biology, comfort and health (refurbishment of old buildings), as well as the preparation of building process experiences for third parties, documentation of best practice examples from housing subsidies and the establishment and support of networks (new buildings). In addition, strategic work was carried out for both the renovation of old buildings and for new buildings.

- Basic economic research: aimed at the generation of projects for the preparation of technical knowledge for the refurbishment of old buildings.

- Accompanying measures: Aimed at strengthening the environmental component in the implementation of the "innovative building concepts" and future building projects. The creation of an information node for the targeted preparation of information for planners, architects and developers.

In the second programme phase "Building of Tomorrow plus", four calls for tenders were issued between 2008 and 2012, which were essentially oriented towards the vision of the PlusEnergy building. To this end, tried and tested instruments were supplemented by new approaches (e.g. leading projects). The main themes of the calls for proposals remained constant in their basic form, but focused on different aspects and facets depending on the call for proposals.

Leading projects in the "Building of Tomorrow Plus" programme are multi-year, strategically oriented joint projects focusing on building associations - housing estates and/or industrial and commercial areas - and on trend-setting modernisation of buildings. Leading projects are subject to integrative overall management and usually consist of a coherent bundle of individual projects, which - integrated into a clearly defined strategy - pursue a concretely 
described goal. The focus here is on compliance with the programme objectives and the degree of innovation of the project.

\section{Leverage}

In total, 450 projects were financed in nine calls for proposals with a funding budget of EUR 63 million. The majority of projects were classic research and development projects, supplemented by a smaller number of investment projects and the accompanying measures mentioned above.

In a two-stage procedure, eight lead projects were selected. These lead projects comprised a total of 60 sub-projects, which could be submitted to the permanent jury on the submission deadlines. Approximately EUR 40,000 per year for a maximum of three years were earmarked for lead project management. The number of sub-projects ranged from 3 to 11 . 211 project partners were involved in the lead projects and the associated sub-projects. The total costs applied for amounted to a EUR 51 million, almost half of which was applied for funding. Approved were total costs of EUR 34.7 million and a grant of EUR 15.3 million. On average, this results in costs of EUR 4.4 million, and a grant of EUR 1.9 million for each lead project.

A calculation of the economic effects of the programme as part of the ex-post evaluation has shown the effects of the programme on the Austrian economy: Over the entire duration of the programme, a total of EUR 204.202 million in additional gross domestic product, an additional mass income of EUR 88.236 million, and 1,643 jobs were created ${ }^{53}$.

From the third call onwards, demonstration projects were also funded, which focused on the practical implementation of innovative concepts, approaches and technologies. This was intended to demonstrate the practical suitability of new developments and to show the achievable energy saving effect. Therefore, all demonstration projects were subjected to an accompanying evaluation and joint monitoring. The collection of energy consumption data, the building evaluation with the tool "Total Quality Building" and the survey of user acceptance were used to check whether the innovative demonstration buildings actually met the quality requirements and the expectations placed in them.

\section{Measurability and Evaluability}

In 2015, a comprehensive evaluation of the entire programme with main focus on the description of the overall programme effects was commissioned by the BMVIT ${ }^{54}$. For this purpose, based on the logical framework approach, the relevant documents and data were analyzed and evaluated. Furthermore, an online survey was conducted among all project managers, in which 84 project managers participated. In addition, 24 interviews with selected project managers as well as national and international experts were conducted.

Building of tomorrow was designed as a learning programme. Jury meetings, expert workshops or consultations for submitters were deliberately used to identify and, if possible, consider possibilities for improvement. The project sponsors were asked for their feedback in a written survey. In addition, interim evaluations and international exchanges with pro-

\footnotetext{
${ }^{53}$ Levenda, J., Pöchhacker, G. (2016), Programmevaluierung Haus der Zukunft 1999 - 2013, Vienna.

${ }^{54}$ Ebda.
} 
gramme managers in other countries were used specifically to take up suggestions for programme content and implementation. In this context, emphasis was also placed on international exchange with other ministries and agencies. This took place within the framework of IEA research cooperation or through bilateral exchanges, e.g. with representatives of the Dutch "EnergieSprong" programme, as well as the reception of international delegations.

\section{$\underline{\text { Reflexivity }}$}

The programme has continuously developed over time. This applies both to the types of projects and instruments as well as the thematic priorities of the calls for proposals. In the beginning, the focus was on studies, technology developments and construction concepts, but gradually, demonstration projects, accompanying measures, investment projects, $R \& D$ cooperation, etc. were also promoted.

In the first call for proposals of the second programme phase, lead projects were funded for the first time, for which a corresponding budgets could be provided. Demonstration projects were funded in most calls for proposals - due to the low response to the call for proposals in 2009, the call for proposals for demonstration projects was repeated and concretised in the following year.

The first two calls for proposals focused on new construction, while the other "Building of Tomorrow" calls focused on new construction and renovation of old buildings. In the second phase of the programme, the goal of the PlusEnergy Building is a common thread running through all calls for proposals. Volumes have overall increased - despite significant fluctuations.

The innovative construction and refurbishment concepts form the core of the programme. With the help of these projects, not only innovative construction methods that meet the above-mentioned criteria are to be planned and realised, but also the results of the basic studies and the technology and component developments are to be applied. The elaboration of idea sketches and innovative redevelopment planning (old building redevelopment) as well as innovative construction concepts (new building) were the focus of the third call for proposals. The aim of the competitions is to learn from remarkable pioneering achievements in residential, office and other commercial construction and to use these projects as a basis for further developments.

The programme shows multiple positive effects: The awareness of the importance and potential of sustainable building was raised, sustainability criteria were considered within the relevant norms and standards, research institutions were set up and strengthened, and the international position of Austria as a technology and innovation leader in sustainable building was significantly improved.

\subsubsection{Main Changes and Opportunities}

The initiative provides a number of opportunities to push the construction of low-energy buildings and advance innovation in relevant fields.

- The programme addressed the challenge of global climate change and sustainability though the framework of the initiative, and several focus groups were formed to create visions of a sustainable future for Austria and to provide relevant recommendations.

- The programme was designed as a learning programme. Jury meetings, expert workshops or consultations for submitters were deliberately used to identify and, if 
possible, consider possibilities for improvement, and international exchange with other ministries and agencies, which helped advancing the debate on relevant issues in Austria and vice versa..

- Stakeholders were actively involved in the development of the programme by means of focus groups and a large delphi survey. Also in the framework of the accompanying measures potential users were involved in identifying needs that helped the development of standards for sustainable buildings.

- The programme's reflexivity was ensured under the umbrella of the accompanying measures, and led to the evolution of the programme to building of tomorrow plus.

On the other hand, a number of challenges have been faced that limited the overall impact of the programme:

- The programme's objective were derived from the grand challenge of sustainability and climate change, but performance targets lacked precision and clear milestones were missing.

- While there was reasonable depth of coverage from basic research to demonstration and lead project, the breadth was limited to sustainable buildings.

- While cooperation of the private and the public sector was stimulated in the framework of the accompanying measures that were directly related to the objectives of the programme, private funds were only leveraged by means of co-financing within the funded projects.

- A monitoring framework focussing on technological indicators was designed and implemented, but no specific indicator framework to support future evaluation studies was designed in the design stage of the programme. 


\subsection{GENERAL OBSERVATIONS ON THE CASE STUDIES}

The four cases display quite a number of similarities, which is explainable by the fact that all four programmes focus on topics, which are not limited to the competences of federal ministries, but rather run across these. In addition, the programmes typically are directed at interdisciplinary research and technological development, affording a combination of social and technological solutions.

However, the case studies also show a few differences, some of which might go back to the fact that topical areas, goals and instruments of these programmes differ. For instance, whilst "Mobility of the Future" deals inter alia with mobility-related infrastructures, which have to be planned and maintained in hindsight of decades or even centuries, "Ambient Assisted Living" finances studies, product and service-development focusing on information and communication technologies, which feature ever shorter development cycles of a few years at best.

\subsubsection{Strategic Orientation}

The following, we will analyse our findings by following the OECD framework. There is a number of similarities regarding the first of the three high-level categories of the OECD framework, strategic orientation of programs. All feature extensive stakeholder participation processes, with the exception of the security related KIRAS programme, which had focused on BMK staff, thus leading to varying degrees of legitimacy. The directionality in general is high, with all programmes featuring clear overarching objectives, which are linked to more details in a several-pronged goal structure.

Leadership is more contested, which partially has to do with the fact that Austrian STI policy in general lacks leadership on the highest governmental level. There are next to no events, where chancellor and ministers rally to present governmental goals in this policy field. On the ministerial level, BMK, the ministry responsible for the four programmes ${ }^{55}$, has a clear ownership.

The intentionality of the programmes is given, with a number of goals and an explicit intervention logic available. However, in all cases no ex-ante key performance indicators allow an impact evaluation of the programmes against preset goals in a detailed manner.

All programmes display a certain flexibility, e.g. "Mobility of the Future" has implemented new instruments on several occasions, which then have been scrutinised internally and externally. Moreover, all schemes are evaluated frequently, yet, there are no formalised processes for institutionalising change. Building of Tomorrow is an exception in so far, as it understands itself as a learning programme featuring also an international exchange of practices.

\footnotetext{
${ }^{55}$ In the case of KIRAS, since early 2020 the Federal Ministry of Agriculture, Regions and Tourism (BMLRT) is responsible for the programme.
} 


\subsubsection{Policy Coordination}

Looking at the second of the high-level categories of the OECD framework, policy coordination, in can be noted that both horizontal and vertical coordination are limited for all programs. This can be attributed to the specific characteristic of Austrian STI policy-making, where coordination on the federal level mostly stays without extra funding and coordination between federal and regional levels is limited to single initiatives and instruments. Indeed, in Austria coordination between federal ministries is focusing on negative coordination, i.e. rather than creating a common agenda, ministries report what they are doing, thus rather claiming stakes than designing joint activities. This is true also for science, technology and innovation policy. ${ }^{56}$

Although there are attempts of formal coordination such as in case of the steering committee of KIRAS, these are only seldomly successful in the sense of actually reading common programmes or activities. At the same time, the intensity of coordination is also weak. In addition,, the exploratory character of policy coordination is rather weak, as with "Mobility of the Future" and "Ambient Assisted Living" or not existent, as with KIRAS and Building of tomorrow.

There are exceptions to this general weakness of coordination, which are limited to singular attempts. One example is the cooperation between several STI related ministries under the leadership of BMVIT, now BMK, in the framework of the Austrian federal STI strategy working group 3 on the "Quality of Life and Demographic Change“57 in the framework of "Mobility of the Future".

Outside the sphere of intragovernmental coordination, the situation changes for all case studies, as all of them feature frequent and intensive cooperation of the responsible ministerial departments with actors of different industrial branches and other stakeholders. This is of specific importance in the area of demand articulation, as for example through A3PS, the Austrian Association for Advanced Propulsion Systems, founded and sponsored by the BMK and on the international level, e.g. in the framework of ERANET or the International Energy Agency (IEA).

\subsubsection{Policy Implementation}

Regarding the third of the high-level categories of those of the framework, policy implementation, the following observations can be made while comparing the four selected Austrian cases. Policy Mix Diversity is given in the four analysed programmes but variations can be observed. In MdZ, the varying logics and market structures of the different thematic fields are reflected in the differentiated use of instruments, but instruments directly targeting social and sociotechnical innovations and budgetary provisions for these topics are underrepresented. The programme Benefit succeeds in policy mix diversity in terms of ensuring cross-sectorial diversity and involving end users such as care and support providers, but it shows only limited innovation cycle diversity. In KIRAS, the available instruments have been covering the value chain of knowledge production from feasibility and usability studies to demonstration projects and thus shows sufficient policy mix diversity for security research. The policy mix of building

\footnotetext{
${ }^{56}$ Pichler et al 2007, Biegelbauer 2013.

${ }^{57}$ Dinges et al 2018
} 
of tomorrow similarly covered the whole value chain of knowledge production from basic research to demonstration projects and was complemented by accompanying measures to foster competence development and dialogue between different stakeholder groups.

Leverage is not achieved in all analysed programmes at equal scale. While MdZ show a high leverage in terms of programme additionality, the leverage of private sector contributions is within Benefit, Building of Tomorrow and KIRAS mainly limited by the by requirement of (private sector) co-funding for projects.

For the third dimension 'Measurability, \& Evaluability, Reflexivity' a heterogeneous picture emerges while comparing the three programmes in these three sub-dimensions. While measurability can be observed only at limited or average scale in the analysed programs, with only limited predefined impact indicators, all case studies demonstrate nevertheless a good degree of evaluability as all programmes under scrutiny have been repeatedly subject to external evaluation studies. Also reflexivity can be observed be in using evaluation results to revise programme structure as in the case of Benefit, or learning activities in the programme 'building of tomorrow' under the umbrella of accompanying measures that led to the evolution of the programme to building of tomorrow plus.

\subsubsection{Resume}

In summary, the Austrian case studies show the following strengths in relation to the given analytical framework: in all programmes considered, good stakeholder involvement in both programme development and implementation can be observed, as well as clear directionality and intentionality. Furthermore, in all programmes evaluations are conducted regularly. In contrast, weaknesses can be identified with regard to vertical and horizontal coordination, the intensity of coordination, and the effectiveness of evaluations. 
Table 3 Comparison of cases after categories of the OECD framework

\begin{tabular}{|c|c|c|c|c|c|}
\hline & & Mdz & BENEFIT/AAL & KIRAS & $\mathrm{HdZ}$ \\
\hline Main & Subcat. & Assessment & Assessment & Assessment & Assessment \\
\hline \multirow[b]{3}{*}{ 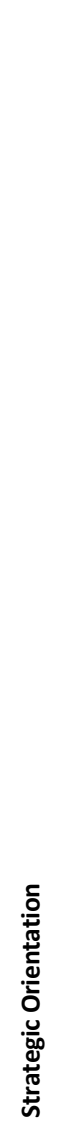 } & Legitimacy & $\begin{array}{l}\text { Legitimacy is obtained to a high degree, since } \\
\text { input for the programme goals comes from a } \\
\text { wide group of stakeholders in different } \\
\text { forms. This happens e.g. in the form of } \\
\text { conferences and workshops during the } \\
\text { preparation and in the form of smaller } \\
\text { meetings during the lifetime of the } \\
\text { programme. However, citizens are not } \\
\text { included into this process, which is an issue } \\
\text { with new mission orientated innovation } \\
\text { programmes. }\end{array}$ & $\begin{array}{l}\text { Benefit partially displays legitimacy by } \\
\text { ensuring that a widevariety of stakeholders, } \\
\text { including those less experienced in STI } \\
\text { activities and end-user organizations, are } \\
\text { engaged in defining the programme's } \\
\text { thematic priorities, participate in } \\
\text { consultations, and involved in projects. } \\
\text { There are however no indications that } \\
\text { actors other than the BMK (e.g. sectoral } \\
\text { ministries, Parliament) were instrumental in } \\
\text { selecting AAL as a challenge to be } \\
\text { prioritized. }\end{array}$ & $\begin{array}{l}\text { The legitimacy of KIRAS is to be seen } \\
\text { as only limited. The programme was } \\
\text { developed in-house in the BMVIT, } \\
\text { without any explicit and/or formal } \\
\text { stakeholder involvement. } \\
\text { Furthermore, the BMVIT did not } \\
\text { carry out a quantifiable national } \\
\text { needs assessment on the topic of } \\
\text { security before the programme was } \\
\text { launched. }\end{array}$ & $\begin{array}{l}\text { Legitimacy was present in the design of the } \\
\text { programme. A process called Austrian } \\
\text { Programme on Technologies for Sustainable } \\
\text { Development (at:sd) was set up in the late } \\
\text { 1990ies. Within this process, several focus } \\
\text { groups were formed to create visions of a } \\
\text { sustainable future for Austria. Additionally to } \\
\text { these focus groups several studies (surveys, } \\
\text { Delphi, studies, etc.) were drafted to come up } \\
\text { with recommendations. }\end{array}$ \\
\hline & Directionality & $\begin{array}{l}\text { The programme features a clear } \\
\text { directionality regarding societal, environ- } \\
\text { mental and economic goals, which is also re- } \\
\text { flected in the overall mission. The clear im- } \\
\text { pact orientation of new mission-oriented } \\
\text { innovation policy is also reflected in the road- } \\
\text { maps specifying the areas of future calls for } \\
\text { proposals. Some of the goals have been criti- } \\
\text { cised for being narrowly defined and } \\
\text { unclearly prioritised, which would be } \\
\text { important for new mission-oriented innova- } \\
\text { tion programmes. }\end{array}$ & $\begin{array}{l}\text { Benefit exhibits directionality: It addresses } \\
\text { two challenges - demographic change and } \\
\text { promoting uptake of scientific advances } \\
\text { into marketable innovations - and, } \\
\text { correspondingly, clearly articulates its pro- } \\
\text { gramme objectives. Benefit follows a broad } \\
\text { understanding of quality of life of the } \\
\text { elderly, from ICT-solutions for specific long- } \\
\text { term diseases to integrated systems for } \\
\text { homes and care facilities. }\end{array}$ & $\begin{array}{l}\text { The programme shows directionality } \\
\text { as it was the first national } \\
\text { programme of this kind within the EU } \\
\text { to increase multiple facets of the } \\
\text { security of the country's citizens. } \\
\text { With the programme a broad } \\
\text { understanding of security has been } \\
\text { addressed reaching from protection } \\
\text { of critical infrastructures to the } \\
\text { increase of subjective security of } \\
\text { citizens. }\end{array}$ & $\begin{array}{l}\text { Directionality was given to a large extent. The } \\
\text { programme addressed the challenge of global } \\
\text { climate change and sustainability. This was } \\
\text { done in the framework of the initiative called } \\
\text { "Nachhaltig Wirtschaften" (which can be } \\
\text { translated roughly with sustainability and } \\
\text { economy) that was set up by the Ministry for } \\
\text { Transport, Innovation and Technology } \\
\text { (BMVIT). This initiative started in the year } \\
\text { 1999 with the programme "Building of } \\
\text { Tomorrow" ("Haus der Zukunft"). }\end{array}$ \\
\hline & Leadership & $\begin{array}{l}\text { There is clear leadership of BMK regarding } \\
\text { MdZ, which is the sole Austrian programme } \\
\text { systematically funding transport research. }\end{array}$ & $\begin{array}{l}\text { Benefit clearly shows leadership: The BMK is } \\
\text { the programme owner and funder of the } \\
\text { programme, as well as taking part and } \\
\text { funding the related European Joint } \\
\text { Programm Active Assisted Living. }\end{array}$ & $\begin{array}{l}\text { Clear leadership of the programme } \\
\text { has been given: the Council for } \\
\text { Research and Technology } \\
\text { Development (RFTE) was } \\
\text { implemented until the end of } 2019 \\
\text { under the responsibility and } \\
\text { guidance of the BMVIT. Since 2020 } \\
\text { The Federal Ministry of Agriculture, } \\
\text { Regions and Tourism (BMLRT) is }\end{array}$ & $\begin{array}{l}\text { Leadership of a high-level body above the } \\
\text { BMVIT was not visible. The programme was } \\
\text { implemented throughout the programme } \\
\text { period under the responsibility and guidance } \\
\text { of the BMVIT, which initiated and financed } \\
\text { the programme. Partner institutions were } \\
\text { commissioned for the operational } \\
\text { programme activities. }\end{array}$ \\
\hline
\end{tabular}




\begin{tabular}{|c|c|c|c|c|c|}
\hline & & & & $\begin{array}{l}\text { responsible for the KIRAS } \\
\text { programme. }\end{array}$ & \\
\hline & Intentionality & $\begin{array}{l}\text { Intentionality is given, with the programme } \\
\text { featuring a pronounced intervention logic } \\
\text { and corresponding goals being clear and } \\
\text { comprehensive. }\end{array}$ & $\begin{array}{l}\text { Benefit displays intentionality only to a } \\
\text { limited degree: Its objectives are clearly } \\
\text { articulated, however, there are no pre- } \\
\text { defined key performance targets (KPIs) or } \\
\text { milestones to be reached in a given } \\
\text { timeframe. }\end{array}$ & $\begin{array}{l}\text { The programme lacks intentionality: } \\
\text { While the intention of the } \\
\text { programme is clearly articulated in } \\
\text { the programme document, the } \\
\text { initiative lacks quantifiable indicators } \\
\text { to evaluate the achievement of said } \\
\text { goals. As such the milestones of the } \\
\text { initiative are rather vague. }\end{array}$ & $\begin{array}{l}\text { There was to some degree intentionality in } \\
\text { the programme. The programme's objective } \\
\text { were derived from the grad challenge of } \\
\text { sustainability and climate change, but } \\
\text { performance targets lacked precision and } \\
\text { clear milestone were missing. }\end{array}$ \\
\hline & Flexibility & $\begin{array}{l}\text { The programme features flexibility, e.g. } \\
\text { featuring the introduction of new } \\
\text { instruments during its lifetime. It is } \\
\text { continuously monitored by the agencies FFG } \\
\text { and AustriaTech that provide feedback to the } \\
\text { ministry. Programme goals and instruments } \\
\text { are reflected through evaluations and } \\
\text { stakeholder engagement processes. } \\
\text { However, changes in the programme are } \\
\text { infrequent and often bound to evaluations. }\end{array}$ & $\begin{array}{l}\text { Flexibility is mostly present: Several re- } \\
\text { orientations of thematic priorities, } \\
\text { programme structure, and instruments } \\
\text { have been introduced on the basis of } \\
\text { evaluations and/or stakeholder } \\
\text { consultation. However, they have not been } \\
\text { used to revise or update overarching goals } \\
\text { and no formalized processes and } \\
\text { information channels for goal revision exist. }\end{array}$ & $\begin{array}{l}\text { Flexibility has been present to some } \\
\text { extent: The results of the evaluations } \\
\text { in } 2009 \text { and } 2014 \text { have fed back into } \\
\text { the programme objectives and } \\
\text { design. This is also evident with the } \\
\text { decision to continue with the } \\
\text { programme to the end of } 2020 \text {. } \\
\text { However, there were no explicit rules } \\
\text { for revising and updating of } \\
\text { programme goals. }\end{array}$ & $\begin{array}{l}\text { Flexibility was present: Building of Tomorrow } \\
\text { was designed as a learning program. Jury } \\
\text { meetings, expert workshops or consultations } \\
\text { for submitters were deliberately used to } \\
\text { identify and, if possible, consider possibilities } \\
\text { for improvement. In this context, emphasis } \\
\text { was also placed on international exchange } \\
\text { with other ministries and agencies. This took } \\
\text { place within the framework of IEA research } \\
\text { cooperation or through bilateral exchanges, } \\
\text { e.g. with representatives of the Dutch } \\
\text { "EnergieSprong" programme, as well as the } \\
\text { reception of international delegations. }\end{array}$ \\
\hline 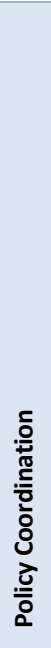 & $\begin{array}{l}\text { Horizontality, } \\
\text { Verticality }\end{array}$ & $\begin{array}{l}\text { Horizontal and vertical coordination, which is } \\
\text { key for new mission-oriented innovation } \\
\text { policy, is insufficient. Coordination between } \\
\text { Austrian Federal ministries generally in most } \\
\text { cases is insufficient and inefficient, } \\
\text { concentrating on negative coordination and } \\
\text { not producing common activities. However, } \\
\text { there was meaningful cooperation between } \\
\text { several STI related ministries e.g. in the } \\
\text { framework of the Working Group } 3 \text { of the } \\
\text { Federal STI Strategy, there is frequent } \\
\text { coordination with the transport directorate } \\
\text { of the BMK and with a variety of industrial } \\
\text { sectors. Also vertical coordination in Austria } \\
\text { is traditionally weak, despite taking place in a } \\
\text { federal system. In MdZ, it is partially } \\
\text { successful within single funding instruments } \\
\text { (e.g. innovation labs). Coordination on the } \\
\text { European level happiness e.g. through the }\end{array}$ & $\begin{array}{l}\text { Benefit partially exhibits horizontality: AAL } \\
\text { as a topic covers a number of policy fields } \\
\text { from ICT innovation to healthcare and social } \\
\text { affairs and has thematic synergies with a } \\
\text { large number of European R\&I initiatives. } \\
\text { The main policy instrument used is } \\
\text { cooperative, interdisciplinary projects, in } \\
\text { addition to targeted R\&D services. } \\
\text { However, it lacks instruments that } \\
\text { specifically bridge the gap from R\&l to } \\
\text { market uptake and/or market-creation } \\
\text { instruments. }\end{array}$ & $\begin{array}{l}\text { Horizontality is to be observedwithin } \\
\text { KIRAS. The programme shows } \\
\text { breadth in terms of policy fields } \\
\text { covered in the different calls reaching } \\
\text { from prevention from natural and } \\
\text { technological disasters to cyber- } \\
\text { security. Also the depth is ensured by } \\
\text { the existing mix of funding } \\
\text { instruments. }\end{array}$ & $\begin{array}{l}\text { Horizontality was partly present. While there } \\
\text { was reasonable depth of coverage from basic } \\
\text { research to demonstration and lead project, } \\
\text { the breadth was limited to sustainable } \\
\text { buildings. }\end{array}$ \\
\hline
\end{tabular}




\begin{tabular}{|c|c|c|c|c|}
\hline & $\begin{array}{l}\text { Conference of European Directors of Roads } \\
\text { (CEDR) as well as the European rail initiative } \\
\text { Shift2Rail. }\end{array}$ & & & \\
\hline Intensity & $\begin{array}{l}\text { Intensity of coordination is mediocre, again } \\
\text { to be attributed to the Austrian political } \\
\text { system rather than the programme itself. In } \\
\text { MdZ there is strong coordination between } \\
\text { industry and agencies, yet much less intense } \\
\text { coordination between different federal } \\
\text { ministries, featuring e.g. no joint calls for } \\
\text { tender or similar. An exception is the } \\
\text { cooperation with the transport directorate of } \\
\text { BMK, which frequently is invited for input to } \\
\text { MdZ. }\end{array}$ & $\begin{array}{l}\text { Benefit displays limited intensity in terms of } \\
\text { policy actor coordination and budget } \\
\text { integration, while coordination of } \\
\text { instruments is given. The BMK is the sole } \\
\text { driver and funder of the programme and } \\
\text { inter-ministerial coordination with sectoral } \\
\text { ministries is mostly limited to informal } \\
\text { dialogue and exchange within the } \\
\text { framework of the working groups of the } \\
\text { national STI-strategy. Coordination } \\
\text { between the federal government and state- } \\
\text { level authorities responsible for the } \\
\text { financing and operation of care takes place } \\
\text { only for purposes of information exchange. } \\
\text { In terms of instruments, benefit's thematic } \\
\text { priorities and calls are closely coordinated } \\
\text { with the European AAL Joint Programme. }\end{array}$ & $\begin{array}{l}\text { Intensity was partly given: while } \\
\text { KIRAS was owned by the BMVIT and } \\
\text { implemented by FFG until the end of } \\
2019 \text {. Within this framework } \\
\text { decisions regarding the intervention } \\
\text { (objectives, modalities, level of } \\
\text { resources) were taken and binding to } \\
\text { the involved actors. Programme } \\
\text { ownership has moved in the } \\
\text { beginning of } 2020 \text { to the BMRT while } \\
\text { the operational implementation has } \\
\text { remained with the FFG. } \\
\text { The programme steering committee } \\
\text { that also included representatives } \\
\text { from other ministries and other } \\
\text { relevant stakeholders proved to be } \\
\text { not working properly. }\end{array}$ & $\begin{array}{l}\text { Intensity was given for the programme. The } \\
\text { "Building of tomorrow" programme shared } \\
\text { its general aims with the other two } \\
\text { programmes of the "Nachhaltig } \\
\text { Wirtschaften" initiative, factory of the future } \\
\text { and energy systems of the future. These } \\
\text { programmes at national level followed the } \\
\text { principle of a "double dividend" } \\
\text { (Doppeldividende), which means that they } \\
\text { should generate an economic and a societal } \\
\text { benefit at the same time. }\end{array}$ \\
\hline Exploratory & $\begin{array}{l}\text { The exploratory character of coordination is } \\
\text { comparatively weak, again being more a } \\
\text { feature of the Austrian political system than } \\
\text { of } \mathrm{MdZ} \text { as such. The programme features a } \\
\text { number of policy instruments with the } \\
\text { potential for coordination, yet the } \\
\text { exploratory character is restricted to only a } \\
\text { few, especially new instruments such as } \\
\text { innovation labs and lighthouse projects. }\end{array}$ & $\begin{array}{l}\text { Benefit exhibits some exploratory elements: } \\
\text { It is thematically open and supports } \\
\text { cooperative R\&I covering the whole } \\
\text { spectrum of ICT-technologies, with a pre- } \\
\text { defined peer review selection process to } \\
\text { allow competition between technological } \\
\text { solutions proposed. However, other } \\
\text { exploratory elements such as formalized } \\
\text { learning processes or ecosystem } \\
\text { approaches to ageing not closely related to } \\
\text { an ICT solution such as social perceptions to } \\
\text { aging, social environments, learning, are not } \\
\text { supported. }\end{array}$ & $\begin{array}{l}\text { The programme has not intentionally } \\
\text { foreseen exploratory elements. } \\
\text { Cooperative R\&D projects are } \\
\text { confined to applied research themes } \\
\text { that reflect the current needs of end } \\
\text { users. }\end{array}$ & $\begin{array}{l}\text { The programme did not foresee exploratory } \\
\text { elements. Under the umbrella of the } \\
\text { accompanying measures end-users were also } \\
\text { involved during the programme } \\
\text { implementation. A further important aspect } \\
\text { is also the development of standards for } \\
\text { sustainable buildings in Austria. }\end{array}$ \\
\hline $\begin{array}{l}\text { Demand- } \\
\text { articulation }\end{array}$ & $\begin{array}{l}\text { Demand articulation is a particularly strong } \\
\text { side of MdZ. The involvement of stakeholders } \\
\text { and regulatory authorities has its strengths } \\
\text { particularly in the creation and rethinking of } \\
\text { the programme. Also, industrial relations are } \\
\text { very pronounced and regulatory authorities } \\
\text { are part of several initiatives. }\end{array}$ & $\begin{array}{l}\text { Demand articulation is a particularly strong } \\
\text { side of MdZ. the involvement of } \\
\text { stakeholders and regulatory authorities has } \\
\text { its strengths particularly in the creation and } \\
\text { rethinking of the programme. Also, } \\
\text { industrial relations are very pronounced } \\
\text { and regulatory authorities are part of } \\
\text { several initiatives. }\end{array}$ & $\begin{array}{l}\text { Demand articulation was partly } \\
\text { ensured mandatory involvement of } \\
\text { potential end-users (companies and } \\
\text { public agencies) in collaborative R\&D } \\
\text { projects. While some projects led to } \\
\text { public procurement actions, this was } \\
\text { not planned in a systematic manner. }\end{array}$ & $\begin{array}{l}\text { Demand articulation was present in the } \\
\text { programme. Stakeholders were actively } \\
\text { involved in the development of the } \\
\text { programme by means of focus groups and a } \\
\text { large Delphi survey. Also in the framework of } \\
\text { the accompanying measures, potential users } \\
\text { were involved ion in identifying needs. }\end{array}$ \\
\hline
\end{tabular}




\begin{tabular}{|c|c|c|c|c|c|}
\hline & & & & & $\begin{array}{l}\text { Furthermore standards for sustainable } \\
\text { buildings were developed. }\end{array}$ \\
\hline & $\begin{array}{l}\text { Policy } \quad \text { Mix } \\
\text { Diversity }\end{array}$ & $\begin{array}{l}\text { The programme features an extensive set of } \\
\text { policy instruments, some of which have been } \\
\text { fine-tuned, others of which are new to MdZ. } \\
\text { In light of its mission orientation, the varying } \\
\text { logics and market structures of the different } \\
\text { thematic fields are reflected in the } \\
\text { differentiated use of instruments. } \\
\text { Instruments directly targeting social and } \\
\text { socio-technical innovations are are } \\
\text { underrepresented, budgets comparatively } \\
\text { low. }\end{array}$ & $\begin{array}{l}\text { Policy mix diversity in terms of } \\
\text { interdisciplinarity is given in benefit: } \\
\text { Interdisciplinarity is a key objective of the } \\
\text { programme and it appears to be more } \\
\text { successful than the European AAL initiative } \\
\text { in promoting interdisciplinary projects. } \\
\text { Benefit succeeds in policy mix diversity in } \\
\text { terms of ensuring cross-sectorial diversity } \\
\text { and successfully involve end users such as } \\
\text { care and support providers, with higher } \\
\text { intensity than other R\&I funding schemes. It } \\
\text { also contributes to intensified networking } \\
\text { between stakeholder groups, better } \\
\text { understanding of end-user needs and } \\
\text { requirements, and increased cooperation } \\
\text { between R\&I-related organizations and } \\
\text { providers of services of general interest. } \\
\text { Benefit has limited innovation cycle } \\
\text { diversity: It provides funding for } \\
\text { cooperative innovation activities with a two } \\
\text { to three year time-to-market horizon, } \\
\text { demonstration projects ('test regions'), and } \\
\text { R\&D services such as feasibility studies. } \\
\text { There are no other dedicated instruments } \\
\text { for AAL to e.g. support market launch or } \\
\text { regulatory reform to enable take-up. }\end{array}$ & $\begin{array}{l}\text { The programme shows sufficient } \\
\text { policy mix diversity for security } \\
\text { research. Available instruments have } \\
\text { been covering the value chain of } \\
\text { knowledge production from } \\
\text { feasibility and usability studies to } \\
\text { demonstration projects. }\end{array}$ & $\begin{array}{l}\text { The policy mix was sufficiently diverse and } \\
\text { covered the whole value chain of knowledge } \\
\text { production from basic research to } \\
\text { demonstration projects. This was } \\
\text { complemented by accompanying measures } \\
\text { to foster competence development and } \\
\text { dialogue between different stakeholder } \\
\text { groups. }\end{array}$ \\
\hline 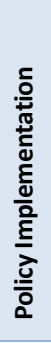 & Leverage & $\begin{array}{l}\text { Programme additionality is high, the leverage } \\
\text { varies strongly depending on thematic fields } \\
\text { and instruments. The average leverage is } 1.5 .\end{array}$ & $\begin{array}{l}\text { Benefit ensures leverage of private sector } \\
\text { contributions by requiring co-funding for } \\
\text { projects. For example, the public funding } \\
\text { rate for projects (2010-2013) is } 58 \% \text {, with } \\
\text { the remainder raised from private } \\
\text { organizations. }\end{array}$ & $\begin{array}{l}\text { Leverage can be seen only as limited. } \\
\text { Private funds have been leveraged to } \\
\text { the most part by means of co- } \\
\text { financing within the funded projects. } \\
\text { This is particularly relevant for the } \\
\text { demonstration projects, which are } \\
\text { large scale in financial terms. }\end{array}$ & $\begin{array}{l}\text { Leverage was partly achieved. On the one } \\
\text { hand, cooperation of the private and the } \\
\text { public sector was stimulated in the } \\
\text { framework of the accompanying measures. } \\
\text { These actions were directly related to the } \\
\text { objectives of the programme, not only the } \\
\text { technology development but also the } \\
\text { establishment of a corresponding } \\
\text { community, the promotion of the application } \\
\text { and market penetration of innovative }\end{array}$ \\
\hline
\end{tabular}




\begin{tabular}{|c|c|c|c|c|}
\hline & & & & $\begin{array}{l}\text { solutions, the development of competence, } \\
\text { etc. } \\
\text { On the other hand private funds were only } \\
\text { leveraged by means of co-financing within } \\
\text { the funded projects. }\end{array}$ \\
\hline $\begin{array}{l}\text { Measurability, } \\
\text { \& Evaluability, } \\
\text { Reflexivity }\end{array}$ & $\begin{array}{l}\text { Measurability is average. Programme } \\
\text { indicators are directly linked to the Austrian } \\
\text { impact assessment scheme (WFA), } \\
\text { mandatory for the civil service on the federal } \\
\text { level in assessing the ex-ante impacts of } \\
\text { planned regulation. All indicators but one are } \\
\text { on track, yet indicators reflecting societal } \\
\text { targets are missing. WFA indicators measure } \\
\text { output, however several MdZ projects } \\
\text { suggesting also outcome and impact } \\
\text { indicators have been funded recently. } \\
\text { Reflexivity is given, with a variety of } \\
\text { monitoring efforts and a mid-term evaluation } \\
\text { leading to a good overview of the programme } \\
\text { results. A final evaluation is foreseen and } \\
\text { hopefully will also be carried out - this was } \\
\text { however not the case for the predecessor } \\
\text { programme. }\end{array}$ & $\begin{array}{l}\text { Benefit has limited measurability and } \\
\text { evaluability: Although external evaluations } \\
\text { are regularly conducted, there are no } \\
\text { outcome or impact indicators beyond the } \\
\text { broadly defined goals and objectives of the } \\
\text { initiative. } \\
\text { Benefit exhibits reflexivity: Evaluation } \\
\text { results are used to revise programme } \\
\text { structure and have led to a consolidation of } \\
\text { thematic priorities, updated participation } \\
\text { rules to emphasize market-orientation, and } \\
\text { decreased the programme's research- } \\
\text { focus. }\end{array}$ & $\begin{array}{l}\text { The programme shows only limited } \\
\text { measurability but a good degree of } \\
\text { evaluability The evaluation process } \\
\text { was initiated in } 2009 \text { with a first } \\
\text { interim evaluation report published } \\
\text { in 2012, the ex-post evaluation was } \\
\text { published in 2014. The initiative has } \\
\text { been extended until the end of } 2020 \\
\text { however and another yet } \\
\text { unpublished evaluation was } \\
\text { completed in } 2018 \text {. }\end{array}$ & $\begin{array}{l}\text { Measurability was partly present. A } \\
\text { monitoring framework focussing on } \\
\text { technological indicators was designed and } \\
\text { implemented, but no specific indicator } \\
\text { framework to support future evaluation } \\
\text { studies was designed in the design stage of } \\
\text { the programme. Reflexivity was ensured } \\
\text { under the umbrella of the accompanying } \\
\text { measures, and led to the evolution of the } \\
\text { programme to building of tomorrow plus. }\end{array}$ \\
\hline
\end{tabular}




\section{Summary, Conclusions and Suggestions for MOP in Austria}

\subsection{OVERALL ASSESSMENT OF THE AUSTRIAN SYSTEM}

\subsubsection{General Characteristics of the Austrian System}

Over the past decades, Austria has seen an increasing R\&D intensity, which has made it one of the most $R \& D$ intensive countries in Europe. Its support to business $R \& D$ is also among the highest in Europe, implying some public leverage on private $R \& D$. In the same vein, during this period, it has also put in place agencies (e.g. FFG, aws, KLIEN) and instruments (e.g. thematic programmes like the ones covered in this report) which would lend themselves well to the development of a mission-oriented innovation policy.

On the other hand, most of the R\&D funding is not ex-ante thematically oriented with large parts of the increases in recent years going to R\&D tax credits and institutional funding of the Higher Education Institutions. Also, not the whole spectrum of portential STI policy tools is equally well developed, e.g. innovation-oriented public procurement much less so than traditional R\&I funding.

Hence, the Austrian STI policy system in recent past - while having pockets of activities that could be the basis for developing MOIPs - was developing rather in the direction of more generic measures, mostly addressing the rate rather than the direction of innovative activity.

\subsubsection{Strategic Orientation}

In the 2011 STI strategy, the need to develop a strategic policy approach to address 'grand societal challenges' was explicitly recognized as well as the need for changes in the governance of STI policies that would have to come along with this orientation. Subsequently, a number of funding channels and programmes were developed which tried to address these challenges. In these thematically oriented programmes, some of which even fall under the core definition of 'mission-oriented' programmes, Austria has accumulated experience with thematically oriented policy, which could form the basis for a broadening and widening of the mission-oriented approach in Austria.

A certain thematic orientation towards 'grand challenges' was developed, also to some extent driven by a similar orientation of the EU Framework Programmes. Especially Horizon 2020 increasingly addressed these challenges, and the Austrian attempts to 'alignment' with EU policies also 'imported' elements of such a thematic orientation. The current discussions about missions in the new Framework Programme 'Horizon Europe' and the Austrian support for this pillar of the programme also have the potential to provide strategic orientation towards MOIPs.

Most of all, the development of a new STI Strategy is a chance to raise MOIPs to become part of the strategic orientations of Austrian STI policy. 


\subsubsection{Policy Coordination}

It has long been recognized that, in order to be able to address grand societal challenges, Austrian STI policy not only needs better coordination within its realm but increasingly with other policy domains (health, energy, transport, security ...). However, so far, it was not specified exactly how the governance mechanisms should look like. The current coordination form (the 'task Force STI', comprising the main ministries) worked mainly as a flow of mutual information and not as a mechanism for joint strategic priority setting. Thus, the OECD Innovation Policy Review from 2018 re-stated and reinforced the need for changes in governance and funding, especially in policy coordination spanning across policy areas, which is essential for most MOIPs.

In response to the challenges of a good 'alignment' to the missions in Horizon Europe, but also to be able to react (pro)actively to new approaches to industrial policy in Europe (e.g.the 'Important Projects of Common European Interest (IPCEIs)') enhanced cross-ministerial coordination is required.

Current policy coordination between STI ministries so far is mostly informal and non-binding, and coordination with other policy domains beyond the confines of STI (such as energy, environment, transport ...) is piecemeal and patchy. Thus, while the existing structures are not yet fully developed for formulating and implementing a coherent mission-oriented policy, there are some attempts underway to recognize the importance of new governance mechanisms.

\subsubsection{Policy Implementation}

While assessments of the STI policy mix (including the OECD Innovation Policy Review of 2018 or an earlier 'systems evaluation') find a developed and far-reaching set of instruments, the balance of the portfolio of the instruments has shifted very much to non-oriented instruments in the recent past (e.g. the tax breaks) which limits the public capabilities to steer thematically. Another weak side of the instruments' toolbox is a lack of emphasis on the use of demand-side instruments, which are very important in a number of mission-oriented policies.

Another feature of the policy mix is that the plethora of instruments is rarely applied in a coordinated manner and does not take into account the effects of other measures. On the level of the individual measures, stakeholder involvement and close interaction between policymakers and implementing agencies are apparently working very smoothly.

On the level of implementing institutions, there are capacities in place in the respective funding agencies to systematically implement thematically oriented and even 'mission-oriented' funding programmes. What is rather lacking is the capacity to apply the funding and other instruments in a concerted way. It has to be added, though, that the respective governance structures and policy mixes have to be tailored to the respective mission. As the case studies and experiences from other countries have shown, the requirements and settings for governance differ considerably between the mission areas. 
Assessments, monitoring and evaluations are well established in Austria. Mostly, they are focussing on 'formative evaluation' and aim at programme and management improvement therefore, 'reflexivity' often resides with the institutions directly responsible for the implementtation of the measure. Monitoring, assessment and evaluation are almost exclusively performed on the level of the individual measures and not in a 'systems' or 'portfolio' perspective (the above mentioned 'systems evaluation of research funding' from 2009 being an exception to the rule). The more widespread adoption of mission-oriented policies would need changes in the evaluation practices as well.

\subsection{WHAT THE CASE STUDIES TELL US ABOUT THE STATE OF AUSTRIAN MOIP}

The four cases analysied in the context of this project (the programmes "Benefit (Ambient Assisted Living)“, „Building of tomorrow“, „KIRAS“ and „Mobility of the Future) display quite a number of similarities, e.g. that all four programmes focus on topics, which are not solely within the confines of single ministries, but rather run across policy areas. In addition, the programmes typically involve interdisciplinary research, affording a combination of socio-economic and scientific-technological research.

However, the case studies also show a few differences, some of which might be traced back to the fact that topical areas, goals and instruments of these programmes differ. For instance, whilst "Mobility of the Future" deals inter alia with mobility-related infrastructures, which have to be planned and maintained with a future perspective of decades or even centuries, "benefit" finances studies as well as the development of products and services with a focus on information and communication technologies, which feature ever shorter development cycles of a few years at best.

\subsubsection{Strategic Orientation}

There are a number of similarities regarding the first of the three high-level categories of the OECD framework, strategic orientation of programs. All case studies feature stakeholder participation processes, although to varying degrees. At minimum, other ministries were involved in programme steering committees, quite often also stakeholders in a broader sense (potential users/addressees) in the specification of calls. In general, directionality was high, with all four programmes featuring clear overarching objectives, which are broken down into more detailed goals at lower aggregation levels.

On the national level, BMK, the ministry responsible for the four programmes ${ }^{58}$, has a clear ownership in these cases, and it exercises clear leadership in defining and steering them.

\footnotetext{
${ }^{58}$ In the case of KIRAS, since early 2020 the Federal Ministry of Agriculture, Regions and Tourism (BMLRT) is responsible for the programme.
} 
Operational implementation of the programmes has been delegated to the Research Promotion Agency FFG, which interacts regularly with BMK on the definition of calls.

The intentionality of the programmes is clearly visible, with a number of goals and an explicit intervention logic in place. However, in all cases no ex-ante key performance indicators allow an impact evaluation of the programmes against preset goals in a detailed manner.

All programmes display a certain degree of flexibility, e.g. "Mobility of the Future" has implemented new instruments on several occasions, which then have been scrutinised internally and externally. Moreover, all schemes are regularly evaluated; yet, formalised processes for institutionalising changes in the programmes in response to evaluation results are not common. In this respect, the programme "House of the Future" stands out, as it understands itself as a learning programme featuring also an international exchange of practices.

\subsubsection{Policy Coordination}

Both horizontal and vertical coordination are present only to a limited extent in all programmes. This can be attributed to the specific characteristic of Austrian STI policy-making, where ministries are highly autonomous in implementing their policies and generally, no specific resources are foreseen for coordination among federal ministries. Coordination between federal and regional levels is limited to single initiatives and instruments. As can generally be observed in Austria, coordination between federal ministries is focusing on negative coordination, i.e. rather than creating a common agenda, ministries inform each other about their respective activities, thus claiming stakes rather than designing joint initiatives.

Although there are attempts of formal coordination, such as in the case of the steering committee of KIRAS, these mechanisms are rarely used for launching joint programmes or activities. At the same time, the intensity of coordination is also limited. In addition, the forwardlooking and strategic potential of policy coordination is hardly exploited in all programmes.

Outside the sphere of intragovernmental coordination, the situation is different for all case studies, as all of them feature frequent and intensive cooperation of the responsible ministerial departments with actors and stakeholders from a variety of branches. This is of specific importance in the area of demand articulation, as shown, for example, on the national level by A3PS, the Austrian Association for Advanced Propulsion Systems, founded and sponsored by the BMK, and on the international level, by the engagement in the ERANET schemes or in the International Energy Agency (IEA). 


\subsubsection{Policy Implementation}

All programmes analysed employ a certain diversity of policy mix, albeit to a varying degree. In MdZ the varying logics and market structures of the different thematic fields are reflected in the differentiated use of instruments, but instruments directly targeting social and socio-technical innovations are underrepresented. 'benefit/AAL' features policy mix diversity in terms of ensuring cross-sectorial diversity and involving end users such as care and support providers, but it also shows only limited innovation cycle diversity. In KIRAS the available instruments cover the value chain of knowledge production from feasibility and usability studies to demonstration projects and thus shows sufficient policy mix diversity for security research. The policy mix of Building of Tomorrow similarly covered the whole value chain of knowledge production from basic research to demonstration projects and was complemented by accompanying measures to foster competence development and dialogue between different stakeholder groups. However, in line with the deficits in policy coordination, limited attention is paid to the coordination with demand-side instruments such as regulation or innovation-oriented public procurement, which are implemented by other public agencies than those in charge of $R \& l$ funding.

Leverage is not achieved at equal scale in the four analysed programs (and was not sought for to the same extent in the different programmes). While MdZ shows a high leverage in terms of programme additionality, the leverage of private sector contributions within Benefit, Building of Tomorrow and KIRAS is mainly limited to the requirement of (private sector) co-funding for projects.

With respect to 'Measurability, \& Evaluability, Reflexivity' a heterogeneous picture emerges when comparing the programmes. While measurability can be observed only at limited scale in the analysed programs, with only a small number of predefined impact indicators, all cases under scrutiny have been repeatedly subject to external evaluation studies. Also reflexivity can be observed, be it in using evaluation results to revise programme structure as in the cases of Benefit and MdZ, or learning activities in the programme 'building of tomorrow' under the umbrella of accompanying measures that led to the evolution of the programme to building of tomorrow plus. 


\section{Summary and tentative suggestions for future MOIP in Austria}

In summary, the Austrian case studies show the following characteristics:

- In all programmes considered, good stakeholder involvement in both programme development and implementation can be observed.

- They are all characterised by clear directionality and intentionality, achieved by a mix of policy instruments that emphasizes the use of supply-side instruments (i.e. R\&D funding) and less so demand-side instruments.

- Furthermore, in all programmes, evaluations are conducted regularly, indicating a rather high level of 'reflexivity'.

- On the other hand, weaknesses can be identified with regard to vertical and horizontal coordination, the intensity of coordination, and the effectiveness of evaluations (in terms of institutionalised learning processes).

The case studies in their strength and weaknesses - though just a small sample of the Austrian STI programmes - can be considered as a good reflection of the general characteristics of the level of development of MOIP in the Austrian STI policy system. The programmes - which were developed at a time before the resurgence of the debate on MOIPs - do not show all the characteristics of what we would define today as a 'fully fledged MOIP'. Yet, they have the potential to be developed in this direction, e.g. by increasing coordination across policy areas, by securing a more comprehensive policy mix and by building in systematic reflection and steering capacities.

The four case-studies presented in this report - even though they are well-chosen goodpractice examples - are a too limited empirical basis to draw strong overarching conclusions and recommendations that could apply across the entire range of MOIPs in Austria. However, based on the cross-cutting analysis of the cases in conjunction with accumulated findings on the framework conditions for MOIPs in Austria, they provide some important pointers to critical issues that will require attention in the future, if the ambition is to strengthen the missionoriented character of thematic STI programmes. Against this background, we conclude and recommend the following:

\section{Overarching findings and recommendations}

- Austria provides some promising starting points for setting up and implementing MOIPs successfully on a larger scale.

- At the same time, it needs to be recognized that there is no simple recipe for the design of mission-oriented programmes, because the conditions in the different fields addressed by the programmes differ considerably, and they will achieve their goals only if well harmonized with adjacent policy areas (e.g. sectoral policies) and levels (e.g. local/regional as well as European)

- In order to further develop MOIPs in Austria and fully exploit their potential, a clear commitment by government is needed (e.g. in the STI Strategy 2030); this is crucial 
because of the cross-cutting nature of missions, affecting several policy areas simultaneously.

- Following on this commitment, the elaboration of a concrete 'mission strategy' aiming to identify and implement a small number of missions should be started. This mission strategy should be harmonized with European missions, European Green Deal actions and IPCEls (Important Projects of Common European Interest). Next to national missions that are congruent with these EU mission-type initiatives, some selected missions that are complementary to EU initiatives could also be considered.

\section{Recommendations regarding strategic orientation}

- Maintain strong ownership by ministries in charge of the specific MOIPs to be implemented (e.g. BMK for Climate-oriented missions, BMLV for defence-related missions...);

- Maintain or even enhance stakeholder engagement in directing MOIPs (e.g. like in KIRAS);

- Better specify appropriate goals ex-ante, and - in the case of longer-term and transformative programmes and policies - correct them explicitly if new evidence is available (e.g. in energy- or mobility-related programmes);

- Build up organisational and institutional capacities for strategic governance of longerterm missions, underpinned by corresponding policy learning processes (e.g. in terms of better aligning national and regional policy initiatives).

\section{Recommendations on policy coordination}

- Recognise the need for time and other resources for effective (positive) coordination among different policy areas (rather than just negative coordination);

- Strengthen and empower existing coordination mechanisms (e.g. inter-ministerial STI Task Force or respective sub-groups thereof) for purposes of effectively providing direction to programmes;

- Intensify interaction with stakeholders, because government policy alone will not be able to reach mission goals. This includes putting stakeholders in a steering role as well (see e.g. KIRAS, Building of Tomorrow);

- Provide experimental spaces for better harmonising STI policy with sectoral "demand side" policies (e.g. regulatory sandboxes, procurement).

\section{Recommendations on policy implementation}

- Provide a strong and proactive management of MOIPs with appropriate implementation capacities and support infrastructure (e.g. by expanding the mandate of existing agencies, or even creating dedicated mission-centric agencies); 
- Include instruments for addressing social and behavioural as well as technological innovations, in line with a broader understanding of innovation needed for missions (e.g. innovation themes "Active Mobility" and "Multimodal Lifestyles" within Mobility of the Future);

- As consequence, mobilise a wider range of non-R\&D actors in programmes and projects;

- Provide instruments to accelerate scaling and generalisation of novel solutions (e.g. Urban Mobility Labs);

- Enhance and strengthen operational reflexivity and new "impact-oriented" monitoring and evaluation processes

In taking up some of these findings and further elaboration of the recommendations, Austria's STI policy has a good basis to enhance its capacities to implement mission-oriented innovation policies, which are likey to be a major strand of STI policy in the future. 


\section{References}

\subsection{GENERAL REFERENCES}

Aho, E., Cornu, J. et al. (2006): "Creating an Innovative Europe: Report of the Independent Expert Group on R\&D and Innovation appointed following the Hampton Court Summit." European Commission, Brussels.

Arundel, A., Soete, L. (eds.) (1993): An Integrated Approach to European Innovation and Technology Diffusion Policy: A Maastricht Memorandum. European Commission, Brussels.

Dachs, B., Dinges, M. et al. (2015): Herausforderungen und Perspektiven missionsorientierter Forschungs- und Innovationspolitik: Studien zum deutschen Innovationssystem 12-2015. Expertenkommission Forschung und Innovation, Berlin.

Edler, J., Georghiou, L. (2007): "Public procurement and innovation: Resurrecting the demand side." Research Policy, 36 (7), pp. 949-963.

ESIR (2018): "Towards a Mission-Oriented Research and Innovation Policy in the European Union: An ESIR Memorandum: Executive Summary." European Commission, Brussels.

Gassler, H. Polt, W., Rammer, C. (2006): "Schwerpunktsetzungen in der Forschungs- und Technologiepolitik: eine Analyse der Paradigmenwechsel seit 1945." Österreichische Zeitschrift für Politikwissenschaft, 2006/1, pp. 7-23.

Gassler, H., Polt, W., Rammer, C. (2008): Priority Setting in Technology Policy - Historical Developments and Recent Trends. In: Nauwelaers, C. Wintjes, R. (Eds.) Innovation Policy in Europe, Edward Elgar, Cheltenham, pp. 203-224.

Georghiou, L., Harper, J. et al. (2008): "Challenging Europe's Research: Rationales for the European Research Area." Report of the ERA Expert Group. European Commission, Brussels.

JIIP (Joanneum Research/Tecnalia/TNO/VTT \& DTI / VVA) (2018): Mission-Oriented Research and Innovation. Inventory and characteristics of initiatives. Project Report for the European Commission. Brussels March 2018 (https://publications.europa.eu/en/publicationdetail/-/publication/3b46ce3f-5338-11e8-be1d-01aa75ed71a1/language-en)

JIIP (Joanneum Research/Tecnalia/TNO/VTT \& DTI / VVA) (2018): Mission-Oriented Research and Innovation. Assessing the Impact of a mission-oriented research and innovation approach. Project Report for the European Commission. Brussels March 2018 (https://publications.europa.eu/en/publication-detail/-/publication/c24b005f-5334-11e8-be1d01aa75ed71a1/language-en)

JIIP et al. (2018a): "Mission-Oriented Research and Innovation: Inventory and characterisation of initiatives. Final report." European Commission, Brussels.

JIIP et al. (2018b): "Mission-Oriented Research and Innovation: Assessing the impact of a mission-oriented research and innovation approach. Final report." European Commission, Brussels.

Kuittinen, H., Polt, W., Weber, K.M. (2018): Mission Europe? A revival of mission-oriented policy in the European Union: In: RFTE - Council for Research and Technology Development 
(Ed.): RE:THINKING EUROPE. Positions on Shaping an Idea. Vienna, September 2018, pp. 191-207.

Lamy, P., Brudermüller, M. et al., (2017): "LAB - FAB - APP. Investing in the European future we want." Report of the independent High Level Group on maximising the impact of EU Research \& Innovation Programmes. European Commission, Brussels.

Mazzucato, M. (2013): The Entrepreneurial State: Debunking Public vs. Private Sector Myths. New PenguinAnthem Press, .

Mazzucato, M. (2018): Mission-Oriented research and Innovation in the European Union. A problem-solving approach to fuel innovation-led growth. European Commission. Brussels February 2018.

Meissner, D, Polt, W.; Vonortas, N. (2017): Towards a broad understanding of innovation and its importance for innovation policy. In: The Journal of Technology Transfer, 2017, vol. 42, issue 5, 1184-1211 DOI: 10.1007/s10961-016-9485-4.

Nelson, R. (1977): The Moon and the Ghetto. An Essay on Public Policy Analysis. New York

Polt, W., Schuch, K., Weber, M., Dall, E., Unger, M., Salomon, N. (2019) Debating Impact and mission-orientation of R\&l Policies, In: „fteval Journal for Research and Technology Policy Evaluation“.

Polt, W., Weber, M., Biegelbauer, P., Unger, M. (2019): Matching type of mission and governance in mission-oriented R\&I policy. Presentation at EU-SPRI Conference, Rome, June 2019.

RISE (2018): "Mission-Oriented Research and Innovation Policy: A RISE Perspective." European Commission, Brussels.

Weber, M., Andreescu, L. et al. (2018): "Transitions at the Horizon: Perspectives for the European Union's future research- and innovation-related policies. Final Report of BOHEMIA project." European Commission, Brussels.

\subsection{REFERENCES CASE STUDY 1 / MOBILITY OF THE FUTURE}

Biegelbauer, P. (2013). Wie lernt die Politik - Lernen aus Erfahrung in Politik und Verwaltung. Wiesbaden, VS Verlag für Sozialwissenschaften.

BKA, BMF, BMUKK, BMVIT, BMWFJ, BMWF (2011). Der Weg zum Innovation Leader: Strategie der Bundesregierung für Forschung, Technologie und Innovation. Wien.

BMVIT (n.a.). Mobilität der Zukunft. Das Forschungs-, Technologie- und Innovationsförderprogramm für Mobilität 2012-2020. Wien, BMVIT.

BMVIT (2014, version 2015). PROGRAMMDOKUMENT „Mobilität der Zukunft“ das FTIProgramm für Mobilität. Wien, BMVIT.

BMVIT (2018a). Zwischenevaluierung des FTI-Programms „Mobilität der Zukunft“ (MdZ). Authors: Iris Fischl, Joachim Kaufmann, Thomas Oberholzner (KMU Forschung Austria) Thorsten Koska (Wuppertal Institut für Klima, Umwelt, Energie). Wien, BMVIT. 
BMVIT (2018b). FTI-politische Agenda und Roadmap zur Ausrichtung der Programmmaßnahmen „Mobilität der Zukunft“ (MdZ) im Themenfeld „Personenmobilität innovativ gestalten“. Wien, BMVIT.

Dinges, M., P. Biegelbauer and D. Wilhelmer (2018). "The Tower of Babylon in the Governance of Research, Technology and Innovation: Participatory Foresight as a Method of Policy Coordination." Futures 100: 34-44.

Karlhofer, F. and E. Tálos, Eds. (2005). Sozialpartnerschaft. Österreichische und Europäische Perspektiven. Wien, Lit Verlag.

Pichler, R., M. Stampfer and R. Hofer (2007). Forschung, Geld und Politik. Die staatliche Forschungsförderung in Österreich 1945-2005. Innsbruck, Studienverlag.

Appendix I: List of interviews

\begin{tabular}{lll}
\hline Name & Organization & Date \\
\hline $\begin{array}{l}\text { Walter Wasner, } \\
\text { Sarah Bittner-Krautsack, }\end{array}$ & BMK & 8.1 .2020 \\
Christian Drakulic & & \\
\hline Walter Schneider & & \\
\hline Andreas Dorda & AustriaTech & 21.2 .2020 \\
\hline Iris Fischl-Ruhland & BMK & 28.2 .2020 \\
\hline
\end{tabular}

\subsection{REFERENCES CASE STUDY 2 / BENEFIT-AMBIENT ASSISTED LIVING}

Austrian Research Promotion Agency (2017). Benefit/AAL: Opportunity through Demographic Change. https://www.ffg.at/sites/default/files/brochuere_benefit_aal_e.pdf

European Commission (1995). Green Paper on Innovation. COM (95) 688 final, 20 December 1995. [Bulletin of the European Union Supplement 5/95].

European Commission (2015). The 2015 Ageing Report: Economic and budgetary projections for the 28 EU Member States (2013-2060), Luxembourg: Publications Office of the European Union.

European Commission (2018). The Silver Economy. Final Report.

Federal Ministry of Labour, Social Affairs, Health and Consumer Protection (BMASGK) (2015). Dementia strategy - Living well with Dementia. https://www.demenzstrategie.at/fxdata/demenzstrategie/prod/media/Demenzstrategie_Neu _englisch.pdf

Federal Ministry of Labour, Social Affairs, Health and Consumer Protection (BMASGK) (2018). Pflegevorsorge - Masterplan Pflege. Vortrag an den Ministerrat, https://www.oegkv.at/fileadmin/user_upload/Aktuell/Masterplan_Pflege.pdf

Geyer, Anton and Good, Barbara (2016). Evaluierung der österreichischen Beteiligung am Ambient Assisted Living Joint Programme (AAL JP 2008-2013) Endbericht. Technical Report. Wien.

Geyer, Anton and Good, Barbara (2018). Evaluierung des Impulsprogramms FIT-IT und der Themeninitiative „IKT der Zukunft“. Endbericht. Technical Report. Wien. 
Appendix I: List of interviews

\begin{tabular}{lll}
\hline Name & Organization & Date \\
\hline Kerstin Zimmermann & BMK & 20.09 .2019 \\
\hline Gerda Geyer & Austrian Research Promotion & 03.12 .2019 \\
& Agency & \\
\hline Uli Waibel & AAL Austria & 05.12 .2019 \\
\hline Georg Aumayr & Die Johanniter & 09.12 .2019 \\
\hline
\end{tabular}

\section{Appendix II: AAL Joint Programme Call Topics 2008-2019}

- Call 1 (2008): ICT-based solutions for Prevention and Management of Chronic Conditions of Elderly People

- Call 2 (2009): ICT-based Solutions for Advancement of Social Interaction of Elderly People

- Call 3 (2010): ICT-based Solutions for Advancement of Older Persons' Independence and Participation in 'Self-Serve Society'

- Call 4 (2011): ICT-based Solutions for Advancement of Older Persons' Mobility

- Call 5 (2012): ICT-based Solutions for Home Care for Older Persons

- Call 6 (2013): ICT-based Solutions for (Self-) Management of Daily Life Activities of Older Adults at Home

- Call 7 (2014): Care for The Future: An Ageing society faces an increasing need for care, how will ICT contribute to sustainable solution

- Call 8 (2015): Living actively and independently at home: Support older adults to live longer in their homes with the contribution of ICT based solutions

- Call 9 (2016): Living Well with Dementia: Providing integrated solutions based on ICT to support the wellbeing of people living with dementia and their communities

- Call 10 (2017): AAL packages/Integrated solutions: Packages integrating different solutions based on ICT to support active, healthy and independent living of older adults

- Call 11 (2018): Smart Solutions for Ageing well

- Call 12 (2019): Sustainable Smart Solutions for Ageing well 


\subsection{REFERENCES CASE STUDY 3 / KIRAS}

BMVIT (2011), Fachtagung Sicherheitsforschung 2011 - Tagungsband

BMVIT (2019), Sicherheitsprogramm KIRAS. Factsheet.

BMVIT (2016), Sicherheitsforschung (national und EU). Factsheet.

Brüggemann, C. (2015), KIRAS. Die bilateralen Projekte. Einreichertag 2015. Presentation.

Brugger, M. (2011), Integration of societal aspects in the Austrian Security Research Programme KIRAS. Presentation.

FFG (2017), Die Grundlagen des KIRAS-Programms, Available at: https://www.ffg.at/content/die-grundlagen-des-kiras-programms [Accessed: 09.01.2018]

Heinrich, S., Riesenberg, D., Ploder, M. (2014), Evaluierung des österreichischen Sicherheitsforschungsprogramms KIRAS. Ex Post-Evaluation 2014, JOANNEUM RESEARCH - POLICIES. Research Report Series 187/2014, Graz, Wien und Berlin.

KIRAS (2010), Leitfaden für den 3. Call der Programmlinie 3 - Kooperative Komponentenentwicklung und Demonstrationsvorhaben

KIRAS (2011-2017 ff), Ausschreibungsleitfaden - Schutz kritischer Infrastrukturen

KIRAS (2018), Geförderte Projekte aller Programmlinien, Available at: http://www.kiras.at/gefoerderte-projekte/ [Accessed: 09.01.2018]

Rechnungshof (2010), Sicherheitsforschungsprogramm KIRAS, Bund 2010/2.

Scheer, J., Brüggemann, C. (2006), Das österreichische Förderungsprogramm für die Sicherheitsforschung (KIRAS)

Appendix I: List of interviews

\begin{tabular}{lll}
\hline Name & Organization & Date \\
\hline Dr. Ralph Hammer & BMLRT & 28.11 .2019 \\
\hline
\end{tabular}




\subsection{REFERENCES CASE STUDY 4 / BUILDING OF TOMORROW}

IIBW (2013), Wohnhaussanierung in Österreich. Study financed by BMWFJ - Federal Ministry for the Economy, Familiy and Youth, Vienna.

Levenda, J., Pöchhacker, G. (2016), Programmevaluierung Haus der Zukunft 1999 - 2013, Vienna.

Mandl, Lüthi \& Partner (2011), Strategisches Monitoring des Programms Haus der Zukunft Plus - Endbericht. Eine Arbeit im Auftrag des Bundesministeriums für Verkehr, Innovation und Technologie.

Österreichische Gesellschaft für Umwelt und Technik [ÖGUT] (2007), Endbericht der Arbeitsgruppe Haus der Zukunft in der ÖGUT - Juli 2004 bis April 2007.

Österreichische Gesellschaft für Umwelt und Technik [ÖGUT] (2010), Unterstützung der Arbeiten zum Programm Haus der Zukunft Plus - Endbericht.

Österreichische Gesellschaft für Umwelt und Technik [ÖGUT] (2011), Unterstützung der Öffentlichkeitsarbeit zum Programm Haus der Zukunft Plus - Endbericht.

Österreichische Gesellschaft für Umwelt und Technik [ÖGUT] (2011b), Unterstützung der strategischen Arbeit und Projektbegleitung zum Programm Haus der Zukunft Plus - Endbericht.

Österreichische Gesellschaft für Umwelt und Technik [ÖGUT] (2011c), Internationale Programmunterstützung der Arbeiten zum Programm Haus der Zukunft Plus - Endbericht.

Österreichische Gesellschaft für Umwelt und Technik [ÖGUT] (2014a), Unterstützungsleistungen zum Programm Haus der Zukunft plus - Endbericht.

Österreichische Gesellschaft für Umwelt und Technik [ÖGUT] (2014b), Diskussion eines „Austrian Standard“ für Gebäude und Entwicklung des Forschungsbereichs „Urbane Technologien.“

Schneider, F., Voigt, J. (2016), Volkswirtschaftliche Analyse der regionalen Wertschöpfungsund Beschäftigungseffekte durch das Programm „Haus der Zukunft“ bzw. „Haus der Zukunft Plus“.

Appendix I: List of interviews

\begin{tabular}{lll}
\hline Name & Organization & Date \\
\hline DI MBA Volker Schaffler & BMK & 28.11 .2019 \\
\hline Mag. (FH) Hannes Warmuth & ÖGUT & 28.11 .2019 \\
\hline Robert Lechner & Österreichisches & $\begin{array}{l}\text { Schriftliche } \\
\text { Beantwortung des } \\
\text { Interviewleitfadens }\end{array}$ \\
\hline
\end{tabular}




\section{Boxes, Figures and Tables}

Box 1 National Framework for Mission-Orientatet Innovation Policy and its main characteristics

Figure 2: Focus of projects, based on 4 operational programme objektives (2017) .............. 23

Figure 3: Instrument Utilisation by Beneficiaries and Organisationtype in MdZ (2017) .......... 30

Figure 4: Number of projects and funding amounts AAL JP and benefit, 2008-2016 ........... 40

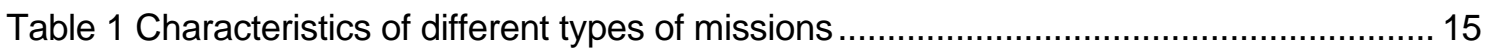

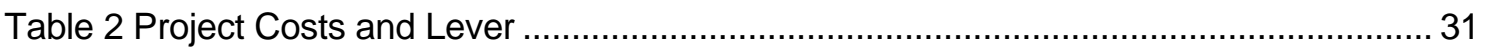

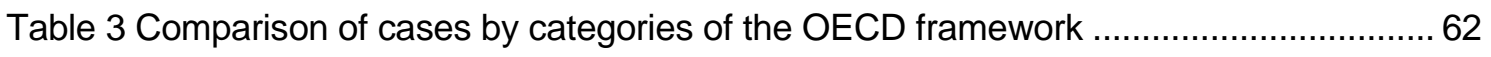




\section{POLICIES Research Report Series}

Research Reports of the Institute for Economic and Innovation Research of JOANNEUM RESEARCH present the results of selected Commissioned research projects of POLICES. Further reports in this series can be downloaded from http://www.joanneum.at/policies/rp.

For further questions please contact policies@joanneum.at.

(C) 2020, JOANNEUM RESEARCH Forschungsgesellschaft mbH - All rights reserved. 
JOANNEUM RESEARCH

Forschungsgesellschaft mbH

POLICIES

Institut für Wirtschafts- und Innovationsforschung

Leonhardstrasse 59

8010 Graz

Tel: +433161488

Fax +433161480

policies@joanneum.at

www.joanneum.at/policies

JOANNEUM RESEARCH

Forschungsgesellschaft mbH

POLICIES

Institut für Wirtschafts- und Innovationsforschung

Haus der Forschung

Sensengasse 1

Tel: +4315817520

Fax +43158175 20-2820

policies@joanneum.at

www.joanneum.at/policies

JOANNEUM RESEARCH

Forschungsgesellschaft mbH

POLICIES

Institut für Wirtschafts- und Innovationsforschung

Lakeside Science \& Technology Park

Lakeside B08a, EG

A-9020 Klagenfurt am Wörthersee

Tel.: +43316 876-7553

Fax: +43 $3168769-7553$

policies@joanneum.at

www.joanneum.at/policies 